\title{
Long-term historical trends in air pollutant emissions in Asia: Regional Emission inventory in ASia (REAS) version 3
}

\author{
Junichi Kurokawa $^{1}$ and Toshimasa Ohara $^{2}$ \\ ${ }^{1}$ Asia Center for Air Pollution Research, 1182 Sowa, Nishi-ku, Niigata, Niigata, 950-2144, Japan \\ ${ }^{2}$ National Institute for Environmental Studies, 16-2 Onogawa, Tsukuba, Ibaraki, 305-8506, Japan \\ Correspondence: Junichi Kurokawa (kurokawa@acap.asia)
}

Received: 4 December 2019 - Discussion started: 20 December 2019

Revised: 6 September 2020 - Accepted: 13 September 2020 - Published: 4 November 2020

\begin{abstract}
A long-term historical emission inventory of air and climate pollutants in East, Southeast, and South Asia during 1950-2015 was developed as the Regional Emission inventory in ASia version 3 (REASv3). REASv3 provides details of emissions from major anthropogenic sources for each country and its sub-regions and also provides monthly gridded data with $0.25^{\circ} \times 0.25^{\circ}$ resolution. The average total emissions in Asia during 1950-1955 and during 20102015 (growth rates in these 60 years estimated from the two averages) are as follows: $\mathrm{SO}_{2}: 3.2 \mathrm{Tg}, 42.4 \mathrm{Tg}$ (13.1); $\mathrm{NO}_{x}$ : $1.6 \mathrm{Tg}, 47.3 \mathrm{Tg}$ (29.1); CO: $56.1 \mathrm{Tg}, 303 \mathrm{Tg}$ (5.4); nonmethane volatile organic compounds: $7.0 \mathrm{Tg}, 57.8 \mathrm{Tg}(8.3)$; $\mathrm{NH}_{3}: 8.0 \mathrm{Tg}, 31.3 \mathrm{Tg}(3.9) ; \mathrm{CO}_{2}: 1.1 \mathrm{Pg}, 18.6 \mathrm{Pg}(16.5)\left(\mathrm{CO}_{2}\right.$ excluding biofuel combustion $0.3 \mathrm{Pg}, 16.8 \mathrm{Pg}$ (48.6)); $\mathrm{PM}_{10}$ : 5.9 Tg, 30.2 Tg (5.1); $\mathrm{PM}_{2.5}$ : 4.6 Tg, 21.3 Tg (4.6); black carbon: $0.69 \mathrm{Tg}, 3.2 \mathrm{Tg}$ (4.7); and organic carbon: $2.5 \mathrm{Tg}, 6.6 \mathrm{Tg}$ (2.7). Clearly, all the air pollutant emissions in Asia increased significantly during these 6 decades, but situations were different among countries and regions. Due to China's rapid economic growth in recent years, its relative contribution to emissions in Asia has been the largest. However, most pollutant species reached their peaks by 2015 , and the growth rates of other species were found to be reduced or almost zero. On the other hand, air pollutant emissions from India showed an almost continuous increasing trend. As a result, the relative ratio of emissions of India to that of Asia has increased recently. The trend observed in Japan was different from the rest of Asia. In Japan, emissions increased rapidly during the 1950s-1970s, which reflected the economic situation of the period; however, most emissions decreased from their peak values, which were approximately 40 years ago, due to the introduction of control measures
\end{abstract}

for air pollution. Similar features were found in the Republic of Korea and Taiwan. In the case of other Asian countries, air pollutant emissions generally showed an increase along with economic growth and motorization. Trends and spatial distribution of air pollutants in Asia are becoming complicated. Data sets of REASv3, including table of emissions by countries and sub-regions for major sectors and fuel types, and monthly gridded data with $0.25^{\circ} \times 0.25^{\circ}$ resolution for major source categories are available through the following URL: https://www.nies.go.jp/REAS/index.html (last access: 31 October 2020).

\section{Introduction}

With an increase in demand for energy, motorization, and industrial and agricultural products, air pollution from anthropogenic emissions is becoming a serious problem in Asia, especially due to its impact on human health. In addition, a significant increase in anthropogenic emissions in Asia is considered to affect not only the local air quality, but also regional, inter-continental, and global air quality and climate change. Therefore, reductions in air and climate pollutant emissions are urgent issues in Asia (UNEP, 2019). Shortlived climate pollutants (SLCPs), which are gases and particles that contribute to warming and have short lifetimes, have been recently considered to play important roles in the mitigation of both air pollution and climate change (UNEP, 2019). SLCPs such as black carbon (BC) and ozone are warming agents, which cause harm to people and ecosystems. A decrease in the emissions of $\mathrm{BC}$ and ozone precursors from fuel combustion led to the decrease in other 
particulate matter (PM) species, such as sulfate and nitrate aerosols. Even though this is a positive step for human health, it has a negative effect on global warming as sulfate and nitrate aerosols act as cooling agents in the troposphere. Therefore, to find effective ways to mitigate both air pollution and climate change, accurate understanding of the current status and historical trends of air and climate pollutants are fundamentally important.

Recently, Hoesly et al. (2018) developed a long-term historical global emission inventory from 1750 to 2014 using the Community Emission Data System (CEDS). This data set is used as input data for the Coupled Model Intercomparison Project Phase 6 (CMIP6). The Emission Database for Global Atmospheric Research (EDGAR) also provides global emissions data of both air pollutants and greenhouse gases, with the current version 4.3.2 ranging from the period between 1970 and 2012 (Crippa et al., 2016). EDGAR is used as the default data of input emissions for the Task Force on Hemispheric Transport of Air Pollution phase 2 (HTAPv2) (Janssens-Maenhout et al., 2015). For SLCPs, the European Union's Seventh Framework Programme project ECLIPSE (Evaluating the Climate and Air Quality Impact of Short-Lived Pollutants) developed a global emission inventory based on the GAINS model. The current version 5 provides gridded emissions for every 5 years from 1990 to 2030 and also from 2040 to 2050 (Stohl et al., 2015). However, data from Asia in global emission inventories are generally based on limited country-specific information. For the Asian region, several project-based emission inventories have been developed, such as Transport and Chemical Evolution over the Pacific (TRACE-P) field campaigns (Streets et al., 2003a, b) and its successor mission, that is, Intercontinental Chemical Transport Experiment-Phase B (INTEX-B) (Zhang et al., 2009). Recently, the MIX inventory (mosaic Asian anthropogenic emission inventory) was developed as input emission data sets for the Model Intercomparison Study for Asia (MICS-Asia) Phase 3 by a mosaic of up-to-date regional emission inventories. The MIX inventory is also a component of the HTAPv2 inventory (Li et al., 2017a). For national emission inventories, numerous studies, research papers, and reports have been published. MEIC (Multi-resolution Emission Inventory for China) developed by Tsinghua University is a widely used emission inventory database for China (Zhang et al., 2009; Li et al., 2014; Zheng et al., 2014; Liu et al., 2015) and is included in the MIX inventory. Zhao et al. $(2011,2012,2013,2014)$ developed recent and projected emission inventories of air pollutants in China. In addition, research papers for regional emission inventories of China were also published recently (Zhu et al., 2018; H. Zheng et al., 2019). In the case of India, Garg et al. (2006) developed a historical emission inventory of air pollutants and greenhouse gases from 1985 to 2005 . For recent years, Sadavarte and Venkataraman (2014) developed multi-pollutant emission inventories for the industry and transport sectors, and Pandey et al. (2014) developed the same for the do- mestic and small industry sectors for the same time period, that is, 1996-2015. For Japan, several project-based emission data sets were developed, such as the Japan Auto-Oil Program (JATOP) Emission Inventory-Data Base (JEI-DB) (JPEC, 2012a, b, c, 2014), East Asian Air Pollutant Emission Grid Database (EAGrid) (Fukui et al., 2014), and emission data sets for Japan's Study for Reference Air Quality Modeling (J-STREAM) (Chatani et al., 2018). In addition, there are studies for other countries and regions, such as the Clean Air Policy Support System (CAPSS) for the Republic of Korea (Lee et al., 2011), Thailand (Pham et al., 2008), Indonesia (Permadi et al., 2017), and Nepal (Jayarathne et al., 2018; Sadavarte et al., 2019). However, these regional and national emission inventories in Asia are available for a limited period, with data of the past missing.

The authors of this study have been devoted to developing the Regional Emission inventory in ASia (REAS) series. The first version of REAS (REASv1.1) was developed by Ohara et al. (2007), which accounted for actual emissions during 1980-2003 and projected ones in 2010 and 2020. Kurokawa et al. (2013) updated the inventory in REASv2.1, which focused on the period between 2000 and 2008, when emissions in China drastically increased. REASv2.1 is used as the default data of the MIX inventory. In this study, a long historical emission inventory in the Asian region from 1950 to 2015 has been newly developed as REAS version 3 (REASv3). This study provides methodology, results, and discussion of REASv3. Section 2 gives the basic methodology, including collecting activity data, settings of emission factors and removal efficiencies, and spatial and temporal allocation of emissions to create monthly gridded data sets of REASv3. In Sect. 3.1, trends in air pollutant emissions in Asia are described in detail and effects of emission controls on emissions in China and Japan are discussed. Spatial and temporal distributions are overviewed in Sect. 3.2. Section 3.3 compares the results of REASv3 with other emission inventories. Uncertainties in REASv3 are discussed in Sect. 3.4. Finally, summary and remarks are presented in Sect. 4.

\section{Methodology and data}

\subsection{General description}

Table 1 summarizes the general information of REASv3. Major updates from previous versions are as follows.

- Target years are from 1950 to 2015, covering much longer periods than REASv1.1 (1980-2003) and REASv2.1 (2000-2008).

- The long historical data sets of activity data were developed by collecting international and national statistics and related proxy data.

- Emission factors and information on emission controls, especially for China and Japan, were surveyed from re- 
search papers of emission inventories in Asia and related literatures.

- Large power plants constructed after 2008 were added as new point sources.

- Allocation factors for spatial and temporal distribution were updated, although several emission inventories developed by other research works were utilized (see Table 2).

- Emissions from Japan, the Republic of Korea, and Taiwan were originally estimated, except for nonmethane volatile organic compound (NMVOC) evaporative sources (see Table 2).

REASv3 focuses on the long historical trends of air pollutant emissions in Asia. The start year was chosen to be 1950 as severe air pollution in Japan started from the mid-1950s. For the emission inventory framework, there are two major changes from REASv2.1. One is the target species. REASv3 includes the following major air and climate pollutants: $\mathrm{SO}_{2}$, $\mathrm{NO}_{x}, \mathrm{CO}, \mathrm{NMVOCs}, \mathrm{NH}_{3}, \mathrm{PM}_{10}, \mathrm{PM}_{2.5}, \mathrm{BC}$, organic carbon (OC), and $\mathrm{CO}_{2}$. However, $\mathrm{CH}_{4}$ and $\mathrm{N}_{2} \mathrm{O}$, which were included in REASv2.1, are not in the scope of this version. $\mathrm{CH}_{4}$ is one of important components of SLCP and will be considered in the next version. Another is the target areas. Figure 1 shows the inventory domain of REASv3 which includes East, Southeast, and South Asia. China, India, and Japan have been divided into 33, 17, and 6 regions, respectively, to reduce the uncertainties in the spatial distribution. Definitions of the sub-regions are the same as for REASv2.1. In REASv3, central Asia and the Asian part of Russia, which were target areas of REASv2.1, are not included because of the difficulty in collecting necessary data for estimating long historical emissions in these areas. The source categories considered in REASv3 are the same as those in REASv2.1. Major sources include fuel combustion in the power plant, industry, transport, and domestic sectors. Non-combustion sources include industrial processes, evaporation (NMVOCs), and agricultural activities $\left(\mathrm{NH}_{3}\right)$. However, $\mathrm{NO}_{x}$ emissions from soil as well as from international and domestic aviation and navigation, including fishing ships, are exceptions. They were not included in REASv3. The spatial and temporal resolutions are the same as those of REASv2.1. Spatial resolution is $0.25^{\circ} \times 0.25^{\circ}$, except in the case of large power plants, which are treated as point sources. Temporal resolution is monthly.

In REASv3, most emissions were originally estimated. However, several emission inventories from other research works and officially opened data were utilized as summarized in Table 2. NMVOC emissions in Japan and the Republic of Korea from evaporative sources were obtained from the Ministry of the Environment of Japan (MOEJ, 2017) and the National Air Pollutants Emission Service of the National Institute of Environmental Research (available at https://

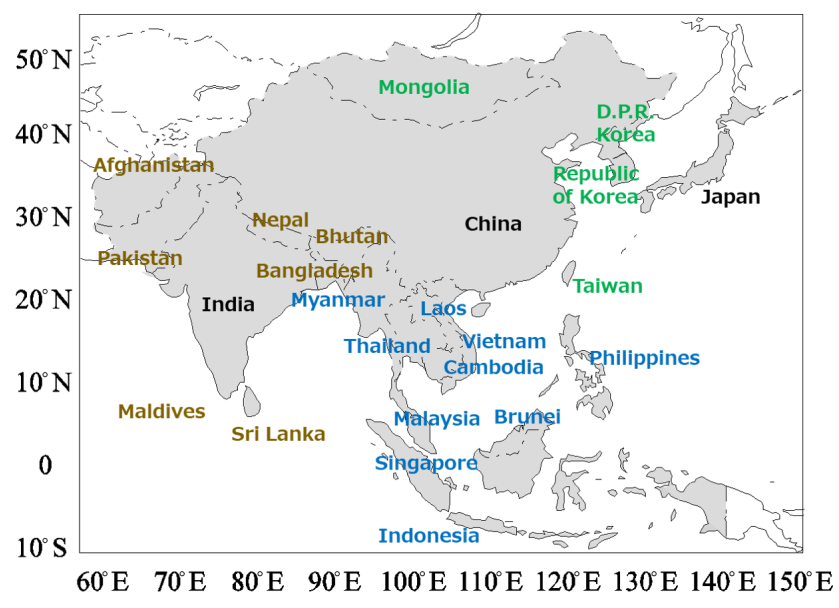

Figure 1. Domain and target countries of REASv3. In this paper, countries written in blue, green, and brown characters were defined as SEA (Southeast Asia), OEA (East Asia other than China and Japan), and OSA (South Asia other than India), respectively.

airemiss.nier.go.kr/mbshome/mbs/airemiss/index.do, last access: 31 October 2020), respectively. For $\mathrm{NH}_{3}$ emissions from agricultural activities, data of base years (2000 and 2005 for Japan and 2000 for others) were obtained from other research works as follows (see Sect. 2.4): REASv2.1 (Kurokawa et al., 2013; JPEC, 2012a, b, c, 2014) for Japan and REASv1.1 (Yamaji et al., 2004; Yan et al., 2003) for other counties and regions. In addition, EDGARv4.3.2 was utilized to create grid allocation factors for the road transport sector for all species and manure management for $\mathrm{NH}_{3}$ (see Sect. 2.6 and 2.4.1, respectively).

In the following sub-sections, general methodologies and data used in REASv3 are overviewed for stationary sources, road transport, agricultural sources, other sources, and spatial and temporal distribution. Details of the methodologies such as data sources and treatments, settings of emission factors and emission controls, and related assumptions are provided in the Supplement "Supplementary information and data to methodology of REASv3" (hereafter, this document is expressed as "the Supplement"). In Sect. S2 of the Supplement, details of the framework of REASv3 including definitions of sub-categories of emission sources, and target countries and sub-regions of China, India, and Japan were provided.

\subsection{Stationary sources}

\subsubsection{Basic methodology}

Emissions from stationary fuel combustion and industrial processes are traditionally calculated using activity data and emission factors, including the effect of control technologies. In order to increase the accuracy of estimation and to analyze the effects of abatement measures, emissions should be calculated using information on technologies related to emission sources as much as possible. In REASv3, emissions 
Table 1. General information on REASv3.

\begin{tabular}{|c|c|}
\hline Item & Description \\
\hline Species & $\mathrm{SO}_{2}, \mathrm{NO}_{x}, \mathrm{CO}, \mathrm{NMVOCs}, \mathrm{NH}_{3}, \mathrm{CO}_{2}, \mathrm{PM}_{10}, \mathrm{PM}_{2.5}, \mathrm{BC}$, and $\mathrm{OC}$ \\
\hline Years & 1950-2015 \\
\hline Areas & East, Southeast, and South Asia \\
\hline Emission sources & $\begin{array}{l}\text { Fuel combustion in the power plant, industry, transport, and domestic sectors; } \\
\text { industrial processes; agricultural activities (fertilizer application and livestock); } \\
\text { and others (fugitive emissions, solvent use, human, etc.) }\end{array}$ \\
\hline Spatial resolution & $0.25^{\circ}$ by $0.25^{\circ}$ \\
\hline Temporal resolution & Monthly \\
\hline Data distribution & https://www.nies.go.jp/REAS/index.html (last access: 31 October 2020) \\
\hline
\end{tabular}

Table 2. Emission inventories from other research works and officially opened data utilized in REASv3.

\begin{tabular}{|c|c|}
\hline Other emission inventories and data sources & How utilized in REASv3 \\
\hline VOC Emission Inventory in Japan (MOEJ, 2017) & Evaporative emissions of NMVOCs in Japan ${ }^{\mathrm{a}}$ \\
\hline $\begin{array}{l}\text { The National Air Pollutants Emission Service of the } \\
\text { National Institute of Environmental Research (https: } \\
\text { //airemiss.nier.go.kr/mbshome/mbs/airemiss/index.do, } \\
\text { last access: } 31 \text { October 2020) }\end{array}$ & $\begin{array}{l}\text { Evaporative emissions of NMVOCs in the Republic of } \\
\text { Korea }^{\text {a }}\end{array}$ \\
\hline $\begin{array}{l}\text { REASv2.1 (Kurokawa et al., 2013; JPEC, 2012a, b, c, } \\
\text { 2014) }\end{array}$ & $\mathrm{NH}_{3}$ emissions from agricultural sources in Japan ${ }^{\mathrm{b}}$ \\
\hline REASv1.1 (Yamaji et al., 2004; Yan et al., 2003) & $\begin{array}{l}\mathrm{NH}_{3} \text { emissions from agricultural sources in countries } \\
\text { and regions other than Japan }{ }^{\mathrm{b}}\end{array}$ \\
\hline $\begin{array}{l}\text { REASv2.1 (Kurokawa et al., 2013; JPEC, 2012a, b, c, } \\
\text { 2014) }\end{array}$ & $\begin{array}{l}\text { Grid allocation factors for the manure management } \\
\text { and road transport } \\
\text { d } \text { sectors for Japan }\end{array}$ \\
\hline EDGARv4.3.1 (Crippa et al., 2016) & $\begin{array}{l}\text { Grid allocation factors for the manure management } \\
\text { and road transport }{ }^{\mathrm{d}} \text { sectors for countries and regions } \\
\text { other than Japan }\end{array}$ \\
\hline
\end{tabular}

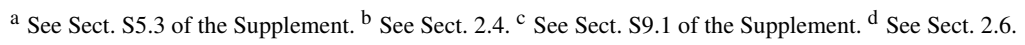

from stationary combustion and industrial processes are estimated based on the following equation:

$E=\sum_{i} \sum_{j} \sum_{k, l}\left\{A_{i, j} \times F_{i, j, k, l} \times \mathrm{EF}_{i, j, k} \times\left(1-R_{i, j, l}\right)\right\}$,

where $E$ represents emission, $i$ is the type of activity data, $j$ is the type of sector category, $k$ is the type of technology related to emission factor, $l$ stands for the control technology after emission, $A$ is the amount of activity data, EF is the emission factor of each technology, $R$ is the removal efficiency of each technology, and $F$ is the fraction rate of activity data for a combination of $i, j, k$, and $l$. When $\mathrm{SO}_{2}$ emissions from combustion sources are estimated using sulfur contents of fuels, $\mathrm{EF}_{i, j, k}$ in Eq. (1) is calculated as follows:

$\mathrm{EF}_{i, j, k}=\mathrm{NCV}_{i, j} \times S_{i, j} \times\left(1-\mathrm{SR}_{i, j, k}\right) \times 2$, where NCV is the net calorific value of fuel, $S$ is the sulfur content of fuel, and SR is the sulfur retention in ash for a combination of $i, j$, and $k ; 2$ is a factor to convert the value of $S$ to $\mathrm{SO}_{2}$.

Unfortunately, in the case of Asia, information available on emission factors and removal efficiencies is limited. Even though there is information on the introduction rates of technologies for both emission factors and removal efficiencies, they are available independently. Therefore, for most cases, an average of the removal efficiencies is calculated using the values of each abatement equipment and its penetration rate. Then, the average removal efficiencies are commonly used to calculate the emission factors of each technology.

Note that several sub-sectors in stationary sources such as coke production and the cement industry include both 
combustion and non-combustion emission sources. See Sects. S2.4.1 and S2.4.2 of the Supplement for details.

\subsubsection{Activity data}

Fuel consumption is the core activity data of the emission inventory of air pollutants and greenhouse gases. For most countries, the amount of energy consumption for each fuel type and sector was primarily obtained from the International Energy Agency (IEA) World Energy Balances (IEA, 2017). For China, province-level tables in the China Energy Statistical Yearbook (CESY) (National Bureau of Statistics of China, 1986, 2001-2017) were used. For countries and regions whose energy data are not included in IEA (2017), fuel consumption data were taken from the United Nations (UN) Energy Statistics Database (UN, 2016) and the UN data, which is a web-based data service of the UN (https: //data.un.org/, last access: 31 October 2020). See Sect. S3.1.1 of the Supplement for definitions of fuel types.

One major obstacle in this study was collecting activity data for the entire target period of REASv3, that is, from 1950 to 2015. IEA (2017) includes data from Japan during 1960-2015 and those from other countries during 19712015; however, for many countries, fuel types, and sector categories, the oldest years when data exist are more later than 1971. Furthermore, past data for sectors do not contain as many categories. For example, coal consumption data in detailed sub-categories of the industrial sector existed in Indonesia only after 2000, but corresponding data are only available for the industry total before 1999. In this case, relative ratios of fuel consumption in detailed sub-categories to total industry in 2000 were used to distribute the total industry data to each sub-category for the years before 1999 . This procedure is performed for similar cases for all sectors and sometimes for total final consumption. In cases where data did not exist beyond a certain year, fuel consumption data were extrapolated using trends of related data for each sub-category. For example, power generation and amount of industrial products were used to observe trends of fuel consumption in power plants and each industry's sub-category, respectively. Data for long historical trends were obtained from a variety of sources. For example, power generation data and amounts of major industrial products were obtained from Mitchell (1998), and national and international statistics as well as related literatures were surveyed. See Sect. S3.1.2 of the Supplement for details of data sources of fuel consumption and assumptions to estimate missing historical data. For China, data of CESY for each province were available from 1985 to 2015. During 1950-1984, first, total energy data in China were developed based on IEA (2017), and then fuel consumption in each province was extrapolated using the total data of China in each fuel type and sector category. See Sect. S3.1.3 of the Supplement for details of regional fuel consumption data in China. For countries which used the Energy Statistics Database, fuel consumption of each fuel and sector was taken from the UN data (available at https://data.un.org/, last access: 31 October 2020) for the period between 1990 and 2015 and was extrapolated using the trend of total consumption of each fuel type obtained from the UN Energy Statistics Database.

As described in Sect. 2.1, India and Japan have 17 and 6 sub-regions, respectively. Therefore, for them, country total data of IEA (2017) need to be divided for each subregion. For Japan, energy consumption statistics of each prefecture that were obtained from the Agency for Natural Resources and Energy (available at https://www.enecho.meti. go.jp/statistics/energy_consumption/ec002/results.html, last access: 31 October 2020) were used as default weighting factors to allocate country total data to the six regions. Similarly, for India, default weighting factors for regional allocation were estimated from the TERI (The Energy and Resources Institute) Energy \& Environment Data Diary and Yearbook (TERI, 2013, 2018), Annual Survey of Industries (Ministry of Statistics \& Programme Implementation, available at http://www.csoisw.gov.in/cms/en/ 1023-annual-survey-of-industries.aspx, last access: 31 October 2020), and Census of India (Chandramouli, 2011), among others. In general, details of these weighting factors are less than those of the country's total fuel consumption. In addition, these data are not available for all the years during 1950-2015. Therefore, regional allocation factors for some sectors were developed independently if corresponding proxy data were available. For the power plant sector, generation capacities of each region and year were calculated as proxy data using the World Electric Power Plants Database (WEPP) (Platts, 2018). For India, traffic volumes (see Sect. 2.3.1) and amount of industrial production in each region (see the last paragraph of this section) were used as proxy data. Details of regional fuel consumption data in India and Japan were provided in Sect. S3.1.4. and S3.1.5, respectively.

Similarly to REASv2.1, large power plants are treated as point sources in REASv3 and are updated based on the REASv2.1 database. Before 2007, power plants that were classified as point sources were the same as those in REASv2.1, and their information, such as generating capacities and start and retire years, was updated using WEPP. During 2000 to 2007, fuel consumption data were the same as those in REASv2.1. In REASv3, power plants whose start years were after 2007 and generation capacities were larger than $300 \mathrm{MW}$ were added as new point sources. Fuel consumption of new power plants were estimated based on relations between fuel consumption amounts and generation capacities of the point data in REASv2.1. If the (A) total fuel consumption of each power plant in a country was larger than (B) the corresponding data in the power plant sector, values of each power plant were adjusted by ratios of (B) per (A). If (B) was larger than (A), differences between (B) and (A) were treated as data of area sources. See also Sect. S3.1.6 of the Supplement for fuel consumption data in power plants. 
For emissions from industrial processes, activity data included the amount of industrial products. Corresponding data were mainly obtained from related international statistics and national statistics. For example, iron and steel production data were taken from the Steel Statistical Yearbook (World Steel Association, 1978-2016) and data for non-ferrous metals and non-metallic minerals were obtained from the United States Geological Survey (USGS) Minerals Yearbook (USGS, 1994-2015). Brick production data were obtained from a variety of sources, such as Zhang (1997), Maithel (2013), Klimont et al. (2017), and the UN data. For China and India, the authors also used Internet database services, namely China Data Online (https://www. china-data-online.com/, last access: 31 October 2020) and Indiastat (https://www.indiastat.com/, last access: 31 October 2020), respectively, which provided both national and regional statistics. The USGS Minerals Yearbook (USGS, 1994-2015) also provided information on plants in each subregion of China, India, and Japan. Data in the aforementioned statistics were not available for the early years of the target period of REASv3. In such cases, data of Mitchell (1998) were used as factors to extrapolate the activity data until 1950. Details of activity data related to industrial production and other transformation were given in Sect. S4.1 of the Supplement.

\subsubsection{Emission factors}

Setting up emission factors and removal efficiencies for stationary combustion and industrial processes is a difficult procedure, especially for a long historical emission inventory. In this study, emission factors without effects of abatement measures were set, which were used for the entire target period of REASv3. Then, effects of control measures were set considering their temporal variations, both for abatement measures before emissions such as using low-sulfur fuels and low- $\mathrm{NO}_{x}$ burners and those after emissions such as flue gas desulfurization (FGD) and electrostatic precipitator (ESP). These settings were done for each country and region based on country- and region-specific information. However, such information is still limited, especially in the Asian region. Therefore, default values of unabated emission factors were selected, and default removal efficiencies were set to zero. Then, these default values were updated in case information and the literature on each country and region were available. For default emission factors, the majority of settings were continuously used from REASv2.1, but some of them, including effects to control measures (net emission factors), were changed to unabated emission factors. Default emission factors were mainly obtained from Kato and Akimoto (1992) for $\mathrm{SO}_{2}$ and $\mathrm{NO}_{x}$; Bond et al. (2004), Kupiainen and Klimont (2004), and Klimont et al. (2002, 2017) for PM species; the 2006 IPCC Guidelines for National Greenhouse Gas Inventories (IPCC, 2006) for $\mathrm{CO}_{2}$; and the AP-42 (US EPA, 1995), the Global Atmospheric Pollution Forum Air Pollutant Emis- sion Inventory Manual (Vallack and Rypdal, 2012), Shrestha et al. (2013), the EMEP/EEA emission inventory guidebook 2016 (EEA, 2016), and other literatures for others (see the last paragraph of this sub-section).

For country- and region-specific settings, in addition to literatures used in REASv2.1 (see Kurokawa et al., 2013), new information, especially for technologies related to settings of emission factors and removal efficiencies, was surveyed. Although such information is still limited in Asia, the volume of accessible information on China is relatively large. General information on China in recent years was mainly obtained from Li et al. (2017b) and Zheng et al. (2018). Introduction rates of technologies were obtained from Hua et al. (2016) for cement, Wu et al. (2017) for iron and steel, Huo et al. (2012a) for coke ovens, and Zhao et al. (2013, 2014 , and 2015) for a variety of sources. For India, information for technology settings was mainly taken from Sadavarte and Venkataraman (2014), Pandey et al. (2014), Guttikunda and Jawahar (2014), and Reddy and Venkataraman (2002a). For power plants, the WEPP database has elements for installed equipment to control $\mathrm{SO}_{2}, \mathrm{NO}_{x}$, and PM species which were used for settings of emission factors and removal efficiencies of power plants treated as point sources. However, these data are not available for most power plants, especially in Asia. Therefore, in the case of South and Southeast Asia, a variety of literatures, such as Sloss (2012) and UN Environment (2018), were referred to, to set emission factors and removal efficiencies. For Japan, introduction of control technologies for air pollutants was initiated earlier than other countries in Asia. A lot of domestic reports for air pollution and control technologies in power and industry plants published in Japanese, such as MRI (2015), Shimoda (2016), Suzuki (1990), and Goto (1981), were referred to, to determine emission factors, removal efficiencies, and their temporal variations.

Details of emission factors and settings of emission controls for stationary combustion sources were provided in Sect. S3.2 of the Supplement. Those for stationary noncombustion emissions from the industrial production and other transformation sectors were described in Sect. S4.2. Activity data and emission factors of NMVOCs from the chemical industry were obtained from Sect. S5.1.5 and S5.2.5, respectively. Those for $\mathrm{NH}_{3}$ emissions from industrial production were provided in Sect. S8.3.

\subsection{Road transport}

\subsubsection{Basic methodology}

The methodology for the road transport sector is the same as that of REASv2.1. Equations to estimate hot and cold start emissions (except for $\mathrm{SO}_{2}$ and $\mathrm{CO}_{2}$ ) are as follows:

$E_{\mathrm{HOT}}=\sum_{i}\left\{\mathrm{NV}_{i} \times \mathrm{ADT}_{i} \times \mathrm{EF}_{\mathrm{HOT} i}\right\}$, 
where $E_{\mathrm{HOT}}$ is the hot emission, $i$ is the vehicle type, $\mathrm{NV}$ is the number of vehicles in operation, ADT is the annual distance traveled, and $\mathrm{EF}_{\mathrm{HOT}}$ is the emission factor. $\mathrm{SO}_{2}$ emissions are calculated using sulfur contents in gasoline and diesel consumed in the road transport sector, assuming sulfur retention in ash is zero. $\mathrm{CO}_{2}$ emissions are estimated by calculating the consumption amounts of fuels (gasoline, diesel, liquefied petroleum gas, and natural gas) and the corresponding emission factors (IPCC, 2006). Details for $\mathrm{SO}_{2}$ and $\mathrm{CO}_{2}$ from road transport were described in Sect. S6.2.3 of the Supplement.

Cold start emissions ( $\left.E_{\mathrm{COLD}}\right)$ are estimated for $\mathrm{NO}_{x}, \mathrm{CO}$, $\mathrm{PM}_{10}, \mathrm{PM}_{2.5}, \mathrm{BC}, \mathrm{OC}$, and NMVOCs using the following equation:

$E_{\mathrm{COLD}}=\sum_{i}\left\{\mathrm{NV}_{i} \times \mathrm{ADT}_{i} \times \mathrm{EF}_{\mathrm{HOT} i} \times \beta_{i}(T) \times F_{i}(T)\right\}$,

where $\beta$ is the fraction of distance traveled driven with a cold engine or with the catalyst operating below the light-off temperature, and $F$ is the correction factor of $\mathrm{EF}_{\mathrm{HOT}}$ for cold start emissions. $\beta$ and $F$ are functions of temperature $T$ and are taken from EEA (2016) (see Sect. S6.2.1 of the Supplement for additional information on the settings). For Japan, the ratios of cold start and hot emissions for each vehicle type were estimated from the JEI-DB. Then, cold start emissions were calculated by hot emissions and the ratios for each vehicle type. In REASv3, effects of regulations on cold start emissions were ignored and need to be considered in the next version.

For evaporation from gasoline vehicles, emissions ( $\left.E_{\mathrm{EVP}}\right)$ were estimated using the following equation of Tier 1 of EEA (2016):

$E_{\mathrm{EVP}}=\sum_{i}\left\{\mathrm{NV}_{i} \times \operatorname{EF}_{\mathrm{EVP} i}(T)\right\}$,

where $\mathrm{EF}_{\mathrm{EVP}}$ is the emission factor as a function of temperature. For Japan, evaporative emissions in 2000, 2005, and 2010 were obtained from the JEI-DB and those between 2000 (2005) and 2005 (2010) were interpolated. For emissions before 2000 and after 2010, emissions from running loss were extrapolated using trends of traffic volume, and those from hot soak loss and diurnal breaking loss were extrapolated by trends of vehicle numbers. See Sect. S6.3 of the Supplement for the NMVOC evaporative emissions.

\subsubsection{Activity data}

Basic activity data of the road transport sector include the number of vehicles in operation for each type. Data on the registered number of vehicles are available in the national statistics of each country and the World Road Statistics (IRF, 1990-2018). If these statistics did not contain data until 1950, the numbers were extrapolated using trends of data for aggregated vehicle categories in Mitchell (1998). For China, data for each sub-region were obtained from the China Statistical Yearbook (National Bureau of Statistics of China, 19862016) and China Data Online. Those for India were taken from the TERI Energy \& Environment Data Diary and Yearbook (TERI, 2013, 2018) and Indiastat. A problem that was encountered was that registered vehicles were not always in operation. For India, the number of vehicles obtained as registered vehicles was corrected based on Baidya and BorkenKleefeld (2009) and Prakash and Habib (2018). For other countries, the number of registered vehicles was considered to be those in operation due to a lack of information. In addition, to estimate emissions, these numbers must be further divided into vehicles based on each fuel type. However, such information is not easily available in national statistics. In this study, settings of Streets et al. (2003a) and REASv2.1 were used as the default and were updated if national information was available, such as He et al. (2005), Yan and Crookes (2009), Sahu et al. (2014), and Malla (2014). If the number of LPG and CNG vehicles were available only for recent years, data were extrapolated using amounts of fuel consumption in the road transport sector in IEA (2017).

Emission factors of the road transport sector used in this study were given as emission amounts per traffic volumes. Therefore, annual vehicle kilometers traveled (VKT) per each vehicle type need to be set for each country. We used data of Clean Air Asia (2012) for many countries. Clean Air Asia (2012) includes data for China and India, but data of China were estimated based on Huo et al. (2012b), and those of India were set following Prakash and Habib (2018) and Pandey and Venkataraman (2014). For Japan, the total annual VKT for detailed vehicle types were obtained from reports of the Pollutants Release and Transfer Register published by the Ministry of Economy, Trade and Industry until 2001 (METI, 2003-2017), which was originally estimated from the Road Transport Census of Japan developed by the Ministry of Land, Infrastructure, Transport and Tourism. Before 2001, the total annual VKT was extrapolated using data of more aggregated vehicle categories in the Annual Report of Road Statistics (MLIT, 1961-2016) until 1960 and from the Historical Statistics of Japan (Japan Statistical Association, 2006) until 1950.

Details of the number of vehicles and annual vehicle kilometers traveled were described in Sect. S6.1.1 of the Supplement.

\subsubsection{Emission factors}

For most countries, road transport is one of the major causes of air pollution. In many Asian countries, vehicle emission standards were introduced after the late 1990s and were strengthened in phases (Clean Air Asia, 2014). Therefore, for road vehicles, year-to-year variation of emission factors must be taken into account for a long historical emission inventory. In REASv3, emission factors of $\mathrm{NO}_{x}, \mathrm{CO}, \mathrm{NMVOCs}$, and PM species for exhaust emissions from road vehicles were estimated by following procedures.

1. Emission factors of each vehicle type in a base year were estimated. 
2. Trends of the emission factors for each vehicle type were estimated considering the timing of road vehicle regulations in each country and the ratios of vehicle production years.

3. Emission factors of each vehicle type during the target period of REASv3 were calculated using those of base years and the corresponding trends.

The information on road vehicle regulations in each country and region was taken from Clean Air Asia (2014). For the ratios of vehicle production years, due to lack of information, data for Macau derived from Zhang et al. (2016) were used for Hong Kong, the Republic of Korea, and Taiwan, and those from the Japan Environmental Sanitation Center and Suuri Keikaku (2011) for Vietnam were used for other countries and regions. Then, trends of emission factors were estimated using the above data and information with values of Europe and United States standards. Finally, emission factors used to estimate emissions were calculated for each vehicle type. For most countries, the years just before the regulations for road vehicles began were set as base years, and non-controlled emission factors that were used in REASv1.1 and REASv2.1 were adopted for emission factors of the base years. Countries for which information on regulations was not obtained, the non-controlled emission factors, were used for the entire target period of REASv3. For China and India, emission factors in 2010 were estimated as the base year's data using recently published papers, such as Huo et al. (2012b), Xia et al. (2016), Mishra and Goyal (2014), and Sahu et al. (2014). For the Republic of Korea and Taiwan, whose emissions were not originally estimated in REASv2.1, emission factors were estimated with high uncertainties based on values of Europe and United States standards, respectively. For Japan, emission factors for each emission standard are available for several vehicle speeds (JPEC, 2012a). Combining these data with information for annual VKT of each vehicle speed, ratios of vehicle ages, and time series of regulation standards, emissions of road transport in Japan were calculated. Details of emission factors of exhaust emissions were provided in Sect. S6.2 of the Supplement.

\subsection{Agricultural sources}

REASv3 includes $\mathrm{NH}_{3}$ emissions from manure management and fertilizer application in agricultural sources. Approaches similar to REASv2.1 were adopted to estimate historical emissions and develop monthly gridded data. First, annual emissions of each country and sub-region except for Japan and their gridded data for the year 2000 were selected from REASv1.1 (Yamaji et al., 2004; Yan et al., 2003) as base data. For Japan, corresponding base data were obtained from REASv2.1 (Kurokawa et al., 2013: JPEC, 2012a, b, c, 2014) for the years 2000 and 2005. Second, trends of emissions during 1950-2015 were estimated for each country and sub- region. Third, annual emissions for the period were calculated using the trends and base data. Fourth, changes in spatial distribution from base years to target years and monthly variations in each country and sub-region were estimated. Finally, monthly gridded data of emissions were developed for 1950-2015. For Japan, emission data during 2001-2004 were interpolated between those in 2000 and 2005. Details for manure management and fertilizer application are given in Sect. 2.4.1 and 2.4.2, respectively.

\subsubsection{Manure management}

Trends in $\mathrm{NH}_{3}$ emissions from manure management of livestock, except for its application as fertilizer, were estimated based on the Tier 1 method of EEA (2016). In this method, emissions are calculated based on the numbers of livestock and the corresponding emission factors. Statistics on the number of animals, such as broilers, dairy cow, and swine, are mainly obtained from FAOSTAT (available at http://www.fao.org/faostat/en/, last access: 31 October 2020) of the Food and Agriculture Organization (FAO) of the UN from the period between 1961 and 2015. For the years before 1960, data were obtained from Mitchell (1998). National statistics were surveyed for data on provinces, states, and prefectures in China, India, and Japan, respectively, to develop activity data for each sub-region. Emission factors are obtained from EEA (2016). For spatial distribution, changes in grid allocation for each country and sub-region from the year 2000 were estimated using EDGARv4.3.2 from 1970 to 2012. Grid allocation factors in 1970 and 2012 were used for the period before and after 1970 and 2012, respectively. For temporal variations, monthly allocation factors are estimated as a function of temperature by referring to the monthly variations of emissions in Japan based on the JEI-DB. Detailed methodologies and data sources for manure management were provided in Sect. S8.1 in the Supplement.

\subsubsection{Fertilizer}

In most countries, fertilizer application is the largest source of $\mathrm{NH}_{3}$ emissions. Emission trends after the application of manure and synthetic $\mathrm{N}$ fertilizer were estimated using EEA (2016). Manure application is one of the processes of manure management, whose emission trend was calculated based on the number of animals and the corresponding emission factor. For synthetic $\mathrm{N}$ fertilizer, trends of total consumption of fertilizer were used in REASv2.1. However, this simple approach causes uncertainties because emission factors are different among types of fertilizer (EEA, 2016). Therefore, in REASv3, emissions from each $\mathrm{N}$ fertilizer, such as ammonium phosphate and urea, were estimated separately, and trends in total emissions were calculated. For spatial distribution, changes in grid allocation factors for each country and sub-region from the year 2000 were estimated using a historical global $\mathrm{N}$ fertilizer application map during 1961- 
2010, developed by Nishina et al. (2017). Data for 1961 and 2010 were used for the period before 1961 and after 2010, respectively. For seasonal variations, monthly factors of China and Japan were determined based on Kang et al. (2016) and the JEI-DB, respectively. For other countries, data from Nishina et al. (2017) have monthly application amounts in each grid. However, there are cases that some months have high factors, whereas the others have almost zero. Referring to Janssens-Maenhout et al. (2015), we adopted the conservative way such that the highest monthly factor was set at 0.2 and the factors of all months were adjusted accordingly. See Sect. S8.2 for details of methodologies and data sources for emissions from fertilizer application.

\subsection{Other sources}

NMVOC emissions from evaporative sources are increasing significantly in Asia along with economic growth. Major sources of NMVOC emissions include usage of solvents for dry cleaning, degreasing operations, and adhesive application as well as for paint use. Fugitive emissions related to fossil fuels, such as extraction and handling of oil and gas, oil refinery, and gasoline stations, are also important. However, statistics on activity data and information of emission factors for these sources are often less available than those for fuel combustion and industrial processes. In this study, default activity data and emission factors were obtained from REASv2.1 and were updated if information was available in recently published papers (such as Wei et al. 2011, for China, and Sharma et al., 2015, for India). In general, activity data of the past years are not available, and, in such cases, proxy data are prepared for trend factors. For example, population numbers were used for dry cleaning and production numbers of vehicles were used for paint application for automobile manufacturing. GDP was used for default trend factors. For emission calculation, the same equation for stationary combustion was adopted. Details of activity data and emission factors for non-combustion sources of NMVOCs were provided in Sect. S5 of the Supplement.

In addition to agricultural activities, latrines are an important source of $\mathrm{NH}_{3}$, especially in rural areas. Activity data are population numbers in no sewage service areas estimated referring settings of REASv2.1 and emission factors were based on EEA (2016) and Vallack and Rypdal (2012). Also, humans themselves are sources of $\mathrm{NH}_{3}$ emissions through perspiration and respiration. For these sources, population numbers are activity data mainly taken from UN (2018) and emission factors are obtained from EEA (2016). The equation to estimate emission is also the same as that of stationary combustion. Additional data and information for emissions from human and latrines were described in Sect. S8.4 and S8.5, respectively.

In REASv3, aviation and ship emissions, including fishing ships, are not included, but emissions of fuel combustion in other transport sectors (namely, except for aviation, naviga- tion, and road), such as railway and pipeline transport, were estimated. Equation (1) is also used for estimating emissions of these sources. See Sect. S7 of the Supplement for additional data and information for other transport sectors.

\subsection{Spatial and temporal distribution}

Procedures for developing gridded emission data were the same as those of REASv2.1. Large power plants were treated as point sources, and longitude and latitude of each power plant were provided. Positions of power plants were surveyed based on detailed information, such as names of units, plants, and companies from WEPP (Platts, 2018). These were searched on Internet sites, such as Industry About (https:// www.industryabout.com/, last access: 31 October 2020) and Global Energy Observatory (http://globalenergyobservatory. org/, last access: 31 October 2020). Positions for newly added power plants in REASv3 as well as those in REASv2.1 were surveyed because some of these services were not available when REASv2.1 was developed. For cement, iron, and steel plants (and non-ferrous metal plants in Japan), REASv3 still did not treat them as point sources due to a lack of activity data. However, positions, production capacities, and start and retire years for large plants were surveyed similarly to power plants and used for developing allocation factors for corresponding sub-sectors. For the road transport sector, REASv2.1 used coarse grid allocation data of REASv1.1 with $0.5^{\circ} \times 0.5^{\circ}$ resolution. Therefore, in REASv3, grid allocation factors for each country and sub-region, except Japan, were updated using gridded emission data of the road transport sector of EDGARv4.3.2 during 1970-2012. Before 1970 (after 2012), data for 1970 (2012) were used. For Japan, gridded emission data of the JEI-DB in 2000, 2005, and 2010 were used to develop grid allocation factors. For the years between 2000 (2005) and 2005 (2010), the JEI-DB data were interpolated. For years before 2000 (after 2010), the JEI-DB data for 2000 (2010) were used. For the residential sectors, rural, urban, and total populations of HYDE 3.2.1 (Klein Goldewijk et al., 2017) with $5^{\prime} \times 5^{\prime}$ were used to create allocation factors. Data of HYDE 3.2.1 were available for 1950, 1960, 1970, 1980, 1990, 2000, 2005, 2010, and 2015, and the years between them were interpolated. Spatial distributions of the total population were used for grid allocation of all other sources. Detailed methodologies and data sources for grid allocation were provided in Sect. S9.1 in the Supplement.

The methodology to estimate monthly emission data in REASv3 was the same as that of REASv2.1. In general, monthly emissions were estimated by allocating annual emissions to each month using monthly proxy data. Monthly generated power and production amounts of industrial products were used as the monthly allocation factors for the power plant sector and the corresponding industry sub-sectors, respectively. Basically, monthly factors of REASv2.1 during 2000-2008 were also used in REASv3 
and were extended if data existed before (after) 2000 (2008). For the years where surrogate data were unavailable, the data of the oldest (newest) year were used before (after) the year. For brick production, monthly allocation factors for Southeast and South Asian countries were estimated by referring to Maithel et al. (2012) and Maithel (2013). For the residential sector, monthly variations of emissions were estimated using surface temperature in each grid cell, similarly to REASv2.1. Surface temperatures during 19502015 were taken from NCEP reanalysis data provided by the NOAA/OAR/ESRL PSD, Boulder, Colorado, USA (https:// psl.noaa.gov/data/gridded/data.ncep.reanalysis.html, last access: 31 October 2020). For Thailand and Japan, most monthly factors were set based on country-specific information from Pham et al. (2008) and JPEC (2014), respectively. See Sect. S9.2 of the Supplement for details of monthly variation factors.

\section{Results and discussion}

\subsection{Trends of Asian and national emissions}

Trends in air pollutant emissions from Asia, China, India, Japan, and other countries are described in this section, mainly focusing on $\mathrm{SO}_{2}, \mathrm{NO}_{x}$, and $\mathrm{BC}$ emissions as they have important roles in both air pollution and climate change. $\mathrm{SO}_{2}$ and $\mathrm{NO}_{x}$ are precursors of sulfate and nitrate aerosols, respectively, which are the major components of secondary $\mathrm{PM}_{2.5} . \mathrm{NO}_{x}$ is also a precursor of ozone. Furthermore, BC is a major component of primary $\mathrm{PM}_{2.5}$. $\mathrm{PM}_{2.5}$ and ozone not only harm human health and ecosystems, but also influence climate change. $\mathrm{BC}$ and ozone have a warming effect on climate change, whereas sulfate and nitrate aerosols have a cooling effect. Note that all the air pollutant emissions from major countries and regions between 1950 and 2015 categorized based on major sectors and fuel types are provided in the Supplement (Figs. S1-S12). $\mathrm{CO}_{2}$ emissions in REASv3 include contribution from biofuel combustion unless otherwise indicated.

\subsubsection{Asia}

Table 3 summarizes the national emissions of each species in 2015 and the total emissions from Asia in 1950, 1960, 1970, 1980, 1990, 2000, and from 2010 to 2015. Figure 2 shows emissions of $\mathrm{SO}_{2}, \mathrm{NO}_{x}, \mathrm{CO}, \mathrm{NMVOCs}, \mathrm{NH}_{3}, \mathrm{CO}_{2}, \mathrm{PM}_{10}$, $\mathrm{PM}_{2.5}$, BC, and OC in China, India, Japan, Southeast Asia (SEA), East Asia other than China and Japan (OEA), and South Asia other than India (OSA) from 1950 to 2015. Average total emissions in Asia during 1950-1955 and 20102015 (growth rates in these 60 years estimated from the two averages) are as follows: $\mathrm{SO}_{2}: 3.2 \mathrm{Tg}, 42.4 \mathrm{Tg}$ (13.1); $\mathrm{NO}_{x}$ : $1.6 \mathrm{Tg}, 47.3 \mathrm{Tg}$ (29.1); CO: $56.1 \mathrm{Tg}, 303 \mathrm{Tg}$ (5.4); NMVOCs: 7.0 Tg, 57.8 Tg (8.3); $\mathrm{NH}_{3}: 8.0 \mathrm{Tg}, 31.3 \mathrm{Tg}$ (3.9); $\mathrm{CO}_{2}$ : $1.1 \mathrm{Pg}, 18.6 \mathrm{Pg}$ (16.5) $\left(\mathrm{CO}_{2}\right.$ excluding biofuel com- bustion $0.3 \mathrm{Pg}, 16.8 \mathrm{Pg}$ (48.6)); $\mathrm{PM}_{10}$ : 5.9 Tg, 30.2 Tg (5.1); $\mathrm{PM}_{2.5}$ : 4.6 Tg, 21.3 Tg (4.6); BC: $0.69 \mathrm{Tg}, 3.2 \mathrm{Tg}$ (4.7); and OC: $2.5 \mathrm{Tg}, 6.6 \mathrm{Tg}$ (2.7). Clearly, all the air pollutant emissions in Asia increased significantly during these 6 decades. However, this increase was different among the aforementioned species. Growth rates of emissions were relatively large for $\mathrm{SO}_{2}, \mathrm{NO}_{x}$, and $\mathrm{CO}_{2}$ because the major sources of these species are power plants, industries, and road transport, for which fuel consumption increased significantly along with economic development in Asia. $\mathrm{SO}_{2}$ increased before the other species because the majority of the emissions were obtained from the combustion of coal, which is easier to obtain than oil and gas. $\mathrm{SO}_{2}, \mathrm{NO}_{x}$, and $\mathrm{CO}_{2}$ emissions increased keenly in the early 2000 s along with rapid growth of emissions of these species in China. For $\mathrm{NO}_{x}$, combustion of oil fuels, especially by road vehicles, contributed to a large growth of emissions in the latter half of 1950-2015. Growth rates of NMVOCs have also increased recently due to an increase in the emissions from road vehicles and evaporative sources, such as paint and solvent usage, in accordance with economic growth of Asian countries. On the other hand, rates of growth of $\mathrm{CO}, \mathrm{PM}_{10}, \mathrm{PM}_{2.5}, \mathrm{BC}$, and $\mathrm{OC}$ are relatively small. One reason is that emissions of these species are mainly from incomplete combustion in low temperature, and thus emissions from power plants and large industry plants are relatively small. Another reason is that a major source of these species is the combustion of coal and biofuels in the residential sector, which dominated over other sectors in earlier times and was relatively large even in recent years in Asia. Recently, emissions of these species from industries, including combustion and non-combustion processes, have been increasing. In addition, gasoline and diesel vehicles have contributed recently to the growth of $\mathrm{CO}$ and $\mathrm{BC}$ emissions, respectively. Agricultural activities, such as manure management of livestock and fertilizer application, which are major sources of $\mathrm{NH}_{3}$, are rising to support a growing population in Asia. Although the growth rate of $\mathrm{NH}_{3}$ emissions is smaller than other species, it still shows an increasing trend.

Differences in the trends of emissions were also observed on the basis of countries and regions. $\mathrm{SO}_{2}$ and $\mathrm{NO}_{x}$ emissions from Japan were relatively large in Asia during the 1950s-1970s. Emissions from Japan in 1965 are comparable with and are larger than those of China for $\mathrm{SO}_{2}$ and $\mathrm{NO}_{x}$, respectively. In 2015, emissions of $\mathrm{SO}_{2}$ and $\mathrm{NO}_{x}$ in Japan decreased greatly and contributed only about $1.5 \%$ and $3.8 \%$ of Asia's total emissions, respectively. Similar tendencies were also observed in the case of other species. In 2015, China was the largest contributor of emissions for all the species. Recently, emissions of most species in China have shown decreasing or stable trends. In the case of $\mathrm{SO}_{2}$, China contributed about $72 \%$ of emissions in 2005 but about $49 \%$ in 2015. On the other hand, emissions and their relative ratios are increasing in the case of India. Actually, contribution rates of $\mathrm{SO}_{2}, \mathrm{NO}_{x}$, and $\mathrm{BC}$ emissions in India increased from $14 \%, 16 \%$, and $23 \%$ in 2005 to $30 \%, 22 \%$, and $27 \%$ 
Table 3. Summary of national emissions in 2015 for each species and total annual emissions in Asia in 1950, 1960, 1970, 1980, 1990, 2000, and 2010-2015 $\left(\mathrm{Gg} \mathrm{yr}^{-1}\right)$.

\begin{tabular}{|c|c|c|c|c|c|c|c|c|c|c|}
\hline Country & $\mathrm{SO}_{2}$ & $\mathrm{NO}_{x}{ }^{\mathrm{a}}$ & $\mathrm{CO}$ & NMVOCs & $\mathrm{NH}_{3}$ & $\mathrm{CO}_{2}{ }^{\mathrm{b}}$ & $\mathrm{PM}_{10}$ & $\mathrm{PM}_{2.5}$ & $\mathrm{BC}$ & $\mathrm{OC}$ \\
\hline China & 18404 & 24318 & 165133 & 28189 & 14063 & $11941(11466)$ & 15501 & 11342 & 1643 & 2860 \\
\hline India & 11438 & 9969 & 64366 & 14286 & 9505 & $2959(2290)$ & 7213 & 5052 & 858 & 1868 \\
\hline Japan & 565 & 1687 & 3877 & 895 & 349 & 1300 (1269) & 129 & 89 & 17 & 13 \\
\hline Korea, D.P.R. & 116 & 200 & 2663 & 134 & 92 & $29(26)$ & 106 & 56 & 11 & 18 \\
\hline Korea, Rep of & 336 & 1120 & 1931 & 960 & 170 & $689(681)$ & 139 & 114 & 19 & 34 \\
\hline Mongolia & 99 & 127 & 986 & 50 & 139 & $18(17)$ & 44 & 20 & 2.9 & 3.2 \\
\hline Taiwan & 124 & 371 & 1027 & 770 & 85 & $281(279)$ & 45 & 37 & 6.9 & 7.3 \\
\hline Brunei & 4.0 & 13 & 29 & 43 & 3.8 & $6.1(6.1)$ & 7.5 & 2.9 & 0.2 & 0.1 \\
\hline Cambodia & 55 & 61 & 1087 & 212 & 78 & $22(8.5)$ & 115 & 69 & 9.0 & 32 \\
\hline Indonesia & 2852 & 2463 & 20517 & 6130 & 1591 & $655(461)$ & 1606 & 1160 & 196 & 556 \\
\hline Laos & 201 & 35 & 325 & 66 & 67 & $12(7.8)$ & 46 & 25 & 3.6 & 10 \\
\hline Malaysia & 233 & 613 & 1288 & 936 & 163 & $230(225)$ & 206 & 119 & 14 & 12 \\
\hline Myanmar & 154 & 121 & 2925 & 867 & 621 & $59(23)$ & 184 & 165 & 29 & 98 \\
\hline Philippines & 786 & 767 & 3292 & 898 & 388 & $134(110)$ & 284 & 183 & 38 & 61 \\
\hline Singapore & 87 & 89 & 76 & 302 & 6.4 & $46(46)$ & 81 & 62 & 1.2 & 0.5 \\
\hline Thailand & 341 & 1137 & 5436 & 1543 & 542 & $320(250)$ & 522 & 363 & 49 & 125 \\
\hline Vietnam & 436 & 507 & 6078 & 1552 & 747 & $250(198)$ & 587 & 362 & 59 & 146 \\
\hline Afghanistan & 24 & 97 & 404 & 93 & 251 & $9.4(8.0)$ & 18 & 14 & 6.9 & 4.4 \\
\hline Bangladesh & 171 & 305 & 2755 & 704 & 883 & $110(77)$ & 519 & 287 & 40 & 102 \\
\hline Bhutan & 3.3 & 6.8 & 269 & 55 & 9.5 & $4.7(0.6)$ & 29 & 19 & 3.0 & 10 \\
\hline Maldives & 3.1 & 4.1 & 9.4 & 3.7 & 0.4 & $0.8(0.8)$ & 0.2 & 0.2 & 0.1 & 0.0 \\
\hline Nepal & 42 & 64 & 2381 & 533 & 321 & $40(7.0)$ & 207 & 161 & 26 & 89 \\
\hline Pakistan & 1310 & 573 & 8576 & 2031 & 1772 & $273(161)$ & 1310 & 841 & 105 & 324 \\
\hline Sri Lanka & 92 & 187 & 1382 & 374 & 103 & 37 (20) & 135 & 98 & 19 & 49 \\
\hline Asia $^{c} 1950$ & 2540 & 1339 & 1804 & 6551 & 7310 & 1005 (262) & 5089 & 4162 & 630 & 2308 \\
\hline Asia $^{c} 1960$ & 9880 & 3639 & 81220 & 8461 & 8968 & $2016(1125)$ & 11405 & 7487 & 1040 & 3185 \\
\hline Asia $^{c} 1970$ & 15287 & 7470 & 100368 & 11599 & 11579 & 3117 (2076) & 14770 & 9217 & 1221 & 3629 \\
\hline Asia $^{c} 1980$ & 21425 & 12080 & 142102 & 16432 & 15632 & $4550(3288)$ & 19900 & 13060 & 1680 & 4602 \\
\hline Asia $^{c} 1990$ & 29721 & 18481 & 182418 & 22670 & 21035 & $6595(5105)$ & 25427 & 17542 & 2264 & 5574 \\
\hline Asia $^{c} 2000$ & 37074 & 27782 & 219516 & 33498 & 25775 & 9083 (7536) & 29461 & 20758 & 2626 & 5682 \\
\hline Asia $^{\mathrm{c}} 2010$ & 43635 & 46368 & 302562 & 52711 & 30621 & $17055(15213)$ & 29880 & 21220 & 3233 & 6757 \\
\hline Asia $^{\mathrm{c}} 2011$ & 45003 & 48868 & 304900 & 55136 & 30878 & $18047(16237)$ & 30540 & 21559 & 3266 & 6652 \\
\hline Asia $^{\mathrm{c}} 2012$ & 44227 & 48962 & 304396 & 57285 & 31283 & $18496(16698)$ & 30414 & 21526 & 3254 & 6587 \\
\hline Asia $^{c} 2013$ & 42725 & 47561 & 304484 & 58971 & 31559 & $19200(17427)$ & 30649 & 21627 & 3227 & 6485 \\
\hline Asia $^{\mathrm{c}} 2014$ & 40864 & 46970 & 302718 & 60801 & 31770 & $19447(17666)$ & 30469 & 21475 & 3219 & 6478 \\
\hline Asia $^{c} 2015$ & 37876 & 44835 & 296809 & 61627 & 31950 & 19423 (17 639) & 29034 & 20644 & 3155 & 6422 \\
\hline
\end{tabular}

${ }^{\mathrm{a}} \mathrm{Gg}_{-\mathrm{NO}_{2}} \mathrm{yr}^{-1}$. ${ }^{\mathrm{b}} \mathrm{Tg} \mathrm{yr}^{-1}$. Values in parentheses are $\mathrm{CO}_{2}$ emissions excluding biofuel combustion. ${ }^{\mathrm{c}}$ Asia in this table includes all target countries and sub-regions in REASv3.

in 2015, respectively. C. Li et al. (2017) suggested that, in 2016, $\mathrm{SO}_{2}$ emissions in India exceeded those in China. Recent increases in air pollutant emissions have also been observed in SEA and OSA. On the other hand, emissions from OEA started to increase slightly later than Japan and then recently have shown decreasing trends mainly reflecting trends of emissions from the Republic of Korea and Taiwan.

\subsubsection{China}

Growth rates of all pollutant emissions in China in these 60 years estimated from averages during 1950-1955 and 20102015 are as follows: $21 \%$ for $\mathrm{SO}_{2}, 54 \%$ for $\mathrm{NO}_{x}, 7.0 \%$ for $\mathrm{CO}, 13 \%$ for NMVOCs, $4.7 \%$ for $\mathrm{NH}_{3}, 28 \%$ for $\mathrm{CO}_{2}$ (105\% for $\mathrm{CO}_{2}$ excluding biofuel combustion), $6.8 \%$ for $\mathrm{PM}_{10}, 6.1 \%$ for $\mathrm{PM}_{2.5}, 5.5 \%$ for $\mathrm{BC}$, and $2.7 \%$ for OC. It was observed that emissions of all pollutants increased largely during these 6 decades, but most species reached their peaks up to 2015, as shown in Fig. 2. Exceptions to this were NMVOCs, $\mathrm{NH}_{3}$, and $\mathrm{CO}_{2}$; however, their growth rates are at least small or almost zero. Emission trends in China for all the pollutants in each sector and for each fuel type during 1950-2015 were presented in Figs. S1 and S2, respectively. Figure 3 shows recent trends in actual emissions (solid colored areas) and reduced emissions by control measures (hatched areas) from each sector for $\mathrm{SO}_{2}, \mathrm{NO}_{x}$, and $\mathrm{BC}$ dur- 
ing 1990-2015 in China. The reduced emission by control measures was the difference between emissions calculated without effects of all control measures (such as FGD, ESP, using low-sulfur fuels, regulated vehicles) and actual emissions. Total $\mathrm{CO}_{2}$ emissions were also plotted for each panel of Fig. 3 as an indicator of energy consumption. Note that reduced emissions here do not include effects of substitution of fuel types, such as from coal to natural gas.

For $\mathrm{SO}_{2}$, most emissions in China were from coal combustion, which controlled trends of total emissions. $\mathrm{SO}_{2}$ emissions in China increased rapidly in the early 2000s but decreased after 2006 and showed a continuous decline until 2015. Drastic changes in the 2000s were mainly caused by emissions from coal-fired power plants, which increased rapidly along with large economic growth and later decreased due to the introduction of FGD based on the 11th Five Year Plan of China. After 2011, control measures for large industry plants started to become effective and, as a result, total emissions in 2015 became comparable with those in 1990. Without effects of emission controls, emissions from power plants and industry in 2015 would be 3.7 and 2.6 times higher than those in 2000, respectively. In this study, the emissions in 2015 were estimated to be reduced by about $90 \%$ for power plants and $76 \%$ for industry. On the other hand, even without emission controls, $\mathrm{SO}_{2}$ emissions from power plants were almost stable after 2010. The same tendencies were also found in $\mathrm{CO}_{2}$. One considerable reason is an increasing energy supply from nuclear power plants. According to IEA (2017), the total primary energy supply from nuclear power plants increased rapidly recently, and those in 2015 were about 2.3 times higher than in 2010.

Similarly to $\mathrm{SO}_{2}, \mathrm{NO}_{x}$ emissions increased rapidly from the early 2000s but continued to increase until 2011, and then started to decline. In the $2000 \mathrm{~s}$, low- $\mathrm{NO}_{x}$ burners to power plants and regulation of road vehicles were introduced, but their effects were limited. From 2011, introduction of denitrification technologies, such as selective catalytic reduction (SCR) to large power plants and regulations for road vehicles, were strengthened based on the 12th Five Year Plan of China. Three major drivers of $\mathrm{NO}_{x}$ emissions in China are power plants, the industry sector, and road transport. If no emission mitigation was considered, their emissions would be increased by 3.6, 3.0, and 4.7 times from 2000 to 2010 , respectively. In 2015 , reduction rates of emissions due to emission controls were about $61 \%, 19 \%$, and $62 \%$ for power plants, industry, and road transport, respectively. As a result, in $2015, \mathrm{NO}_{x}$ emissions were about $81 \%$ of their peak values in 2011. In 2015, actual $\mathrm{NO}_{x}$ emissions from the industry sector were larger than those from power plants and road transport, which were comparable with each other. Major industries such as the iron and steel, chemical and petrochemical, and cement industries were large contributors of $\mathrm{NO}_{x}$ emissions in China.

For BC, emissions also increased from the early 2000s, but growth rates were smaller than $\mathrm{SO}_{2}$ and $\mathrm{NO}_{x}$ due to the ef- fects of control equipment in the industrial sector. Actually, trends of $\mathrm{BC}$ emissions assuming no emission controls were close to those of $\mathrm{CO}_{2}$, and the $\mathrm{BC}$ emissions in 2015 were increased by 2.2 times from 2000. The emissions in 2015 were reduced by about $41 \%$ by abatement measures in industry plants and $9 \%$ by regulations, especially for diesel vehicles. In 2015, large contributors in the industry sectors were brick production, coke ovens, and coal combustion in other industry plants. Another reason for relatively small growth rates could be that $\mathrm{BC}$ emission factors for coal-fired power plants are originally low. Recently, $\mathrm{BC}$ emissions from the residential sector as well as industrial sector show decreasing trends. In this study, the reductions in $\mathrm{BC}$ emissions in the residential sector were mainly caused by a decrease in emissions from biofuel combustion. During 2010 to 2015, consumptions of primary solid biofuels were reduced about $28 \%$, whereas consumption of natural gas and liquefied petroleum gas increased about $62 \%$ in the residential sector.

For CO, most emissions in the 1950s were from residential sectors and gradually increased with increasing coal consumption in the industrial sector. $\mathrm{CO}$ emissions increased largely in the 2000s due to coal combustion and iron and steel production processes. Recently, CO emissions have seen a decline. A major reason for this declining trend is the decrease in biofuel consumption in the residential sector and the phasing out of shaft kilns with high $\mathrm{CO}$ emission factors in the cement industry. NMVOC emissions increased significantly from the early 2000 s, similarly to other species. However, their major sources were different from others. Recent increasing trends are not caused by stationary combustion sources but by road transport and evaporative sources, such as paint and solvent use. In particular, emissions from non-combustion sources increased largely from 2000 to 2015 (about 3.7 time), and as a result, their contribution rate in 2015 was about $65 \%$. Growth rates of NMVOC emissions tended to slow down around 2015, but emissions increased almost monotonically after the $2000 \mathrm{~s}$. $\mathrm{NH}_{3}$ emissions were mostly from agricultural activities. In China, emissions from fertilizer application showed a significant increase from the early 1970 s to the early 2000 s. In recent years, $\mathrm{NH}_{3}$ emissions are almost stable. For $\mathrm{PM}_{10}$ and $\mathrm{PM}_{2.5}$, the majority of the emissions are from the industrial sector, followed by the residential sector and power plants. Emissions increased largely from the early 1990s mainly due to coal combustion and industrial processes, especially in cement plants. Compared to $\mathrm{SO}_{2}$ and $\mathrm{NO}_{x}$, growth rates of $\mathrm{PM}_{10}$ and $\mathrm{PM}_{2.5}$ emissions during the early 2000s were small, and later decreased due to the effects of control equipment in industrial plants. OC emissions were mostly from biofuel combustion in the residential sector. Contributions from the industrial sector have been increasing recently, but total OC emissions have decreased due to reduced usage of biofuels. $\mathrm{CO}_{2}$ emissions were mainly controlled by coal combustion, and their trends were similar to those of $\mathrm{SO}_{2}, \mathrm{NO}_{x}$, and $\mathrm{BC}$ without emission controls as shown in Fig. 3. After 2011, $\mathrm{CO}_{2}$ emis- 

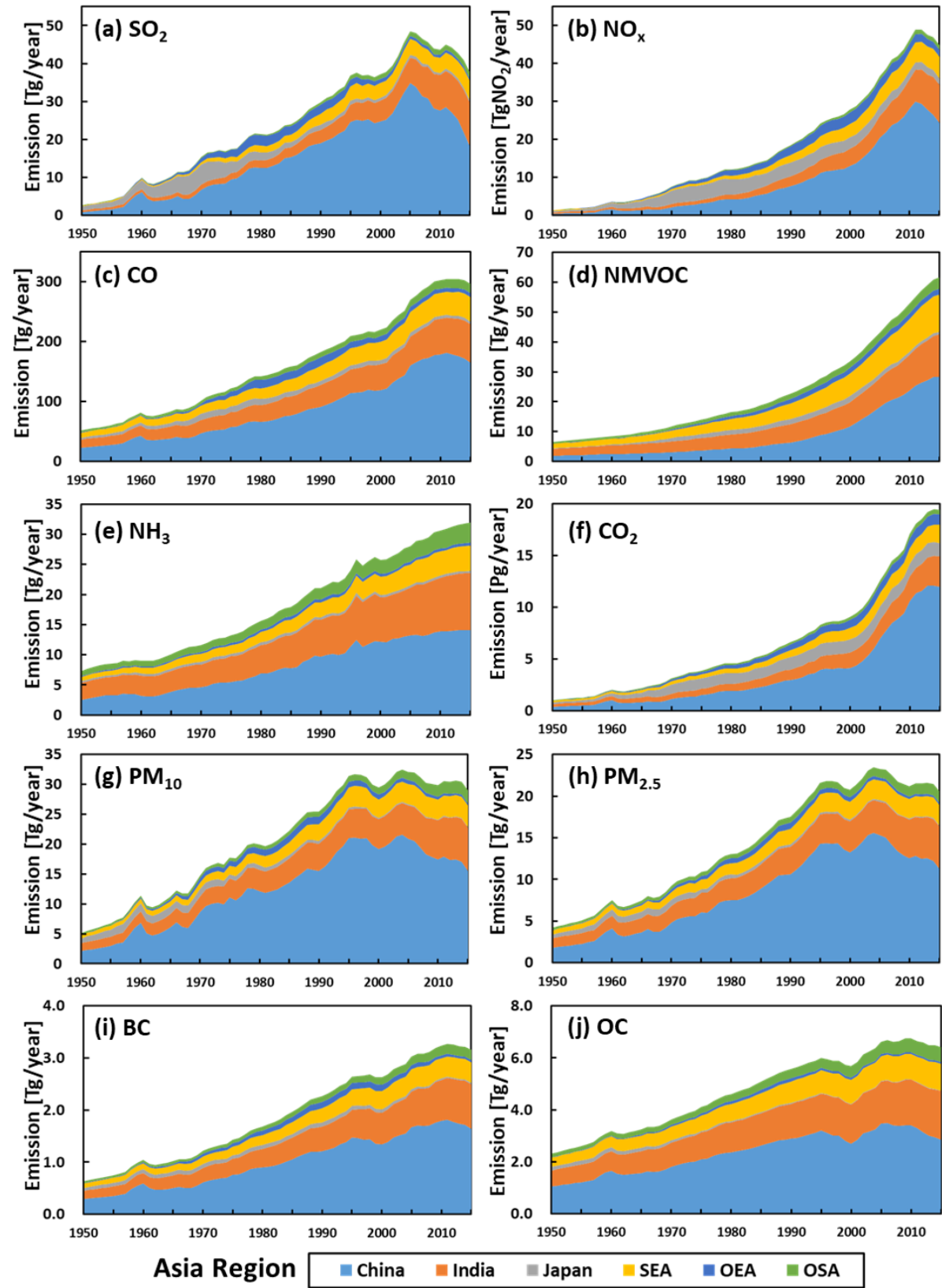

Figure 2. Trends of (a) $\mathrm{SO}_{2}$, (b) $\mathrm{NO}_{x}$, (c) $\mathrm{CO}$, (d) NMVOCs, (e) $\mathrm{NH}_{3}$, (f) $\mathrm{CO}_{2}$, (g) $\mathrm{PM}_{10}$, (h) $\mathrm{PM}_{2.5}$, (i) $\mathrm{BC}$, and (j) $\mathrm{OC}$ emissions in Asia during 1950-2015 for each region. See Fig. 1 for countries included in SEA, OEA, and OSA.

sions in China were found to be almost stable. As described above, one reason is a trend of emissions from power plants. In addition, emissions from coal combustion in industry sectors were slightly decreased from 2014 to 2015.

\subsubsection{India}

Growth rates of air pollutant emissions in India based on averaged values during 1950-1955 and 2010-2015 are as follows: $19 \%$ for $\mathrm{SO}_{2}, 23 \%$ for $\mathrm{NO}_{x}, 4.2 \%$ for $\mathrm{CO}, 5.3 \%$ for NMVOCs, $3.1 \%$ for $\mathrm{NH}_{3}, 8.9 \%$ for $\mathrm{CO}_{2}\left(29 \%\right.$ for $\mathrm{CO}_{2}$ excluding biofuel combustion), $4.8 \%$ for $\mathrm{PM}_{10}, 4.0 \%$ for $\mathrm{PM}_{2.5}, 4.8 \%$ for BC, and $2.8 \%$ for OC. Figures S3 and S4 provide trends of emissions in India from each sector and fuel type for all the pollutants, respectively, from 1950 to 2015. In general, all the air pollutants show monotonous increase from 1950 to 2015 and growth rates (especially of recent years) are larger for $\mathrm{SO}_{2}, \mathrm{NO}_{x}, \mathrm{NMVOCs}$, and $\mathrm{CO}_{2}$, which is similar to the case of Asia.

Figure 4 shows trends in emission of $\mathrm{SO}_{2}, \mathrm{NO}_{x}$, and $\mathrm{BC}$ from each fuel type as well as sectors with total $\mathrm{CO}_{2}$ emis- 


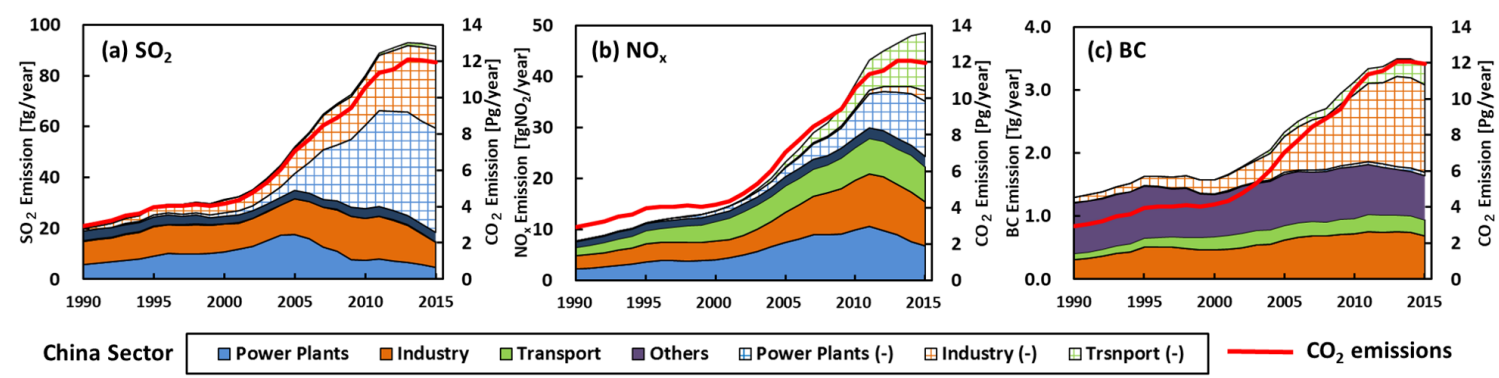

Figure 3. Emissions of (a) $\mathrm{SO}_{2}$, (b) $\mathrm{NO}_{x}$, and (c) BC from each major sector in China during 1990-2015. Solid colored areas are actual emissions, and hatched ones (-) are reduced emissions due to control measures. Red lines in the panels are total $\mathrm{CO}_{2}$ emissions.

sions during 1950-2015 in India. Clear differences were seen in the structure of emissions in these species. For $\mathrm{SO}_{2}$, large parts of emissions were from coal combustion in power plants and the industry sector. $\mathrm{SO}_{2}$ emissions in 2015 were about 3.3 times larger than those in 1990, and contribution rates of the increases from power plants and industry sectors were about $66 \%$ and $33 \%$, respectively. Trends of total $\mathrm{NO}_{x}$, emissions were close to those of $\mathrm{SO}_{2}$ and contributions from coal-fired power plants were also large. In addition, for $\mathrm{NO}_{x}$, contribution from road transport especially diesel vehicles were comparable with those of power plants. Around the year 2005, the contributions from road transport were almost the same as or slightly larger than power plants. However, from 2005 to 2015, growth rates of $\mathrm{NO}_{x}$ emissions from power plants were about twice as high than those of road transport emissions. For BC, contributions from the residential sector and biofuel combustion were large, especially in the 1950s-1960s. Contribution rates of the residential sector were $73 \%$ in 1950 and $38 \%$ in 2015, and those of biofuel combustion, which were mainly used in the residential sector and some parts used in the industry sector, were $86 \%$ in 1950 and $45 \%$ in 2015. On the other hand, recent increasing trends of BC emissions were also caused by growth of emissions from diesel vehicles and the industry sector. From 1990 to 2015 , contribution rates of increased emissions from the industry, road transport, and residential sectors were $27 \%$, $43 \%$, and $23 \%$, respectively. For recent trends, relative ratios of $\mathrm{SO}_{2}$ emissions from power plants were increased from $43 \%$ to $59 \%$ during $1990-2015$. For $\mathrm{NO}_{x}$, contribution rates from both power plants and road transport were increased and accounted for about $75 \%$ of the total emissions in 2015 . Even in 2015, about half of the BC emissions were from the residential sector. However, as previously described, recent emission growths were mainly caused by the industrial sector and road transport. These tendencies were similar to Japan and China during their rapid emission growth periods. These features were consistent with trends of $\mathrm{CO}_{2}$ emissions. $\mathrm{Be}-$ fore the mid-1980s, the majority of $\mathrm{CO}_{2}$ emissions were from biofuel combustion, and the trends were close to those of BC. Then, recently, contributions from fossil fuel combustion in- creased greatly, and trends of $\mathrm{CO}_{2}$ became close to those of $\mathrm{SO}_{2}$ and $\mathrm{NO}_{x}$, especially after the early 2000s.

Trends and structure of $\mathrm{CO}$ emissions were similar to those of $\mathrm{BC}$, but contribution rates of the residential sector were larger and those from road transport (mainly from gasoline vehicle) were smaller, as compared to BC. On the other hand, for recent trends, half $(51 \%)$ of increased emissions during 2005 and 2015 were from the industry sector. A similar tendency was also found in OC; however, relative ratios of emissions from the residential sector were much larger (about $71 \%$ in 2015), and those of the industry and road transport sectors were much smaller. For $\mathrm{PM}_{10}$ and $\mathrm{PM}_{2.5}$, the majority of the emissions were from the residential and industrial sectors. Both amounts were almost comparable in $\mathrm{PM}_{10}$, and those from residential sectors were larger in $\mathrm{PM}_{2.5}$. Different from $\mathrm{BC}$ and $\mathrm{OC}$, contributions from coal-fired power plants exist in $\mathrm{PM}_{10}$ and $\mathrm{PM}_{2.5}$, whose contribution rates in 2015 are about $20 \%$ and $13 \%$, respectively. For NMVOCs, most emissions were from biofuel combustion before the 1980s. Later, emissions from a variety of sources, such as road transport, extraction, and handling of fossil fuels, usage of paint and solvents, are increasing and are controlling recent trends. For increases in emissions from 1990 to 2015, about $52 \%$ were from stationary combustion and road transport and the rest were from stationary non-combustion sectors such as paint and solvent use. Most $\mathrm{NH}_{3}$ emissions are from agricultural activities. Contributions from manure management and fertilizer use were comparable before the 1980s. However, emissions from fertilizer application have increased largely, which are now determining recent trends.

\subsubsection{Japan}

As described in Sect. 3.1.1, trends of air pollutant emissions in Japan were different from other countries and regions in Asia. The trends from each sector and fuel type during 19502015 in Japan were shown in Figs. S5 and S6. Compared to the rest of Asia, emissions of all species in Japan except $\mathrm{CO}_{2}$ were reduced significantly after reaching peak values. In addition, peak years were mostly 40 years ago (about 1960 for $\mathrm{PM}_{10}, \mathrm{PM}_{2.5}$, and $\mathrm{OC}, 1970$ for $\mathrm{SO}_{2}$ and $\mathrm{CO}, 1980$ for $\mathrm{NO}_{x}$ and $\mathrm{NH}_{3}, 1990$ for $\mathrm{BC}$, and 2000 for NMVOCs). Fig- 

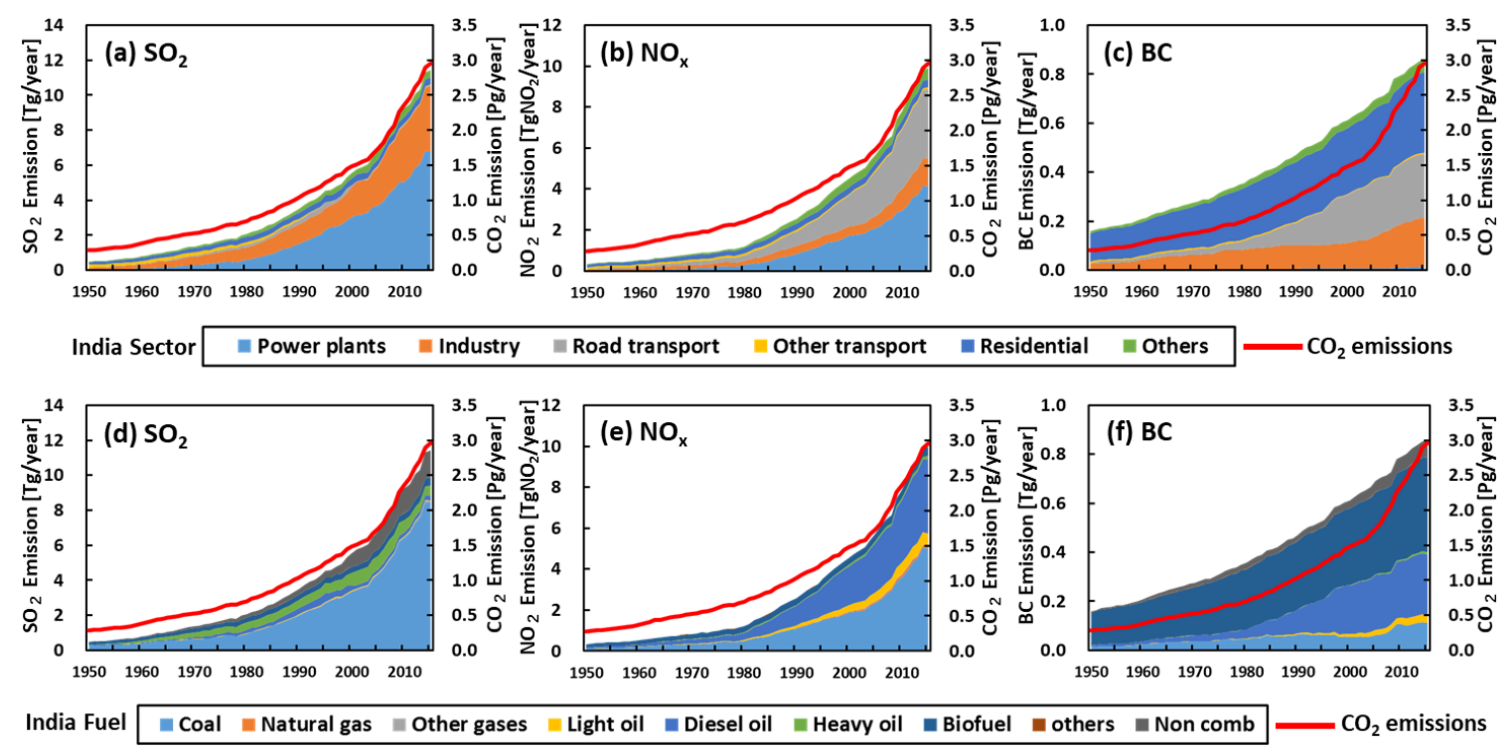

Figure 4. Emissions of (a, d) $\mathrm{SO}_{2}$, (b, e) $\mathrm{NO}_{x}$, and (c, f) $\mathrm{BC}$ from each major sector category $(\mathbf{a}, \mathbf{b}, \mathbf{c})$ and fuel type (d, e, f) in India from 1950 to 2015 ("Non comb": non-combustion sources). Red lines in the panels are total $\mathrm{CO}_{2}$ emissions.

ure 5, similarly to Fig. 3, shows trends of actual emissions (solid colored areas) and reduced emissions by control measures (hatched areas) from each sector for $\mathrm{SO}_{2}, \mathrm{NO}_{x}$, and $\mathrm{BC}$ during 1950-2015. Total $\mathrm{CO}_{2}$ emissions were also plotted to each panel of Fig. 5. $\mathrm{CO}_{2}$ emissions increased rapidly in the 1960s and have generally continued to increase, but growth rates are much smaller than those in the 1960s, reflecting trends of economic status of Japan.

$\mathrm{SO}_{2}$ emissions, especially from power plants and the industry sector, increased significantly in the 1960s (reflecting the rapid economic growth) and caused severe air pollution in Japan. In the 1950s, more than half the emissions were from coal combustion, and then contributions from heavy fuel oil increased rapidly in the 1960s (more than $50 \%$ around the peak year). In order to mitigate air pollution, first, regulation of sulfur contents, especially in heavy fuel oil, was strengthened. Then, desulfurization equipment was mainly introduced from the mid-1970s. As a result, about $68 \%, 84 \%$, and $93 \%$ of the $\mathrm{SO}_{2}$ emissions were reduced by regulatory measures in 1975,1990 , and 2015 , respectively. Furthermore, although coal consumption in power plants increased in the $1990 \mathrm{~s}, \mathrm{SO}_{2}$ emissions almost did not change due to these measures. For trends of $\mathrm{SO}_{2}$ emissions assuming without emission controls and those of $\mathrm{CO}_{2}$, there are clear differences in the 1970s and after the 1980s. The causes of the differences in the 1970s were decreases in heavy fuel oil consumption, whose contribution rates to $\mathrm{SO}_{2}$ were much higher than $\mathrm{CO}_{2}$. By contrast, causes of the differences in the 1980s were increasing consumption of gas and light fuel oil whose sulfur contents were small.

$\mathrm{NO}_{x}$ emissions also increased rapidly from the 1960s, mainly by steep increases in traffic volumes and fossil fuel combustion in power and large industry plants. The largest contribution to $\mathrm{NO}_{x}$ emissions during the peak periods was from the road transport sector, that is, greater than $50 \%$ of total emissions. Regulations for road vehicles became effective from the late 1970s, but an increase in the number of vehicles partially cancelled the effects. For stationary sources, the number of introduced denitrification equipment increased largely in the 1990s. As a result, $\mathrm{NO}_{x}$ emissions peaked later; furthermore, reduction rates after the peak were smaller compared to that of $\mathrm{SO}_{2}$. From 1975 to 2015, emissions assuming no emission mitigations would be increased by about 2.0 times for power plants and 2.4 times for road transport. In 2015 , by emission abatement equipment for power plants and control measures for road vehicles, the emissions were reduced by $77 \%$ and $90 \%$, respectively. As a result, the reduction rate of total $\mathrm{NO}_{x}$ emissions in 2015 was $78 \%$, but it was smaller than $\mathrm{SO}_{2}$ as described above.

For BC, contributing sectors changed during 1950-2015. In the 1950s, most emissions were from industries and the residential sector, and their amounts were almost comparable. After the 1960s, both types of emissions declined, but reasons for declines were different. In the 1950s, coal and biofuels, which have large $\mathrm{BC}$ emission factors were mainly used in residential sectors. However, these fuels were substituted for cleaner ones, such as natural gas and liquefied petroleum gas, which reduced $\mathrm{BC}$ emissions significantly. Emissions in industrial sectors decreased gradually after the 1960s due to the introduction of abatement equipment for PM. Instead, emissions from the road transport sector from diesel vehicles increased from the late 1960s to around 1990. Then, regulations for road vehicles were strengthened and $\mathrm{BC}$ emissions were reduced largely from peak values. Before 


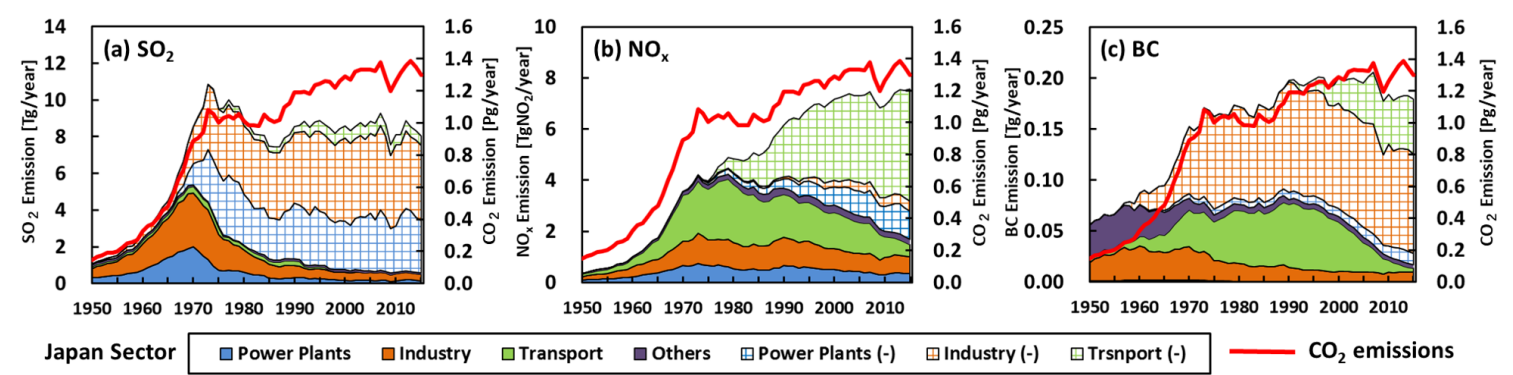

Figure 5. Emissions of (a) $\mathrm{SO}_{2}$, (b) $\mathrm{NO}_{x}$, and (c) $\mathrm{BC}$ from each major sector in Japan during 1950-2015. Solid colored areas are actual emissions, and hatched ones (-) are reduced emissions due to control measures. Red lines in the panels are total $\mathrm{CO}_{2}$ emissions.

1986, emission controls for BC were only considered for stationary sources. In 1985, by effects of abatement equipment to power and industrial plants, emissions were reduced by about $58 \%$ from those assuming no emission controls. Then, by introducing regulations for diesel vehicles, the reduction rates became about $91 \%$ in 2015 .

For CO and OC, most emissions in the 1950s were from biofuel combustion in the residential sector. $\mathrm{CO}$ and NMVOC emissions in road transport increased largely in the 1960s and then decreased gradually, similarly to the case of $\mathrm{NO}_{x}$. Recently, the majority of NMVOC emissions were from evaporative sources, such as paint and solvent use. These started to increase from the 1980s and then decreased after 2000. Emissions of $\mathrm{CO}$ and OC from the industrial sector showed a similar increase before 1970, whereas OC emissions started to decrease due to control equipment for PM species and CO emissions were almost stable after 1970. The majority of $\mathrm{NH}_{3}$ emissions in Japan were from agricultural activities, especially manure management; however, contributions from latrines were also large in the past years. Overall, $\mathrm{NH}_{3}$ emissions increased from 1950 to the 1970s but showed slightly decreasing trends after the 1990s. PM $_{10}$ and $\mathrm{PM}_{2.5}$ emission trends were almost the same. The majority of emissions were from the industrial sector, which grew during the 1950s but decreased largely in the 1970s due to the effects of abatement equipment for PM. Contributions from the residential sector were relatively large from the 1950s to the 1960s. Furthermore, contributions from road transport increased from the 1970s and started to decrease after 1990, similarly to BC.

\subsubsection{Other regions}

Similarly to India, air pollutant emissions in SEA and OSA tended to increase during these 6 decades. Figures S7 and S8 (S11 and S12) provide trends for all the air pollutant emissions in SEA (in OSA) for each sector and fuel type, respectively, from 1950 to 2015. Figures 6 and 7 show emission trends of $\mathrm{SO}_{2}, \mathrm{NO}_{x}$, and $\mathrm{BC}$ for each sector category and contribution rate of each country from 1950 to 2015 in SEA and OSA, respectively. Total $\mathrm{CO}_{2}$ emissions were also plotted in the upper panels of Figs. 6 and 7.
Contributing sources and their relative ratios in $\mathrm{SO}_{2}, \mathrm{NO}_{x}$, and $\mathrm{BC}$ emissions are generally close between these regions. For both the regions, major sources of $\mathrm{SO}_{2}$ emissions are power plants and the industry sector. For fuel types, contributions from heavy fuel oil were large in the case of $\mathrm{SO}_{2}$ emissions in OSA and were almost comparable with those of coal in SEA during the 1990s. After 2010, emissions from coalfired power plants in SEA increased rapidly which were doubled during 2010-2015. On the other hand, in OSA, heavy fuel consumption in power plants increased by 1.8 times from 2005 to 2015 which mainly caused the large increase in $\mathrm{SO}_{2}$ emission. For $\mathrm{NO}_{x}$, the majority of the emissions were from road transport, mainly diesel vehicles. This controlled the recent trends in both regions. Contributions from gasoline vehicles were small in OSA but relatively large in SEA (about $16 \%$ in 2015). On the other hand, $\mathrm{NO}_{x}$ emissions from natural gas vehicles increased from the $2000 \mathrm{~s}$ in OSA and contribution rates in the road transport sector were more than $15 \%$ after the late 2000s. Recently, similarly to $\mathrm{SO}_{2}, \mathrm{NO}_{x}$ emissions from power plants have been increasing by coal and heavy fuel oil combustion in SEA and OSA, respectively. From 2010 to 2015, increases in emissions were mainly caused by power plants in both regions (about $67 \%$ for SEA and $82 \%$ for OSA). Although trends are almost stable, emissions from biofuel combustion in the residential sector are relatively large in OSA. BC emissions are mostly from biofuel combustion in the residential sector, especially in OSA. and increased constantly during the period of REASv3. After the late 2000s, BC emissions from road transport show decreasing trends due to effects of emission regulations, especially in SEA. Relations between trends of $\mathrm{SO}_{2}, \mathrm{NO}_{x}, \mathrm{BC}$, and $\mathrm{CO}_{2}$ emissions were similar to the case of India that trends of $\mathrm{CO}_{2}$ were close to those of $\mathrm{BC}$ before the 1980s and then those of $\mathrm{SO}_{2}$ and $\mathrm{NO}_{x}$ after the 1990s. In the case of country-wise emissions, currently, the largest contributing countries are Indonesia and Pakistan in SEA and OSA, respectively. In 2015, the second and third highest contributing countries in SEA were Philippines and Vietnam for $\mathrm{SO}_{2}$, Thailand and Philippines for $\mathrm{NO}_{x}$, and Vietnam and Thailand for BC. Relative ratios of $\mathrm{SO}_{2}$ emissions in Thailand were large in the early 1990s but decreased 


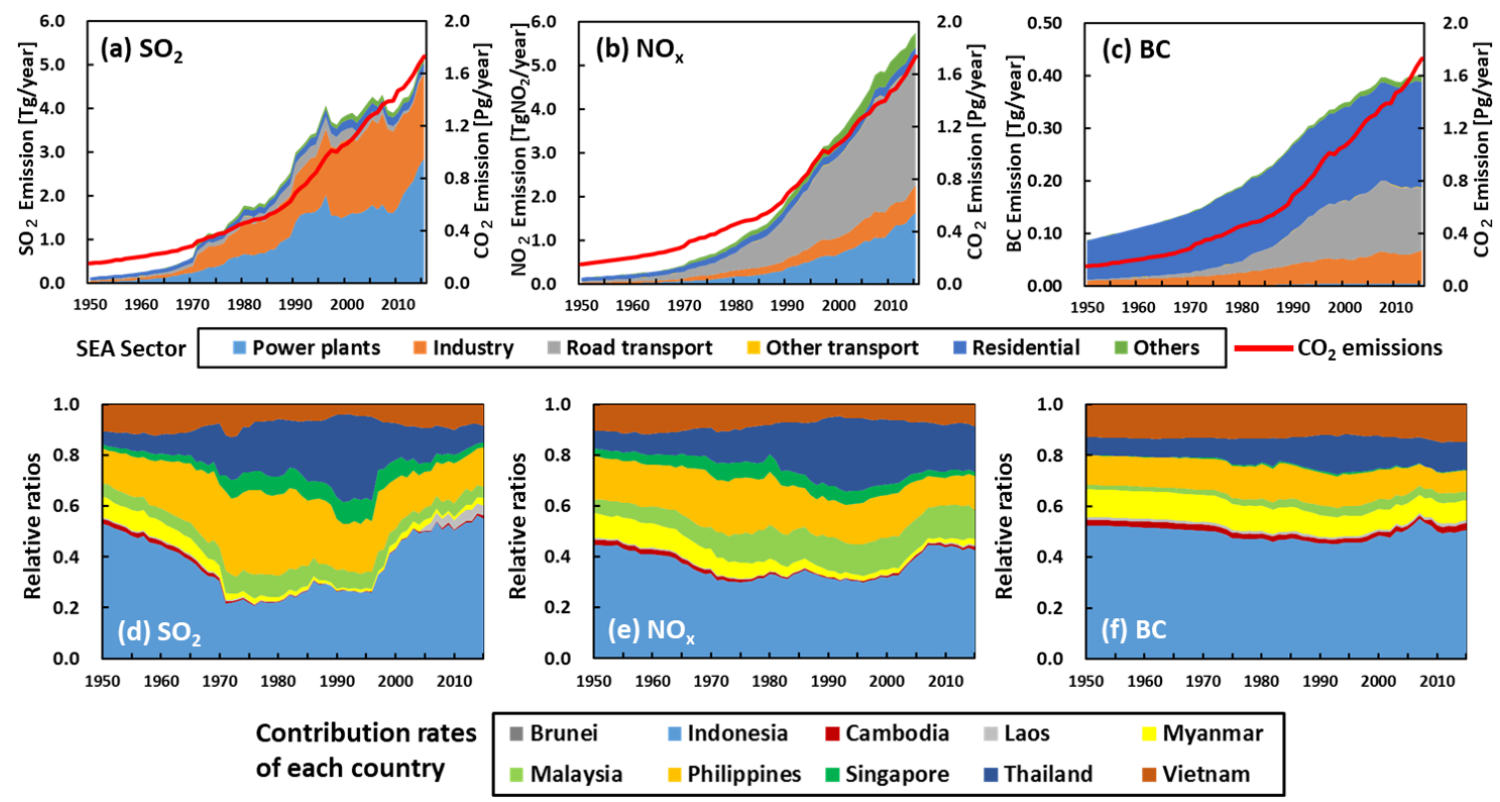

Figure 6. Emissions of (a) $\mathrm{SO}_{2}$, (b) $\mathrm{NO}_{x}$, and (c) BC from each major sector in SEA (a, b, c) and (d, e, f) relative ratios of emissions from each country in SEA (d, e, f) during 1950-2015. Red lines in the upper panels are total $\mathrm{CO}_{2}$ emissions.
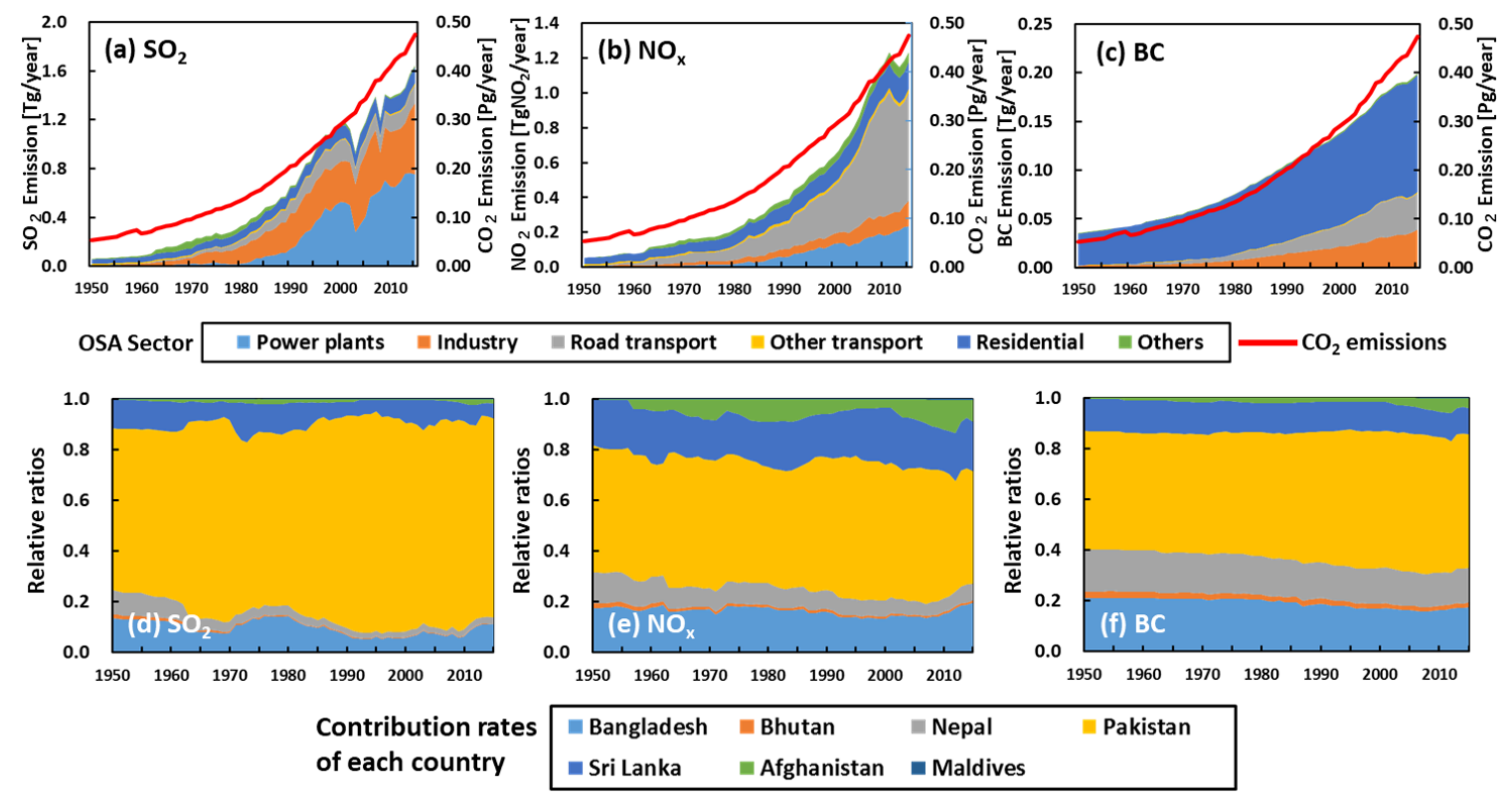

Figure 7. Emissions of (a) $\mathrm{SO}_{2}$, (b) $\mathrm{NO}_{x}$, and (c) $\mathrm{BC}$ from each major sector in OSA (a, $\mathbf{b}$, $\mathbf{c}$ ) and (d, e, f) relative ratios of emissions from each country in OSA (d, e, f) from 1950 to 2015. Red lines in the upper panels are total $\mathrm{CO}_{2}$ emissions.

significantly due to the introduction of FGD in large coalfired power plants. For OSA, the second highest contributing country is Bangladesh; Sri Lanka is ranked third for $\mathrm{SO}_{2}$ and $\mathrm{NO}_{x}$ and Nepal for BC.

Emission trends in OEA from each sector during 19502015 were presented for all the air pollutants in Figs. S9 and S10. Emission trends in the Republic of Korea and Taiwan were similar to those of Japan. $\mathrm{SO}_{2}$ emissions increased rapidly in the 1970s and reduced largely from their peak values due to the introduction of low-sulfur fuels and FGD. $\mathrm{NO}_{x}$ emissions started to increase steeply from the 1980s due to emissions from road vehicles, in addition to those from power and industry plants. Then, $\mathrm{NO}_{x}$ emissions decrease after 2000 due to regulations related to road vehicles and the introduction of control equipment to power plants. However, their rate of decrease was lower than that of $\mathrm{SO}_{2}$. $\mathrm{BC}$ emis- 
sion trends were similar to those of $\mathrm{NO}_{x}$ until around the year 2000, but the ratio of decrease after 2000 is much larger than that of $\mathrm{NO}_{x}$. The differences of reduction rates of emissions between $\mathrm{NO}_{x}$ and $\mathrm{BC}$ were caused by effects of emission controls in the road transport sector. These features and drivers of trends were generally similar to the case of Japan. For the Democratic People's Republic of Korea, emissions of $\mathrm{SO}_{2}, \mathrm{NO}_{x}, \mathrm{CO}_{2}$, and PM species decreased and those of $\mathrm{CO}$, NMVOCs, and $\mathrm{NH}_{3}$ were almost stable recently. The recent decreasing trends were mainly caused by coal consumption amounts in the industry sector. For Mongolia, emissions of all the air pollutants, except PM species, show increasing trends recently. The increasing trends were mainly caused by coal-fired power plants for $\mathrm{SO}_{2}$ and $\mathrm{CO}_{2}$, road transport for $\mathrm{NO}_{x}, \mathrm{CO}$, NMVOCs, and $\mathrm{BC}$, and the domestic sector for OC. For $\mathrm{PM}_{10}$ and $\mathrm{PM}_{2.5}$, due to effects of abatement equipment in power plants, emissions were almost stabilized after 2000. Note that information on these two countries is limited, and therefore uncertainties are large.

\subsection{Spatial distribution and monthly variation}

Figure 8 presents the emission map of $\mathrm{SO}_{2}, \mathrm{NO}_{x}, \mathrm{CO}$, NMVOCs, $\mathrm{NH}_{3}, \mathrm{PM}_{2.5}, \mathrm{BC}$, and OC in 1965 and 2015 at $0.25^{\circ} \times 0.25^{\circ}$ resolution. Emission maps of $\mathrm{CO}_{2}$ and $\mathrm{PM}_{10}$ are presented in Fig. S13. In 1965, high emission grids appeared in industrial areas of Japan, especially for $\mathrm{NO}_{x}, \mathrm{SO}_{2}$, and $\mathrm{CO}_{2}$. On the other hand, high emission grids were seen in wide areas in China and India for CO and PM species, especially OC. This is because emissions of these species were mainly from the residential sector and small industrial plants. In 2015, high emission areas for all species clearly appeared in China and India, especially in the northeastern area, around Sichuan Province and the Pearl River Delta for China and the Indo-Gangetic Plain, around Gujarat, and southern areas for India. High emission areas of $\mathrm{SO}_{2}$ and PM species in Japan disappeared or shrank in 2015 compared to 1965 but still remained in the $\mathrm{NO}_{x}, \mathrm{CO}, \mathrm{NMVOCs}$, and $\mathrm{CO}_{2}$ maps. In SEA, high emission areas were seen in Java in Indonesia and around large cities, such as Bangkok (Thailand) and Hanoi (Vietnam). $\mathrm{NH}_{3}$ and $\mathrm{OC}$ emissions, whose major sources were the agriculture and residential sectors, respectively, were found in relatively large areas of China, India, and SEA.

As described in Sect. 2.6, seasonality of emissions is taken into account for sectors where proxy data for monthly profiles were available or could be estimated. Monthly variations of total emissions of $\mathrm{SO}_{2}, \mathrm{NO}_{x}, \mathrm{BC}$, and $\mathrm{NH}_{3}$ are shown for China, India, Japan, SEA, OEA, and OSA for the year 2015 in Fig. 9. For $\mathrm{SO}_{2}$ and $\mathrm{NO}_{x}$, monthly variations were generally small. In China, emissions were slightly larger in the second half of the year. Monthly factors of $\mathrm{SO}_{2}$ emissions in OSA were high from December to May and low during July and September due to the timings of brick production. For $\mathrm{BC}$, emissions in winter season were relatively large, especially in China and OEA. This seasonality was mainly determined by fuel consumption in the residential sector for the purposes of heating. Therefore, monthly variations of $\mathrm{BC}$ emissions were smaller in SEA. For $\mathrm{NH}_{3}$, seasonality of emissions was controlled by the seasonality of emissions from fertilizer application and manure management. In China, Japan, and OEA, peaks of emissions appeared during summertime. Monthly variations of emissions in the whole of SEA were small, but seasonality was different from each country. Finally, it must be noted that monthly variations of emissions in each grid were different to each other because they were determined by monthly profiles of major emission sources in each grid cell.

\subsection{Comparison with other inventories}

In this section, estimated emissions of REASv3 were compared with other global, regional, and national bottom-up inventories and several top-down estimates. Figures 10 and 11 compare the results of REASv3 with other studies for $\mathrm{SO}_{2}$, $\mathrm{NO}_{x}$, and $\mathrm{BC}$ emissions in China and India, respectively. For other species, results based on comparison with China are presented in Fig. S14, and those with India are shown in Fig. S15. Furthermore, Figs. S16-S19 provide the comparisons of emissions from Japan, SEA, OEA, and OSA, respectively. In Figs. 10, 11, and S14-S19, error bars were plotted in 2015, 1985, and 1955 of emissions in REASv3. These error bars were based on uncertainties estimated in this study for corresponding emissions. See Sect. 3.4 for details about the uncertainties in emissions in REASv3. Note that as described in Sect. 2.1, emissions from domestic and fishing ships are not included in REASv3. Therefore, corresponding data need to be excluded from values of other inventories in the comparisons. This procedure was done for REAS series, EDGARv4.3.2, CEDS, and several research works. For other inventories where emissions from domestic ships were not available independently, total emissions were plotted in the figures. It was confirmed that other sources out of scope of REASv3 such as open biomass burning were not included in the other inventories.

\subsubsection{China}

For long historical trends of $\mathrm{SO}_{2}$ emissions in China, most studies generally agreed with the trends of REASv3, although values of REASv3 during 1995 and 2005 were slightly larger than other inventories. Emissions increased almost monotonically until around 1995 and became stable during the late 1990s. Then, emission increased rapidly from the early 2000s and started to decrease from the late 2000s. However, the decreasing rates were different, especially after 2010. Recent rapid decreasing tendency in REASv3 was similar to that of Zheng et al. (2018), but decreasing rates of other studies such as Xia et al. (2016) and Sun et al. (2018) were smaller than REASv3. Values of REASv3 
(a) $\mathrm{SO}_{2}$ in 1965

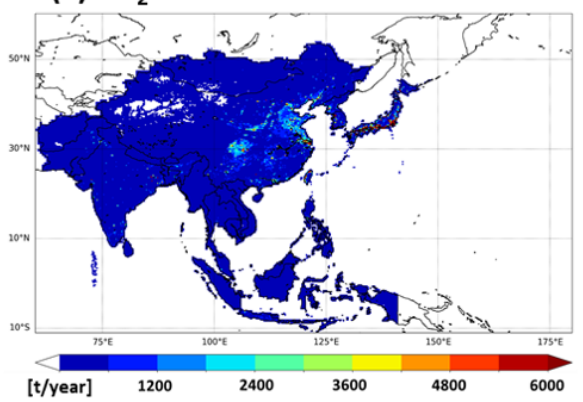

(c) $\mathrm{NO}_{\mathrm{x}}$ in 1965

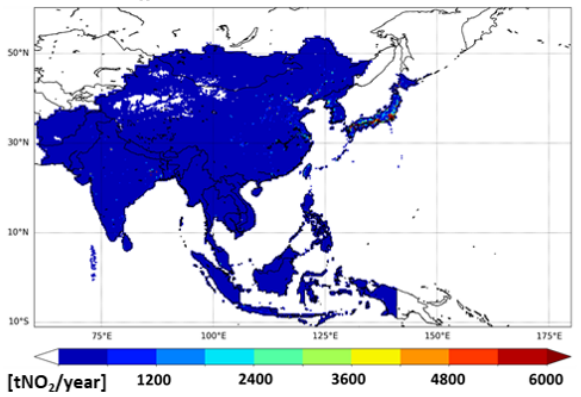

(e) $\mathrm{CO}$ in 1965

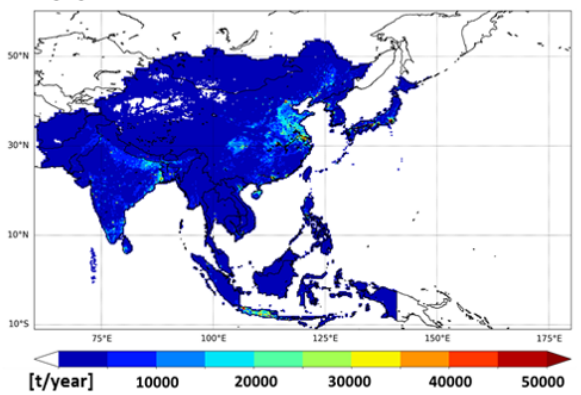

(g) NMVOC in 1965

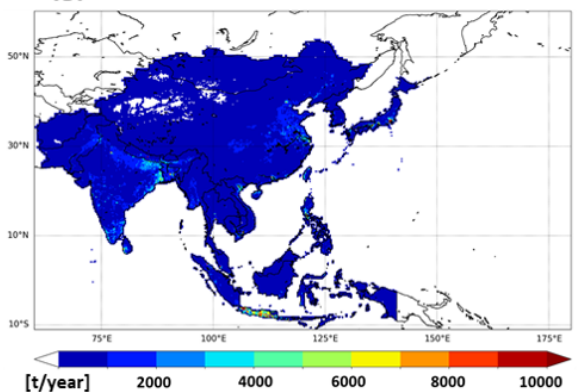

(b) $\mathrm{SO}_{2}$ in 2015

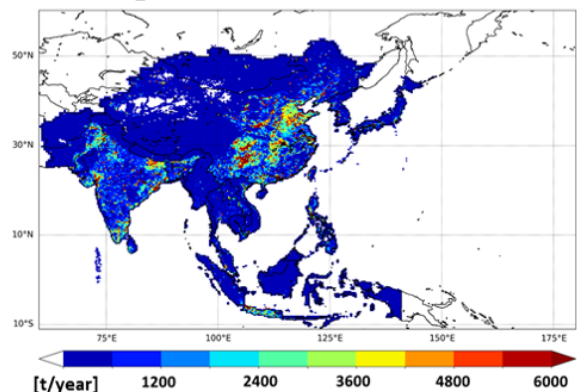

(d) $\mathrm{NO}_{\mathrm{x}}$ in 2015

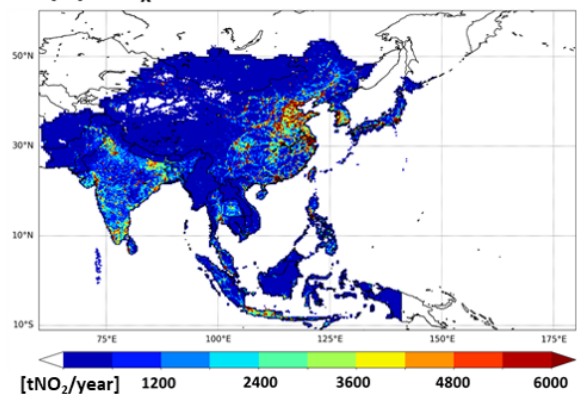

(f) $\mathrm{CO}$ in 2015

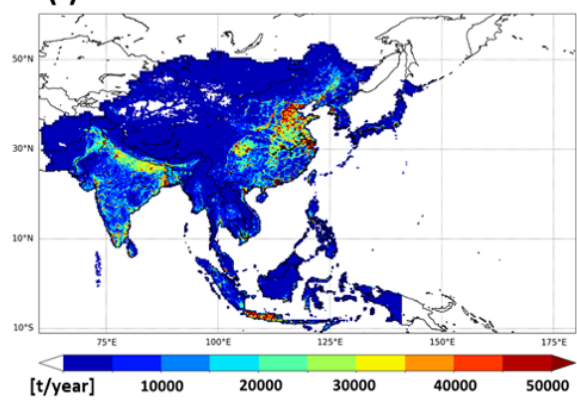

(h) NMVOC in 2015

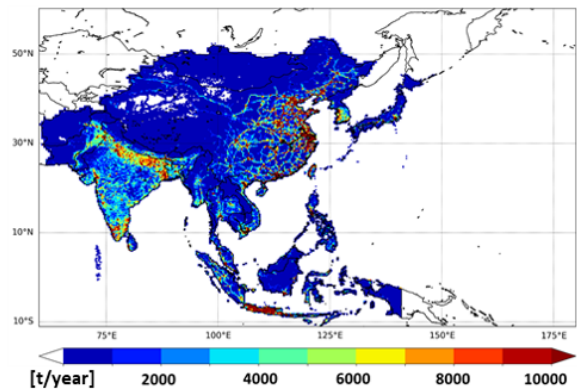

Figure 8.

were slightly larger than REASv2.1 during 2000-2005, but the discrepancies were reduced due to a larger decreasing rate of REASv3. For top-down estimates (Qu et al., 2019 (based on retrieval products by National Aeronautics and Space Administration (NASA) standard (SP) and Belgian Institute for Space Aeronomy - BIRA; Miyazaki et al., 2020), emission amounts were smaller than most bottom-up inventories, but all top-down results showed large decreasing trends after the late 2000 s.
Variability of $\mathrm{NO}_{x}$ emissions among estimations plotted in Fig. 10 was smaller than that of $\mathrm{SO}_{2} \cdot \mathrm{NO}_{x}$ emissions in most results increased largely in the 2000s and then decreased or stabilized. Growth rates of Sun et al. (2018) were smaller than others after 2005 but showed similar decreasing trends after 2010. Values of CEDS were slightly larger than other studies. Similarly to $\mathrm{SO}_{2}$, values of top-down estimates (Ding et al., 2017, based on OMI and GOME-2; Itahashi et al., 2019; Miyazaki et al., 2020) were generally 
(i) $\mathrm{NH}_{3}$ in 1965

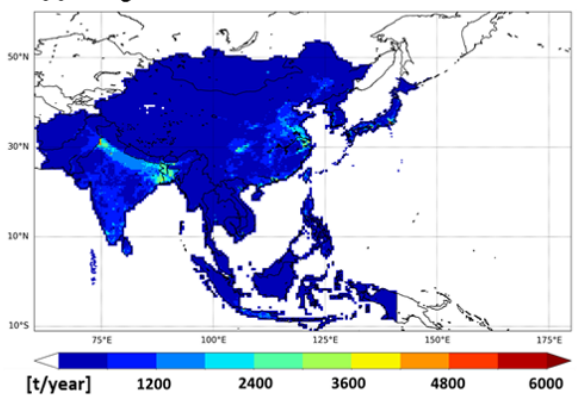

(k) $\mathrm{PM}_{2.5}$ in 1965

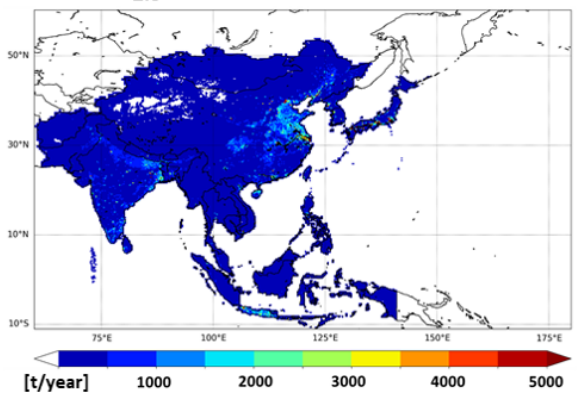

(m) BC in 1965

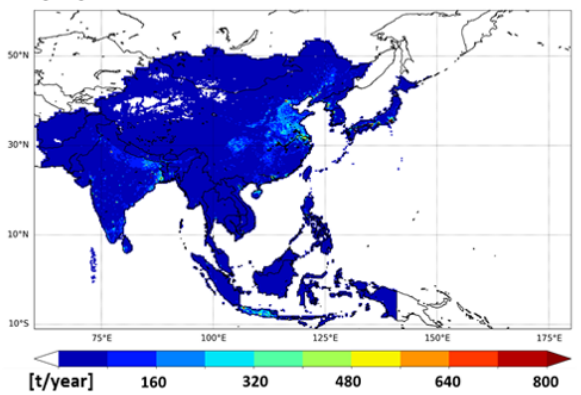

(o) OC in 1965

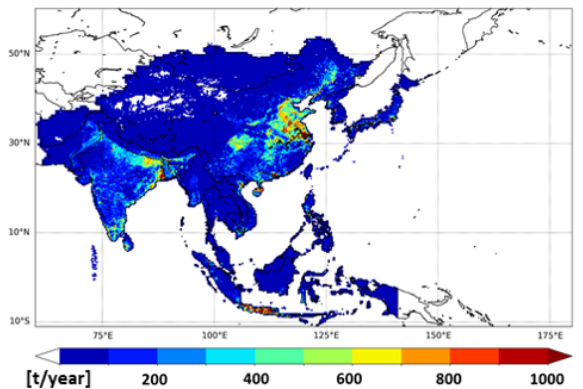

(j) $\mathrm{NH}_{3}$ in 2015

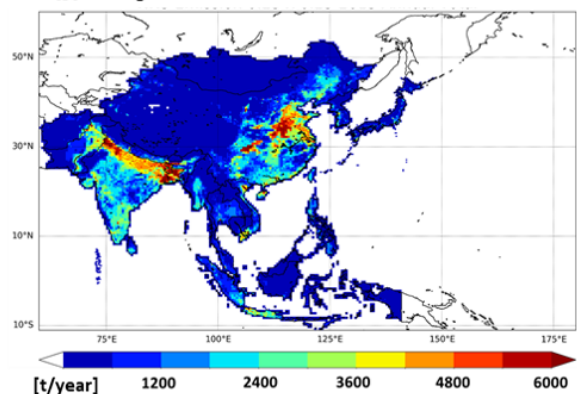

(I) $\mathrm{PM}_{2.5}$ in 2015

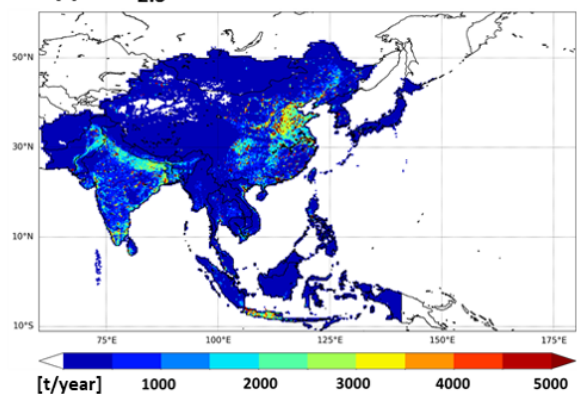

(n) BC in 2015

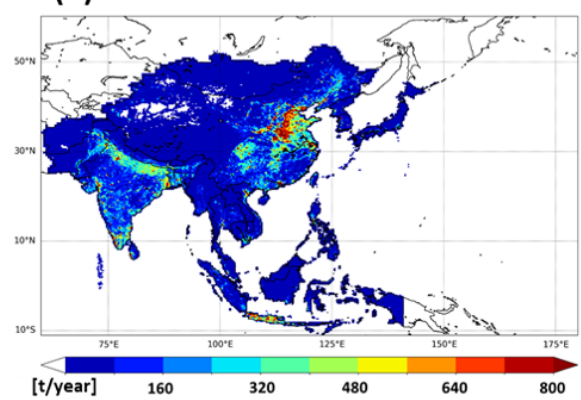

(p) OC in 2015

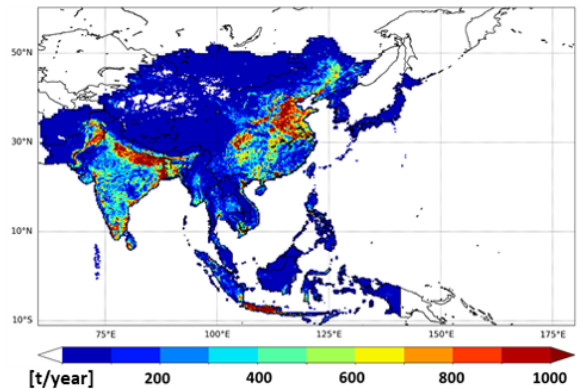

Figure 8. Grid maps of annual emissions of $(\mathbf{a}, \mathbf{b}) \mathrm{SO}_{2},(\mathbf{c}, \mathbf{d}) \mathrm{NO}_{x},(\mathbf{e}, \mathbf{f}) \mathrm{CO},(\mathbf{g}, \mathbf{h}) \mathrm{NMVOCs},(\mathbf{i}, \mathbf{j}) \mathrm{NH}_{3},(\mathbf{k}, \mathbf{l}) \mathrm{PM}_{2.5},(\mathbf{m}, \mathbf{n}) \mathrm{BC}_{\text {, and }}(\mathbf{o}$, p) OC in 1965 (left panels) and 2015 (right panels).

smaller than those of bottom-up results, but top-down emissions showed similar tendencies that emission increased until the early 2010s and turned to decrease. Trends of Itahashi et al. (2019), where emissions in 2008 of REASv2.1 were used as a priori data, were close to those of REASv3.

Compared to $\mathrm{SO}_{2}$ and $\mathrm{NO}_{x}$, relatively large discrepancies were observed in BC emissions among plotted results in Fig. 10. Emissions of REASv3 increased until 1995, slightly decreased during the late 1990s, increased from the early 2000s, and then turned to decrease from the early 2010s. The decreasing rate in the late 1990s of Wang et al. (2012) was much larger than that of REASv3. On the other hand, emissions of Klimont et al. (2017) increased from 1995 to 2000. The majority of results showed increasing trends during the early 2000s, but the following trends were different. Emissions of CEDS increased constantly after 2005, but those of 

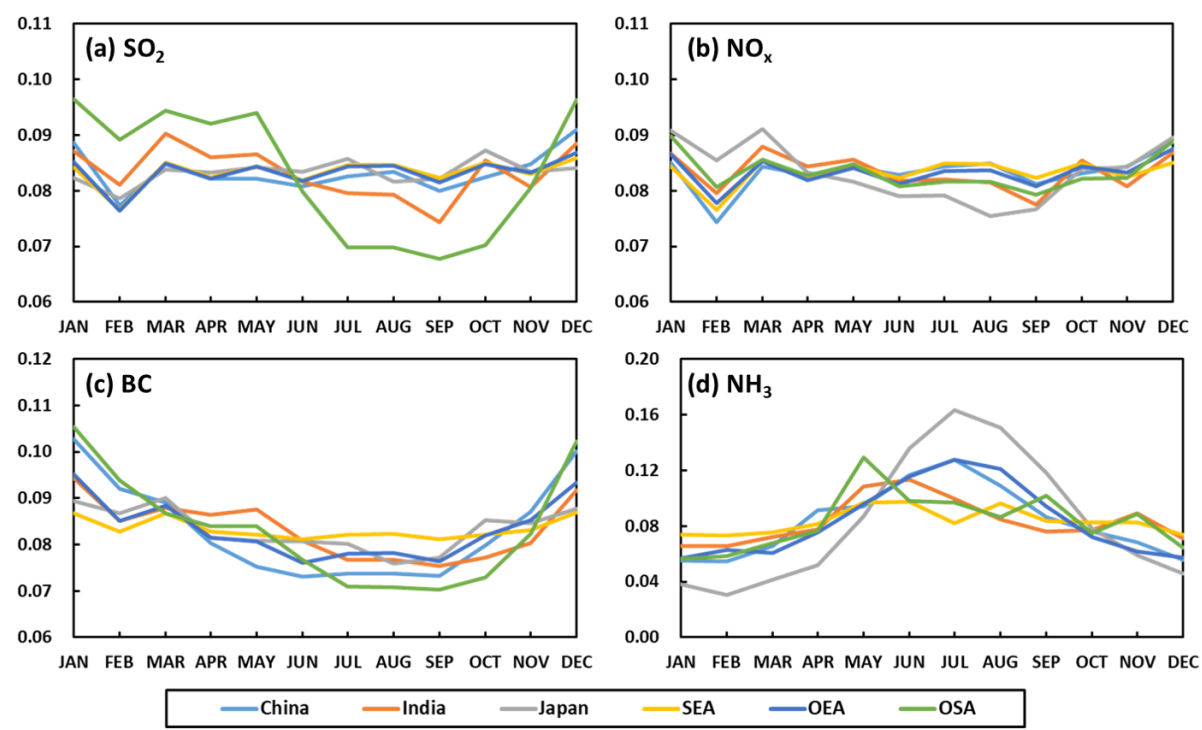

Figure 9. Monthly variations of (a) $\mathrm{SO}_{2}$, (b) $\mathrm{NO}_{x}$, (c) BC, and (d) $\mathrm{NH}_{3}$ emissions for each region of Asia in 2015. See Fig. 1 for definitions of SEA, OEA, and OSA.

Wang et al. (2012) decreased after 2005 and then started to increase slightly after 2010. BC emissions of both REASv3 and Zheng et al. (2018) decreased from the early 2010s, but the ratio of decrease was larger in Zheng et al. (2018). Values of BC emissions of REASv3 were larger than those of REASv2.1, especially in the early 2000s, but the difference in 2008 was small. For trends and emission amounts of $\mathrm{PM}_{10}$ and $\mathrm{PM}_{2.5}$, tendencies of relationships among each result were similar. The majority of results showed clear decreasing trends after 2005 except for REASv2.1, EDGARv4.3.1, and Klimont et al. (2017). For OC, most results decreased from 1995 to 2000 and then increased from the early 2000s. After 2005, trends of OC emissions were different among studies.

$\mathrm{CO}$ emission trends were relatively similar among most studies. Increasing rates after the early 2000 s are close except for EDGARv4.3.2, but emission amounts of REASv3 were smaller than other studies before 2010. After 2010, the majority of results showed decreasing trends which agreed with top-down estimates (Jiang et al., 2017 - A: MOPITT Column, B: MOPITT Profile, and C: MOPITT Lower Profile; B. Zheng et al., 2019; Miyazaki et al., 2020). However, before the late 2000s, the trends of $\mathrm{CO}$ emissions were much different between bottom-up inventories and top-down results. For NMVOCs, most studies showed significant increasing trends after the early 2000s. Compared to bottomup inventories, top-down estimates of Stavrakou et al. (2017) were almost stable between 2007 and 2012 but increased rapidly after that. Values of REASv3 were generally smaller than others before 2010. Differences among studies of $\mathrm{NH}_{3}$ emissions were large not only in emission amounts, but also in temporal variations. REAS inventories, CEDS, and EDGARv4.3.2 generally showed increasing trends. On the other hand, trends of MEICv1.2 and Zheng et al. (2018) were almost stable after 2000 and the results of Kang et al. (2016) showed decreasing trends after the mid-2000s. Emissions of REASv3 were also almost stable after 2010.

\subsubsection{India}

For $\mathrm{SO}_{2}$, emissions of most bottom-up inventories showed monotonically increasing trends. However, after the 1990s, two different emission pathways were shown among studies. The growth rates of REASv3 were close to those of Klimont et al. (2013), CEDS (scaled to REASv2.1 for India; Hoesly et al., 2018), Streets et al. (2000), and REASv2.1. On the other hand, the increasing rates of national studies by Garg et al. (2006), Pandey et al. (2014) and Sadavarte and Venkataraman (2014) were smaller than those of REASv3. In 2005, top-down estimates of Qu et al. (2019) were close to results of Pandey et al. (2014) and Sadavarte and Venkataraman (2014). Another top-down emissions of Miyazaki et al. (2020) were smaller than other inventories. Both bottom-up and top-down emissions after 2005 show increasing trends, but growth rates of bottom-up inventories were higher than those of top-down estimates.

$\mathrm{NO}_{x}$ emissions of REASv3 also increased monotonically during 1950-2015, and the majority of other bottom-up inventories generally agreed with the trends, including national studies of Sahu et al. (2012). However, similarly to $\mathrm{SO}_{2}$, growth rates of Pandey et al. (2014) and Sadavarte and Venkataraman (2014) were smaller than REASv3, although emission amounts in 2000 and 2005 were almost comparable with each other. For the increasing rates, those of topdown estimates of Itahashi et al. (2019) using REASv2.1 as a priori emissions were close to those of REASv3. On the other hand, growth rates of another top-down results of $\mathrm{Qu}$ 


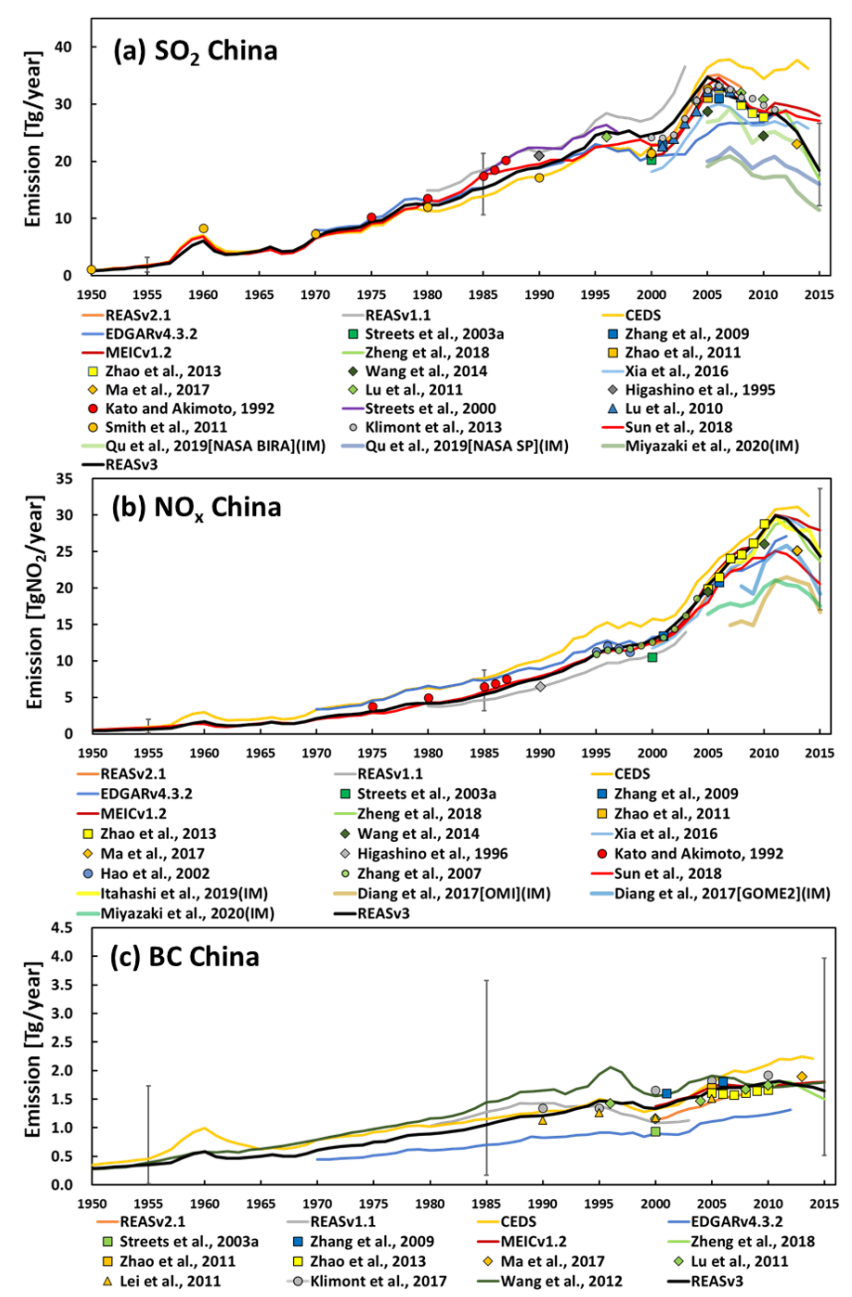

Figure 10. Comparison of (a) $\mathrm{SO}_{2}$, (b) $\mathrm{NO}_{x}$, and (c) $\mathrm{BC}$ emissions in China between REASv3 and other studies. Note that emissions from domestic and fishing ships were excluded from REAS series, CEDS, EDGARv4.3.2, and Higashino et al. (1996). IM means estimates by inverse modeling. Error bars indicate the uncertainty range of REASv3 in 1955, 1985, and 2015.

et al. (2019) were similar to those of Pandey et al. (2014) and Sadavarte and Venkataraman (2014). Emission amounts of the top-down estimates were much higher than REASv3.

For BC, as in the case of China, discrepancies among studies plotted in Fig. 11 were large. These tendencies were also found in the comparisons of $\mathrm{PM}_{10}, \mathrm{PM}_{2.5}$, and $\mathrm{OC}$ emissions provided in Fig. S15. Generally, the majority of bottom-up emission inventories of PM species showed slightly continuous increasing trends, and growth rates were smaller than those of $\mathrm{SO}_{2}$ and $\mathrm{NO}_{x}$. By contrast with the case of $\mathrm{SO}_{2}$ and $\mathrm{NO}_{x}$, emissions of $\mathrm{BC}$ and $\mathrm{PM}_{2.5}$ of REASv3 were slightly smaller than those of Pandey et al. (2014) and Sadavarte and Venkataraman (2014), but their growth rates were almost comparable.
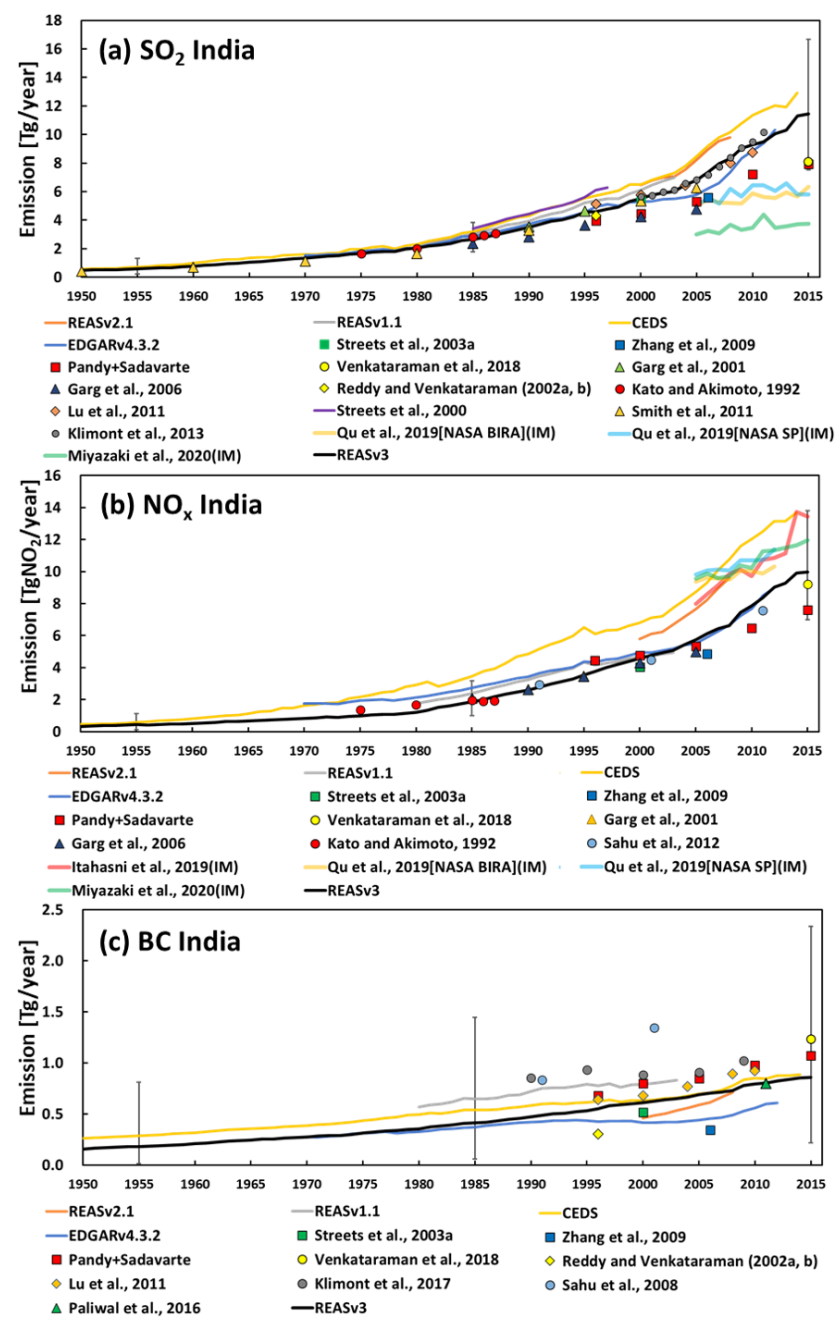

Figure 11. Comparison of (a) $\mathrm{SO}_{2}$, (b) $\mathrm{NO}_{x}$, and (c) $\mathrm{BC}$ emissions in India between REASv3 and other studies. Note that values of "Pandy+Sadavarte" are calculated from Pandey et al. (2014) and Sadavarte and Venkataraman (2014). Emissions from domestic and fishing ships were excluded from REAS series, CEDS, EDGARv4.3.2, Garg et al. (2006) and Paliwai et al. (2016). IM means estimates by inverse modeling. Error bars indicate the uncertainty range of REASv3 in 1955, 1985, and 2015.

Amounts and trends of $\mathrm{CO}$ emissions compared in Fig. S15 generally agreed well except for those of REASv1.1, which were much higher than others. Emission increased almost constantly until around 2005, and then growth rates increased slightly. Values of REASv3 were much smaller than top-down results of Jiang et al. (2017) (A: MOPITT Column, B: MOPITT Profile, and C: MOPITT Lower Profile) and Miyazaki et al. (2020). However, recent growth rates of REASv3 were close to those of top-down estimates except for Jiang et al. (2017) (C). For NMVOCs, plotted results were generally comparable except for REASv2.1 and CEDS and indicated increasing trends of emissions. Similarly to the case of $\mathrm{SO}_{2}$ and $\mathrm{NO}_{x}$, 
growth rates of REASv3 were smaller than those of Pandey et al. (2014) and Sadavarte and Venkataraman (2014). For $\mathrm{NH}_{3}$, a comparison of the emissions in Fig. S15 show similar increasing trends. Differences in emission amounts are also relatively small, except for EDGARv4.3.2.

\subsubsection{Other regions}

Comparisons of emissions in Japan between REASv3 and other studies were provided in Fig. S16. For trends of $\mathrm{SO}_{2}$ emissions in Japan, the majority of studies agreed with results of REASv3 of rapid increases in the 1960s, keen decreases in the 1970s, and gradually decreasing trends, except for EDGARv4.3.2 and Streets et al. (2000), whose values were larger and smaller, respectively. For $\mathrm{NO}_{x}$, emissions amounts of REASv3 were larger than those of most studies especially before 2000, except for CEDS (scaled to preliminary historical data of REAS for Japan; Hoesly et al., 2018), Kannari et al. (2007), Zhang et al. (2009) based on Kannari et al. (2007) and Fukui et al. (2014). For PM species, the majority of results in Fig. S16 agreed with decreasing trends of REASv3 after 1990. On the other hand, emissions of BC and OC of CEDS increased almost monotonically until their peak around 1990. These tendencies were much different from REASv3. For CO, emission amounts of REASv3 were larger than other results of especially REASv1, EDGARv4.3.2, and CEDS. However, after 2000, emissions and their decreasing trends of other studies were generally comparable with those of REASv3. For NMVOCs, results of REASv3 after 2000 generally agreed well with other studies which showed large decreasing trends, except for EDGARv4.3.2 and Zhang et al. (2009) based on Kannari et al. (2007). Trends of $\mathrm{NH}_{3}$ emissions shown in Fig. S16 were similar except for EDGARv4.3.2 before the mid-1990s, which showed larger growth rates. Emission amounts of REASv3 were smaller than national inventories by Kannari et al. (2001) and Fukui et al. (2014).

For SEA (see Fig. S17), increasing trends and amounts of $\mathrm{SO}_{2}$ emissions of REASv3 agreed with other results except for CEDS in the 1990s, Zhang et al. (2009), and Klimont et al. (2013). In CEDS, emissions decreased keenly during the late 1990s. A similar feature was also seen in REASv3, but its rate of decrease was much smaller. For $\mathrm{NO}_{x}$, all results plotted in Fig. S17 indicated monotonically increasing trends of emissions and agreed well until the early 2000s. After that, growth rates of REASv3 became larger than EDGARv4.3.2 and smaller than CEDS (scaled to REASv2.1 for SEA; Hoesly et al., 2018). For BC, REAS series and CEDS showed similar growth rates until around 2005. On the other hand, increasing rates of Klimont et al. (2017) and EDGARv4.3.2 after 1990 were much smaller and close to those of REASv3 after 2005.

Most results of $\mathrm{SO}_{2}$ emissions in OEA in Fig. S18 show increasing and decreasing trends from the late 1960s and the early 1990s, respectively, although amounts in CEDS from 1970 and 2000 were much smaller. For $\mathrm{NO}_{x}$, all results agreed well until the late 1980s, and REASv3, REASv1.1, and EDGARv4.3.2 showed similar increasing trends until around 2000. Emissions of CEDS became almost stable after the late 1980s and started to decrease after 2005 . The decreasing rates of REASv3 and CEDS are close after 2005. On the other hand, emissions of EDGARv4.3.2 did not change largely after around 2000 . The similar tendencies were shown in the case of $\mathrm{SO}_{2}$. $\mathrm{BC}$ emissions of REASv3 and CEDS showed similar trends until 2000. Then, emissions of REASv3 decreased almost monotonically, while those of CEDS were almost stable. Similarly, decreasing rates of EDGARv4.3.2 after 2000 were much smaller than those of REASv3.

For OSA, increasing trends and amounts of $\mathrm{SO}_{2}$ and $\mathrm{NO}_{x}$ emissions were generally similar among studies plotted in Fig. S19. $\mathrm{SO}_{2}$ emissions of Streets et al. (2003a) and Zhang et al. (2009) and $\mathrm{NO}_{x}$ emissions of CEDS (scaled to REASv2.1; Hoesly et al., 2018) were higher than other results. For BC, discrepancies among studies were larger than those of $\mathrm{SO}_{2}$ and $\mathrm{NO}_{x}$, but similar small monotonically growth rates were shown in all results.

\subsubsection{Relative ratios of emissions from each country and region in Asia}

Figure 12 compares trends of total emissions in Asia and relative ratios of emissions from China, India, Japan, SEA, OEA, and OSA among REASv3, CEDS, and EDGARv4.3.2 for $\mathrm{SO}_{2}, \mathrm{NO}_{x}$, and $\mathrm{BC}$. Comparisons of other species are presented in Fig. S20. From 1950 to the early 2000s, total $\mathrm{SO}_{2}$ emissions in Asia of all inventories showed similar results. For relative ratios, REASv3 and CEDS values were similar until the mid-2000s. Contributions from Japan were relatively large from 1950 until around 1970 and then decreased keenly. This was also found in EDGARv4.3.2, but the rate of decrease was smaller than that of REASv3 and CEDS. Then, while emissions of REASv3 decreased largely after the mid-2000s, those of CDES and EDGARv4.3.2 continued to increase. These discrepancies were mainly due to different trends of emissions from China. Actually, after the mid-2000s, relative ratios of $\mathrm{SO}_{2}$ emissions in China were stable in CEDS and EDGARv4.3.2, but those in REASv3 decreased significantly. Recently, increasing trends of relative ratios of $\mathrm{SO}_{2}$ emissions in India are a common feature in REASv3, EDGARv4.3.2, and CEDS.

For $\mathrm{NO}_{x}$, Asia total emissions of REASv3 and EDGARv4.3.2 were close. Although emissions of CEDS were larger than REASv3 and EDGARv4.3.2, trends were similar until early 2010 . The different trends after 2010 between REASv3 and CEDS were caused by those of emissions in China. For the contributing rates, REASv3 and CEDS generally showed similar temporal variations, although relative ratios of OSA were larger in CEDS. Contribution rates of Japan were large around 1970 and then grad- 


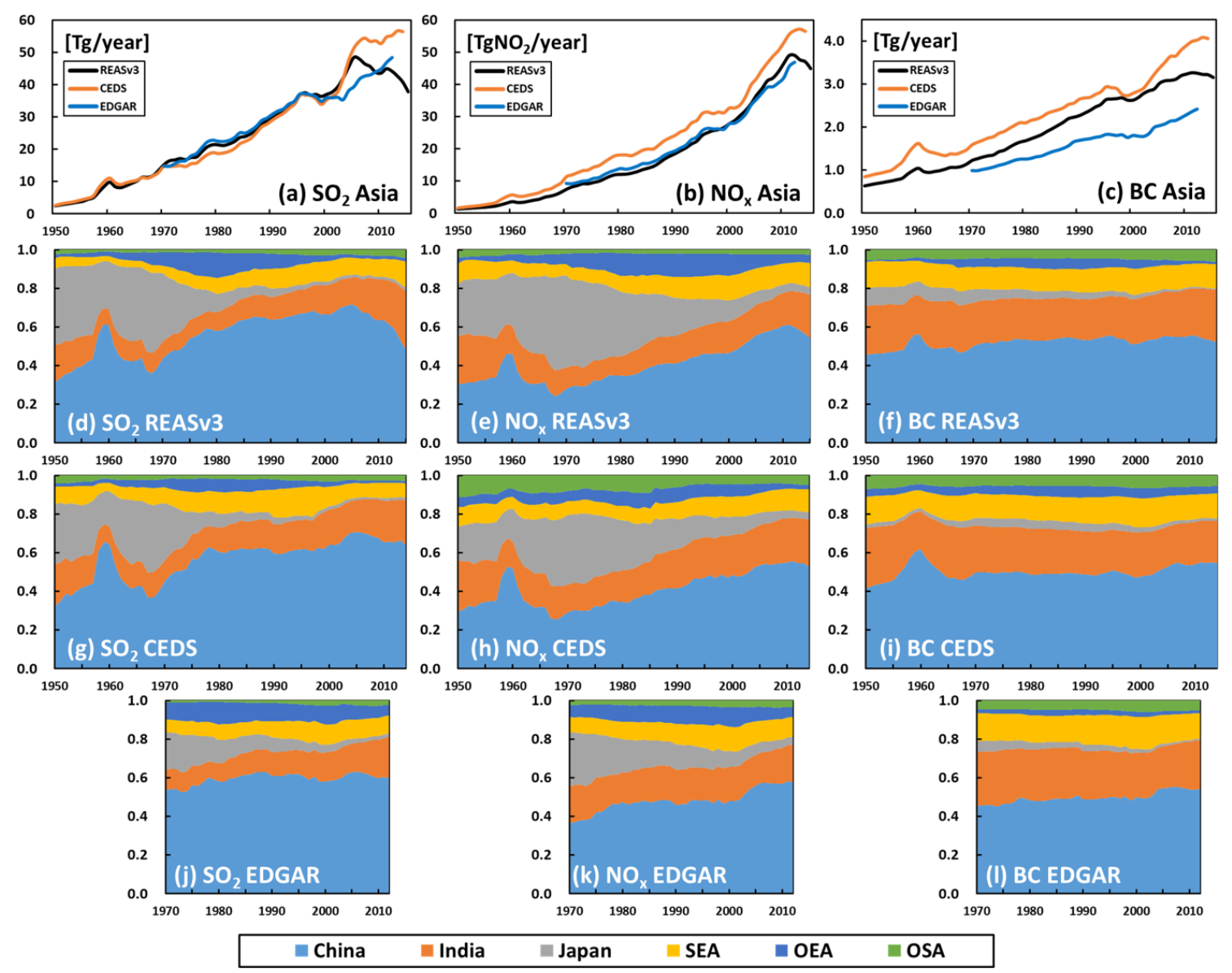

Figure 12. Comparison of trends of (a) $\mathrm{SO}_{2}$, (b) $\mathrm{NO}_{x}$, and (c) $\mathrm{BC}$ emissions in Asia and relative ratios of emissions from China, India, Japan, SEA, OEA, and OSA for (d, g, j) $\mathrm{SO}_{2},(\mathbf{e}, \mathbf{h}, \mathbf{k}) \mathrm{NO}_{x}$, and (f, i, l) BC among (d, e, f) REASv3, (g, h, i) CEDS, and (j, k. l) EDGARv4.3.2. Note that periods of CEDS and EDGARv4.3.2 shown here are during 1950-2014 and 1970-2012, respectively. See Fig. 1 for definitions of SEA, OEA, and OSA.

ually decreased. Instead, those from China increased almost monotonically until 2010. Similarly to the case of $\mathrm{SO}_{2}$, relative ratios of China decreased recently in REASv3, but they were almost stable in CEDS and EDGARv4.3.2. In addition, contribution rates from India showed gradual increasing trends in all the results.

For total Asia emissions of BC, trends of REASv3 and CEDS were similar until the late 1990s, but after 2000, while growth rates of CEDS became larger, emissions of REAS did not change greatly and turned to decrease after 2010 . Emission amounts and growth rates of EDGARv4.3.2 were smaller than others until the mid-1990s, but after that the trends were similar to those of REASv3. Compared to $\mathrm{SO}_{2}$ and $\mathrm{NO}_{x}$, temporal variations of relative ratios of $\mathrm{BC}$ emissions from each country and regions were small in all the results. In REASv3, contribution rates of Japan were large before 1970 and then decreased afterwards. On the other hand, in CEDS, contribution rates of Japan after 1970 were larger than those before 1970. After 2000, relative ratios of China in REASv3 were almost stable and showed a marginal decrease after 2011. In CEDS and EDGARv4.3.2, contribution rates of China increased during the first half of the 2000s and then became almost stable. Similar tendencies were seen in OC. Compared to $\mathrm{BC}$, relative ratios of China started to decrease earlier only in REASv3.

For Asia total emissions of $\mathrm{CO}$, although amounts of CEDS were larger than others, trends of all results were close until the early 2000s. After that, REASv3 showed large increases until 2010 and then started to decrease slightly. These tendencies were mainly controlled by emissions in China. Trends of the relative ratios were similar to those of $\mathrm{BC}$, but contribution rates of China in REASv3 increased gradually until the mid-2000s and then decreased, while those in CEDS and EDGARv4.3.2 were almost stable. For NMVOCs, total emissions in Asia of REASv3 were smaller than others, but large increases in emissions were found from the early 1990s. The corresponding feature was shown in contribution rates. Relative ratios of emissions from China in REASv3 increased largely during the 1990s and 2000s. Similar increasing trends were seen in EDGARv4.3.2, but growth rates of 
REASv3 were much larger. On the other hand, both temporal variations and values of contribution rates of China were relatively small in CEDS.

For $\mathrm{NH}_{3}$, trends of total emissions in Asia of REASv3 were close to EDGARv4.3.2 and slightly larger than CEDS until around 2000. After that, growth rates of REASv3 were close to CEDS and those of EDGARv4.3.2 became larger. As a result, amounts of total Asia emissions of all inventories became almost the same after 2010 . For relative ratios of regions, contribution rates of China in REASv3 increased gradually until the mid-2000s and then became almost stable, whereas those in CEDS and EDGARv4.3.2 show slightly decreasing and increasing trends, respectively. In 2015, relative ratios of $\mathrm{NH}_{3}$ emissions from China in REASv3 were between those of EDGARv4.3.2 and CEDS. Compared to EDGARv4.3.2 and CEDS, contribution rates of $\mathrm{NH}_{3}$ emissions from SEA region were relatively small in REASv3.

\subsection{Uncertainty}

In REASv3, uncertainties in emissions were estimated for each country and region in 1955, 1985, and 2015 using basically the same methodology as that of REASv2.1 (Kurokawa et al., 2013). First, uncertainties in all parameters used to calculate emissions, such as activity data, emission factors, removal efficiencies, and sulfur contents of fuels, were estimated in the range of 2\%-150\%. In estimation of the uncertainties except for activity data, the following three causes need to be considered: uncertainties in the data themselves, those caused by selections of the data, and those in settings related to emission controls such as timing of introduction and penetration rates of abatement equipment. In this study, uncertainties in settings of emission controls were explicitly considered only for removal efficiencies. The uncertainties in removal efficiencies were assumed to be zero for emission sources where no emission controls were considered, which means that uncertainties caused by neglecting emission controls were not considered. Furthermore, for emission sources where introduction rates of abatement equipment were small, uncertainties caused by settings of emission controls were assumed to be small. Then, uncertainties in emissions from the power plant, industry, road transport, other transport, domestic, and other sectors, as well as uncertainties in total emissions, were calculated for all the species. The uncertainties in different sub-sectors and activities were combined in quadrature assuming they were independent. On the other hand, for uncertainties in national emissions in China, India, and Japan, those in their sub-regions were added linearly. Details of the methodology and settings of uncertainties in each component were described in Sect. S10 of the Supplement. Similarly to REASv2.1, uncertainties in emissions that were not originally developed in REASv3 $\left(\mathrm{NH}_{3}\right.$ emissions from manure management and fertilizer application, and NMVOC evaporative emissions from Japan and the Republic of Korea) were not evaluated in this study.
Table 4 summarizes the estimated uncertainties in total emissions of each species for China, India, Japan, SEA, OEA, and OSA in 1955, 1985, and 2015. Uncertainties in emissions from each sector were provided in the Supplement tables (Table $\mathrm{S} 1$ for $\mathrm{SO}_{2}, \mathrm{NO}_{x}, \mathrm{CO}, \mathrm{CO}_{2}, \mathrm{PM}_{10}, \mathrm{PM}_{2.5}, \mathrm{BC}$, and OC, Table S2 for NMVOCs, and Table S3 for $\mathrm{NH}_{3}$ ). For most regions and years, uncertainties for $\mathrm{SO}_{2}, \mathrm{NO}_{x}$, and $\mathrm{CO}_{2}$ are smaller than other species. Major emission sources of these species are power plants and large industry sectors. Uncertainties in activity data of these species were assumed to be small because power plants and large industries are critically important for each country and related statistics are expected to be accurate. In addition, uncertainties in emission factors of combustion at high temperature in power plants and large industries are considered to be small. For $\mathrm{SO}_{2}$ emissions in China, uncertainties in 2015 were estimated to be slightly larger than those in 1985 due to uncertainties for removal efficiencies which were not considered in 1985. The same situation was found in uncertainties in $\mathrm{NO}_{x}$ emissions from power plants in China between 1985 and 2015. Lack of detailed information for changes in technologies such as combustion burners and abatement equipment affects uncertainties in recent emission trends in Asia. For South and Southeast Asia, uncertainties in $\mathrm{SO}_{2}$ emissions in 1985 were slightly smaller than those in 2015. This is because settings of sulfur contents in fuels were based on surveys conducted in 1990 (Kato and Akimoto, 1992), and thus the uncertainties in 1985 were assumed to be smaller than those in 2015. In REASv3, information on temporal variations of sulfur contents in fuels both by changes in fuel properties and by lowsulfur fuel regulations was limited, which were also causes of uncertainties in emission trends. In general, uncertainties in emissions in REASv3 were smaller in recent years because activity data of recent years are more accurate. However, detailed surveys for recent changes in technologies and information on emission controls are essential in future studies.

On the other hand, uncertainties in PM species are large compared to other species for most regions and years. For most countries in Asia, the majority of their emissions were from combustion at relatively low temperatures in small industries and residential sectors. Accuracies of activity data and emission factors for these sources are assumed to be low, especially for biofuel combustion. Therefore, uncertainties in OC emissions, mainly from biofuel combustion in Asia, are the largest for most regions and years. Uncertainties in $\mathrm{PM}_{10}$ are generally smaller than other PM species. This is because for $\mathrm{PM}_{10}$ emissions, contribution rates of power plants and industry sectors are generally larger than those of other PM species. For CO and NMVOCs, in general, uncertainties in emission factors are assumed to be greater than $\mathrm{SO}_{2}, \mathrm{NO}_{x}$, and $\mathrm{CO}_{2}$ but smaller than $\mathrm{PM}_{2.5}, \mathrm{BC}$, and $\mathrm{OC}$. Therefore, uncertainties in total $\mathrm{CO}$ and NMVOC emissions are generally between those of other species. For Southeast and South Asia, uncertainties in $\mathrm{CO}$ and NMVOCs are comparable with 
Table 4. Uncertainties [\%] of emissions in China, India, Japan, SEA, OEA, and OSA in 1955, 1985, and 2015. See Fig. 1 for definitions of SEA OEA, and OSA.

\begin{tabular}{lrrrrrrrrrr}
\hline & $\mathrm{SO}_{2}$ & $\mathrm{NO}_{x}$ & $\mathrm{CO}$ & $\mathrm{NMVOCs}$ & $\mathrm{NH}_{3}$ & $\mathrm{CO}_{2}$ & $\mathrm{PM}_{10}$ & $\mathrm{PM}_{2.5}$ & $\mathrm{BC}$ & $\mathrm{OC}$ \\
\hline 1955 & & & & & & & & & & \\
\hline China & \pm 85 & \pm 167 & \pm 291 & \pm 277 & \pm 174 & \pm 133 & \pm 253 & \pm 315 & \pm 334 & \pm 365 \\
India & \pm 96 & \pm 122 & \pm 265 & \pm 295 & \pm 161 & \pm 116 & \pm 257 & \pm 294 & \pm 277 & \pm 314 \\
Japan & \pm 59 & \pm 62 & \pm 157 & \pm 135 & \pm 141 & \pm 49 & \pm 94 & \pm 117 & \pm 170 & \pm 270 \\
SEA & \pm 134 & \pm 153 & \pm 260 & \pm 272 & \pm 169 & \pm 126 & \pm 291 & \pm 307 & \pm 323 & \pm 317 \\
OEA & \pm 73 & \pm 88 & \pm 146 & \pm 184 & \pm 148 & \pm 59 & \pm 120 & \pm 157 & \pm 157 & \pm 262 \\
OSA & \pm 70 & \pm 112 & \pm 272 & \pm 270 & \pm 168 & \pm 110 & \pm 219 & \pm 281 & \pm 310 & \pm 345 \\
\hline 1985 & & & & & & & & & & \\
\hline China & \pm 36 & \pm 53 & \pm 157 & \pm 150 & \pm 139 & \pm 39 & \pm 101 & \pm 129 & \pm 182 & \pm 250 \\
India & \pm 40 & \pm 60 & \pm 196 & \pm 212 & \pm 135 & \pm 58 & \pm 160 & \pm 201 & \pm 191 & \pm 259 \\
Japan & \pm 30 & \pm 31 & \pm 44 & \pm 50 & \pm 93 & \pm 14 & \pm 72 & \pm 71 & \pm 53 & \pm 67 \\
SEA & \pm 40 & \pm 56 & \pm 185 & \pm 162 & \pm 141 & \pm 56 & \pm 157 & \pm 191 & \pm 218 & \pm 259 \\
OEA & \pm 48 & \pm 70 & \pm 72 & \pm 78 & \pm 113 & \pm 27 & \pm 80 & \pm 82 & \pm 88 & \pm 102 \\
OSA & \pm 36 & \pm 44 & \pm 144 & \pm 137 & \pm 134 & \pm 33 & \pm 108 & \pm 137 & \pm 176 & \pm 248 \\
\hline 2015 & & & & & & & & & & \\
\hline China & \pm 40 & \pm 35 & \pm 73 & \pm 76 & \pm 82 & \pm 19 & \pm 83 & \pm 94 & \pm 111 & \pm 193 \\
India & \pm 41 & \pm 35 & \pm 136 & \pm 115 & \pm 111 & \pm 27 & \pm 120 & \pm 151 & \pm 133 & \pm 233 \\
Japan & \pm 34 & \pm 32 & \pm 45 & \pm 63 & \pm 103 & \pm 13 & \pm 68 & \pm 74 & \pm 58 & \pm 100 \\
SEA & \pm 46 & \pm 38 & \pm 124 & \pm 86 & \pm 115 & \pm 25 & \pm 125 & \pm 155 & \pm 161 & \pm 232 \\
OEA & \pm 38 & \pm 60 & \pm 67 & \pm 63 & \pm 94 & \pm 19 & \pm 69 & \pm 85 & \pm 82 & \pm 168 \\
OSA & \pm 40 & \pm 34 & \pm 87 & \pm 73 & \pm 93 & \pm 19 & \pm 96 & \pm 112 & \pm 124 & \pm 211 \\
\hline
\end{tabular}

$\mathrm{PM}_{10}$ as their relative contribution from biofuel combustion is large.

Uncertainties in emissions from Japan are less than those of other countries and regions. This is mainly due to the accuracy of activity data. Accessibility to detailed information in Japan is relatively high compared to other countries in REASv3. In Japan, uncertainties in emission in 1985 were comparable with or slightly smaller than those in 2015 . This is because relative ratios of emissions from road transport, whose uncertainties were the smallest in Japan, were reduced largely from 1985 to 2015. For China and India, accuracies of emissions are generally improved for most species compared to REASv2.1 using information from recently published literatures of emission inventories of these countries. However, the improvement is not significant due to the lack of country-specific information. This situation is almost the same for other countries and regions. Although studies of national emission inventories in Asia are being published, as described in Sect. 1, information on technologies related to emissions and their introduction rates is not as easily available. Therefore, continuous efforts to update emission inventories by collecting information on each country and region are essential. For all countries, uncertainties in emissions in 1955 were much larger than those in 2015. This is because most activity data were not obtained directly from statistics, especially in the early half of the target period of REASv3. In this study, activity data, which were not available in statistics, were extrapolated or assumed using proxy data as described in Sect. 2. In order to reduce uncertainties in emissions in long past years, these procedures need to be considered based on detailed information on each country and region during the period.

\section{Summary and remarks}

A long historical emission inventory of major air and climate pollutants in Asia during 1950-2015 was developed as the Regional Emission inventory in ASia version 3 (REASv3). Target species were $\mathrm{SO}_{2}, \mathrm{NO}_{x}, \mathrm{CO}$, NMVOCs, $\mathrm{NH}_{3}, \mathrm{PM}_{10}$, $\mathrm{PM}_{2.5}, \mathrm{BC}, \mathrm{OC}$, and $\mathrm{CO}_{2}$, and the domain areas included East, Southeast, and South Asia. Emissions from fuel combustion in power plants, industries, transport, and domestic sectors and those from industrial processes were estimated for all the species. In addition, emissions from evaporative sources were included in NMVOCs, and those from agricultural activities and human physiological phenomena were considered for $\mathrm{NH}_{3}$. REASv3 provides gridded data as well as emissions from each country and sub-region. Spatial resolution is mainly $0.25^{\circ} \times 0.25^{\circ}$ and large power plants are treated as point sources. Temporal resolution is monthly. Emissions were estimated based on information on technologies related to emission factors and removal efficiencies, al- 
though available data and literatures are limited in the case of Asia. Activity data for recent years were collected from international and national statistics, and those of past years, when detailed information was not available, were extrapolated using proxy data for the target period of REASv3. Details of methodologies such as data sources and treatments, settings of emission factors and emission controls, and related assumptions were provided in the Supplement document entitled "Supplementary information and data to methodology of REASv3".

Total emissions in Asia averaged during 1950-1955 and 2010-2015 (growth rates in these 60 years estimated from the two averages) are $\mathrm{SO}_{2}: 3.2 \mathrm{Tg}, 42.4 \mathrm{Tg}$ (13.1); $\mathrm{NO}_{x}$ : 1.6 Tg, 47.3 Tg (29.1); CO: 56.1 Tg, $303 \mathrm{Tg}$ (5.4); NMVOCs: 7.0 Tg, 57.8 Tg (8.3); $\mathrm{NH}_{3}: 8.0 \mathrm{Tg}, 31.3 \mathrm{Tg}(3.9) ; \mathrm{CO}_{2}$ : 1.1 Pg, 18.6 Pg (16.5); $\mathrm{PM}_{10}: 5.9 \mathrm{Tg}, 30.2 \mathrm{Tg}$ (5.1); $\mathrm{PM}_{2.5}$ : 4.6 Tg, 21.3 Tg (4.6); BC: $0.69 \mathrm{Tg}, 3.2 \mathrm{Tg}$ (4.7); and OC: $2.5 \mathrm{Tg}, 6.6 \mathrm{Tg}$ (2.7). Clearly, all the air pollutant emissions in Asia increased significantly during these 6 decades. However, situations were different among countries and regions. In recent years, the relative contribution of air pollutant emissions from China was the largest along with rapid increase in economic growth, but most species have reached their peaks, and the growth rates of other species have become at least small or almost zero. For $\mathrm{SO}_{2}$ and $\mathrm{NO}_{x}$, introduction of abatement equipment, especially for coal-fired power plants such as FGD and SCR were considered to be effective in reducing emissions. For PM species, in addition to control equipment in industrial plants, emissions decreased recently due to reduced usage of biofuels. On the other hand, air pollutant emissions from India showed an almost continuous increase. Growth rates were larger for $\mathrm{SO}_{2}$ and $\mathrm{NO}_{x}$, but their structures of emissions were different. Large parts of $\mathrm{SO}_{2}$ emissions were obtained from coal combustion in power plants and the industrial sector, and the recent rapid increase in $\mathrm{SO}_{2}$ emission was mainly from coal-fired power plants. For $\mathrm{NO}_{x}$, contribution from road transport especially diesel vehicles were almost comparable with those of power plants. For PM species, the majority of emissions were from the residential sector in the 1950s-1960s, and its contribution is still considered to be large. Recent increasing trends were mainly caused by emissions from power and industrial plants and road vehicles. Trends in Japan were much different than those of the whole of Asia. Emissions increased rapidly along with economic growth during the 1950s-1970s, but those of most species were reduced largely from peak values. In addition, peak years were mostly 40 years ago, reflecting the time series of introduction of control measures to mitigate air pollution. Similar features were found in the Republic of Korea and Taiwan. For other countries in Asia, emissions of air pollutants generally showed increasing trends along with economic situation and motorization. As described above, trends and spatial distribution of air pollutants in Asia are not simple and are becoming complicated.
Mitigation of air and climate pollutant emissions is an urgent issue in most Asian countries, but the situation is different country-wise. In this study, detailed discussion on effects of emission controls was conducted only for China and Japan due to limitation of information. Therefore, continuous efforts to develop and update emission inventories in Asia based on country-specific information are essential, especially for countries and regions other than China and Japan. On the other hand, there are inevitable uncertainties in parameters required to develop emission inventories, such as activity data and emission factors. In addition, it is fundamentally impossible to develop a real-time emission inventory because there is a time lag in the publication of basic statistics essential to estimate emissions. Recently, satellite observation data of air pollutants have become available at a finer scale for many species, such as $\mathrm{NO}_{x}, \mathrm{SO}_{2}$, and $\mathrm{NH}_{3}$. Evaluations and improvements of REASv3 based on these data as well as results of modeling studies, such as inverse modeling, are more important next steps. Also, addition of target species, especially $\mathrm{CH}_{4}$, which is one of the key species in mitigating both air pollution and global warming, is another important task for future studies.

Data availability. Monthly gridded emission data sets at $0.25^{\circ} \times$ $0.25^{\circ}$ resolution for major sectors and emission table data for major sectors and fuel types in each country and region during 1950 2015 developed in this study are available from https://www.nies. go.jp/REAS/index.html\#REASv3.2 (Kurokawa and Ohara, 2020) in a data download site of REAS (https://www.nies.go.jp/REAS/ index.html, last access: 31 October 2020). Note that data sets of REASv3.1 were released after a publication of Kurokawa et al. (2019) from December 2019. The data sets were revised and the updated data are available as REASv3.2 together with a publication of this paper. Differences between REASv3.2 and REASv3.1 were presented and discussed in the Supplement document entitled "Differences between REASv3.2 and REASv3.1".

Supplement. The supplement related to this article is available online at: https://doi.org/10.5194/acp-20-12761-2020-supplement.

Author contributions. JK and TO conducted the study design. JK contributed to actual works for development of REASv3 such as collecting data and information, settings of parameters, calculating emissions, and creating final data sets. JK and TO analyzed and discussed the estimated emissions in REASv3. JK prepared the manuscript with contributions from TO.

Competing interests. The authors declare that they have no conflict of interest.

Acknowledgements. We appreciate Kazumasa Kawashima (Mitsubishi UFJ Research and Consulting Co., Ltd.) and Tetsuo Fukui 
(The Institute of Behavioral Sciences) for their great support in collecting activity data and survey information for settings of parameters. We acknowledge Keiya Yumimoto (Kyushu University), Syuichi Itahashi (Central Research Institute of Electric Power Industry), Tatsuya Nagashima (National Institute for Environmental Studies), and Takashi Maki (Meteorological Research Institute) for their valuable suggestions to improve REAS. We are grateful to Daisuke Goto (National Institute for Environmental Studies) for his support to update the data download site of REAS. We thank Yusuke Kiriyama (Asia Center for Air Pollution Research) for his help in drawing figures of gridded emission maps.

Financial support. This research has been supported by the Environmental Research and Technology Development Fund (grant no. S-12) of the Environmental Restoration and Conservation Agency of Japan and the Japan Society for the Promotion of Science, KAKENHI (grant no. 19K12303).

Review statement. This paper was edited by Qiang Zhang and reviewed by two anonymous referees.

\section{References}

Baidya, S. and Borken-Kleefeld, J.: Atmospheric emissions from road transportation in India, Energy Policy, 37, 3812-3822, https://doi.org/10.1016/j.enpol.2009.07.010, 2009.

Bond, T. C., Streets, D. G., Yarber, K. F., Nelson, S. M., Woo, J.-H., and Klimont, Z.: A technology-based global inventory of black and organic carbon emissions from combustion, J. Geophys. Res., 109, D14203, https://doi.org/10.1029/2003JD003697, 2004.

Chandramouli, C.: Census of India 2011, Tables on Houses, Household Amenities and Assets, the Indian Administrative Service Registrar General \& Census Commissioner, India, 2011.

Chatani, S., Yamaji, K., Sakurai, T., Itahashi, S., Shimadera, H., Kitayama, K., and Hayami, H.: Overview of model inter-comparison in Japan's Study for Reference Air Quality Modeling (J-STREAM), Atmosphere, 9, 19, https://doi.org/10.3390/atmos9010019, 2018.

Clean Air Asia: Accessing Asia: Air Pollution and Greenhouse Gas Emissions Indicators for Road Transport and Electricity, Pasing City, Philippines, 2012.

Clean Air Asia: Developments in the Asia-Pacific Region, the 10th Global Partnership Meeting of the Partnership for Clean Fuels and Vehicles, 13 May 2014, Paris, 2014.

Crippa, M., Janssens-Maenhout, G., Dentener, F., Guizzardi, D., Sindelarova, K., Muntean, M., Van Dingenen, R., and Granier, C.: Forty years of improvements in European air quality: regional policy-industry interactions with global impacts, Atmos. Chem. Phys., 16, 3825-3841, https://doi.org/10.5194/acp-163825-2016, 2016.

Ding, J., Miyazaki, K., van der A, R. J., Mijling, B., Kurokawa, J.-I., Cho, S., Janssens-Maenhout, G., Zhang, Q., Liu, F., and Levelt, P. F.: Intercomparison of $\mathrm{NO}_{x}$ emission inventories over East Asia, Atmos. Chem. Phys., 17, 10125-10141, https://doi.org/10.5194/acp-17-10125-2017, 2017.
EEA (European Environment Agency): EMEP/EEA air pollutant emission inventory guidebook 2016, EEA Report, 21, available at: https://www.eea.europa.eu/publications/ emep-eea-guidebook-2016 (last access: 1 August 2020), 2016.

Fukui, T., Kokuryo, K., Baba, T., and Kannari, A.: Updating EAGrid2000-Japan emissions inventory based on the recent emission trends (in Japanese), J. Jpn. Soc. Atmos. Environ., 49, 117-125, https://doi.org/10.11298/taiki.49.117, 2014.

Garg, A., Shukla, P. R., Bhattacharaya, S., and Dadhwal, V. K.: Sub-region (district) and sector level $\mathrm{SO}_{2}$ and $\mathrm{NO}_{x}$ emissions for India: assessment of inventories and mitigation flexibility, Atmos. Environ., 35, 703-713, https://doi.org/10.1016/S13522310(00)00316-2, 2001.

Garg, A., Shukla, P. R., and Kaphe, M.: The sectoral trends of multigas emissions inventory of India, Atmos. Environ., 40, 46084620, https://doi.org/10.1016/j.atmosenv.2006.03.045, 2006.

Goto, S: Progress of non-ferrous metal smelting in recent 10 years, J. Jpn. Mining Ind. Assoc., 97, 602-608, https://doi.org/10.2473/shigentosozai1953.97.1122_602, 1981 (in Japanese).

Guttikunda, S. K. and Jawahar, P.: Atmospheric emissions and pollution from the coal-fired thermal power plants in India, Atmos. Environ., 92, 449-460, https://doi.org/10.1016/j.atmosenv.2014.04.057, 2014.

Hao, J., Tian, H., and Lu, Y.: Emission Inventories of $\mathrm{NO}_{x}$ from Commercial Energy Consumption in China, 1995-1998, Environ. Sci. Technol., 36, 552-560, https://doi.org/10.1021/es015601k, 2002.

He, K., Huo, H., Zhang, Q., He, D., An, F., Wang, M., and Walsh, M. P.: Oil consumption and $\mathrm{CO}_{2}$ emissions in China's road transport: current status, future trends, and policy implications, Energy Policy, 33, 1499-1507, https://doi.org/10.1016/j.enpol.2004.01.007, 2005.

Higashino, H., Tonooka, Y., Yanagisawa, Y., and Ikeda, Y.: Emission inventory of air pollutants in East Asia - Anthropogenic emissions of sulfur dioxide in China, J. Jpn. Soc. Atmos., 30, 374-390, https://doi.org/10.11298/taiki1995.30.6_374, 1995 (in Japanese).

Higashino, H., Tonooka, Y., Yanagisawa, Y., and Ikeda, Y.: Emission inventory of air pollutants in East Asia (II) - Focused on estimation of $\mathrm{NO}_{x}$ and $\mathrm{CO}_{2}$ emissions in China, J. Jpn. Soc. Atmos., 31, 262-281, https://doi.org/10.11298/taiki1995.31.6_262, 1996 (in Japanese).

Hoesly, R. M., Smith, S. J., Feng, L., Klimont, Z., JanssensMaenhout, G., Pitkanen, T., Seibert, J. J., Vu, L., Andres, R. J., Bolt, R. M., Bond, T. C., Dawidowski, L., Kholod, N., Kurokawa, J.-I., Li, M., Liu, L., Lu, Z., Moura, M. C. P., O'Rourke, P. R., and Zhang, Q.: Historical (1750-2014) anthropogenic emissions of reactive gases and aerosols from the Community Emissions Data System (CEDS), Geosci. Model Dev., 11, 369-408, https://doi.org/10.5194/gmd-11-369-2018, 2018.

Hua, S., Tian. H., Wang, K., Zhu, C., Gao, J., Ma, Y., Xue, Y., Wang, Y., Duan, S., and Zhou, J.: Atmospheric emission inventory of hazardous air pollutants from China's cement plants: Temporal trends, spatial variation characteristics and scenario projections, Atmos. Environ., 128, 1-9, https://doi.org/10.1016/j.atmosenv.2015.12.056, 2016.

Huo, H., Lei, Y., Zhang, Q., Zhao, L., and He, K.: China's coke industry: Recent policies, technology shift, and implica- 
tion for energy and the environment, Energy Policy, 51, 397-404, https://doi.org/10.1016/j.enpol.2012.08.041, 2012a.

Huo, H., Zhang, Q., He, K., Yao, Z., and Wang, M.: Vehicle-use intensity in China: Current status and future trend, Energy Policy, 43, 6-16, https://doi.org/10.1016/j.enpol.2011.09.019, 2012b.

IEA (International Energy Agency): World Energy Balances, IEA, Paris, 2017.

IPCC (Intergovernmental Panel on Climate Change): the National Greenhouse Gas Inventories Programme, edited by: Eggleston, H. S., Buendia, L., Miwa, K., Ngara, T., and Tanabe, K., 2006 IPCC Guidelines for National Greenhouse Gas Inventories, published by the Institute for Global Environmental Strategies (IGES), Hayama, Japan on behalf of the IPCC, available at: http: //www.ipcc-nggip.iges.or.jp/public/2006gl/index.html (last access: 1 August 2020), 2006.

IRF (International Road Federation): World Road Statistics 19632015, International Road Federation, Geneva, 1990-2018.

Itahashi, S., Yumimoto, K., Kurokawa, J., Morino, Y., Nagashima, T., Miyazaki, K., Maki, T., and Ohara, T.: Inverse estimation of $\mathrm{NO}_{x}$ emissions over China and India 2005-2016: contrasting recent trends and future perspectives, Environ. Res. Lett., 14, 124020, https://doi.org/10.1088/1748-9326/ab4d7f, 2019.

Janssens-Maenhout, G., Crippa, M., Guizzardi, D., Dentener, F., Muntean, M., Pouliot, G., Keating, T., Zhang, Q., Kurokawa, J., Wankmüller, R., Denier van der Gon, H., Kuenen, J. J. P., Klimont, Z., Frost, G., Darras, S., Koffi, B., and Li, M.: HTAP_v2.2: a mosaic of regional and global emission grid maps for 2008 and 2010 to study hemispheric transport of air pollution, Atmos. Chem. Phys., 15, 11411-11432, https://doi.org/10.5194/acp-15-11411-2015, 2015.

Japan Environmental Sanitation Center and Suuri Keikaku: Report for prevention of air pollution in East Asia Annex I: Emission inventory in Vietnam and policy analysis for prevention of air pollution, 2011 (in Japanese).

Japan Statistical Association: Historical Statistics of Japan New Edition Volume 3, Statistics Bureau, Ministry of Internal Affairs and Communications, 2006.

Jayarathne, T., Stockwell, C. E., Bhave, P. V., Praveen, P. S., Rathnayake, C. M., Islam, Md. R., Panday, A. K., Adhikari, S., Maharjan, R., Goetz, J. D., DeCarlo, P. F., Saikawa, E., Yokelson, R. J., and Stone, E. A.: Nepal Ambient Monitoring and Source Testing Experiment (NAMaSTE): emissions of particulate matter from wood- and dung-fueled cooking fires, garbage and crop residue burning, brick kilns, and other sources, Atmos. Chem. Phys., 18, 2259-2286, https://doi.org/10.5194/acp18-2259-2018, 2018.

Jiang, Z., Worden, J. R., Worden, H., Deeter, M., Jones, D. B. A., Arellano, A. F., and Henze, D. K.: A 15-year record of $\mathrm{CO}$ emissions constrained by MOPITT CO observations, Atmos. Chem. Phys., 17, 4565-4583, https://doi.org/10.5194/acp17-4565-2017, 2017.

JPEC (Japan Petroleum Energy Center): Emission inventory of road transport in Japan, JPEC Technical Report, JPEC-2011AQ-0206, 136 pp., 2012a (in Japanese).

JPEC: Emission inventory of sources other than road transport in Japan, JPEC Technical Report, JPEC-2011AQ-02-07, 288 pp., 2012b (in Japanese).
JPEC: Speciation profiles of VOC, $\mathrm{PM}$, and $\mathrm{NO}_{x}$ emissions for atmospheric simulations of $\mathrm{PM}_{2.5}$, JPEC Technical Report, JPEC2011AQ-02-08, 69 pp., 2012c (in Japanese).

JPEC: Emission inventory of $\mathrm{PM}_{2.5}$ and profiles of emission sources, Report of Ministry of Environment of Japan, 2014.

Kang, Y., Liu, M., Song, Y., Huang, X., Yao, H., Cai, X., Zhang, H., Kang, L., Liu, X., Yan, X., He, H., Zhang, Q., Shao, M., and Zhu, T.: High-resolution ammonia emissions inventories in China from 1980 to 2012, Atmos. Chem. Phys., 16, 2043-2058, https://doi.org/10.5194/acp-16-2043-2016, 2016.

Kannari, A., Baba, T, and Hayami, H.: Estimation of ammonia emissions in Japan (in Japanese), J. Jpn. Soc. Atmos. Environ. 36, 29-38, https://doi.org/10.11298/taiki1995.36.29, 2001.

Kannari, A., Tonooka, Y., Baba, T., and Murano, K.: Development of multiple-species $1 \mathrm{~km} \times 1 \mathrm{~km}$ resolution hourly basis emissions inventory for Japan, Atmos. Environ., 41, 3428-3439, https://doi.org/10.1016/j.atmosenv.2006.12.015, 2007.

Kato, N. and Akimoto, H.: Anthropogenic emissions of $\mathrm{SO}_{2}$ and $\mathrm{NO}_{x}$ in Asia: emissions inventories, Atmos. Environ., 26, 2997 3017, https://doi.org/10.1016/0960-1686(92)90291-R, 1992.

Klein Goldewijk, K., Beusen, A., Doelman, J., and Stehfest, E.: Anthropogenic land use estimates for the Holocene - HYDE 3.2, Earth Syst. Sci. Data, 9, 927-953, https://doi.org/10.5194/essd9-927-2017, 2017.

Klimont, Z., Cofala, J., Bertok, I., Amann, M., Heyes, C., and Gyarfas, F.: Modeling particulate emissions in Europe: A framework to estimate reduction potential and control costs, IIASA, Interim Report IR-02-076, 2002.

Klimont, Z., Smith, S. J., and Cofala, J.: The last decade of global anthropogenic sulfur dioxide: 2000-2011 emissions, Environ. Res., Lett., 8, 014003, https://doi.org/10.1088/17489326/8/1/014003, 2013.

Klimont, Z., Kupiainen, K., Heyes, C., Purohit, P., Cofala, J., Rafaj, P., Borken-Kleefeld, J., and Schöpp, W.: Global anthropogenic emissions of particulate matter including black carbon, Atmos. Chem. Phys., 17, 8681-8723, https://doi.org/10.5194/acp-178681-2017, 2017.

Kupiainen, K. and Klimont, Z.: Primary emissions of submicron and carbonaceous particles in Europe and the potential for their control, IIASA, Interim Report IR-04-079, 2004.

Kurokawa, J. and Ohara, T.: Long-term historical trends in air pollutant emissions in Asia: Regional Emission inventory in ASia (REAS) version 3, available at: https://www.nies.go.jp/REAS/ index.html\#REASv3.2 (last access: 31 October 2020), 2020.

Kurokawa, J., Ohara, T., Morikawa, T., Hanayama, S., JanssensMaenhout, G., Fukui, T., Kawashima, K., and Akimoto, H.: Emissions of air pollutants and greenhouse gases over Asian regions during 2000-2008: Regional Emission inventory in ASia (REAS) version 2, Atmos. Chem. Phys., 13, 11019-11058, https://doi.org/10.5194/acp-13-11019-2013, 2013.

Lee, D.-G., Lee, Y.-M., Jang, K.-W., Yoo, C., Kang, K.-H., Lee, J.H., Jung, S.-W., Park, J.-M., Lee, S.-B., Han, J.-S., Hong, J.-H., and Lee, S.-J.: Korean national emissions inventory system and 2007 air pollutant emissions, Asian J. Atmos. Environ., 5, 278 291, https://doi.org/10.5572/ajae.2011.5.4.278, 2011.

Lei, Y., Zhang, Q., He, K. B., and Streets, D. G.: Primary anthropogenic aerosol emission trends for China, 1990-2005, Atmos. Chem. Phys., 11, 931-954, https://doi.org/10.5194/acp-11-9312011, 2011. 
Li, M., Zhang, Q., Streets, D. G., He, K. B., Cheng, Y. F., Emmons, L. K., Huo, H., Kang, S. C., Lu, Z., Shao, M., Su, H., Yu, X., and Zhang, Y.: Mapping Asian anthropogenic emissions of non-methane volatile organic compounds to multiple chemical mechanisms, Atmos. Chem. Phys., 14, 5617-5638, https://doi.org/10.5194/acp-14-5617-2014, 2014.

Li, M., Zhang, Q., Kurokawa, J.-I., Woo, J.-H., He, K., Lu, Z., Ohara, T., Song, Y., Streets, D. G., Carmichael, G. R., Cheng, Y., Hong, C., Huo, H., Jiang, X., Kang, S., Liu, F., Su, H., and Zheng, B.: MIX: a mosaic Asian anthropogenic emission inventory under the international collaboration framework of the MICS-Asia and HTAP, Atmos. Chem. Phys., 17, 935-963, https://doi.org/10.5194/acp-17-935-2017, 2017a.

Li, M., Liu, H., Geng, G., Hong, C., Liu, F., Song, Y., Tong, D., Zheng, B., Cui, H., Man, H., Zhang, Q., and He, K.: Anthropogenic emission inventories in China: a review, National Science Review, 4, 834-866, https://doi.org/10.1093/nsr/nwx150, $2017 b$.

Li, C., McLinden, C., Fioletov, V., Krotkov, N., Carn, S., Joiner, J., Streets, D., He, H., Ren, X., Li, Z., and Dickerson, R.: India is overtaking China as the world's largest emitter of anthropogenic sulfur dioxide, Sci. Rep., 7, 14304, https://doi.org/10.1038/s41598-017-14639-8, 2017.

Liu, F., Zhang, Q., Tong, D., Zheng, B., Li, M., Huo, H., and He, K. B.: High-resolution inventory of technologies, activities, and emissions of coal-fired power plants in China from 1990 to 2010, Atmos. Chem. Phys., 15, 13299-13317, https://doi.org/10.5194/acp-15-13299-2015, 2015.

Lu, Z., Streets, D. G., Zhang, Q., Wang, S., Carmichael, G. R., Cheng, Y. F., Wei, C., Chin, M., Diehl, T., and Tan, Q.: Sulfur dioxide emissions in China and sulfur trends in East Asia since 2000, Atmos. Chem. Phys., 10, 6311-6331, https://doi.org/10.5194/acp-10-6311-2010, 2010.

Lu, Z., Zhang, Q., and Streets, D. G.: Sulfur dioxide and primary carbonaceous aerosol emissions in China and India, 1996-2010, Atmos. Chem. Phys., 11, 9839-9864, https://doi.org/10.5194/acp-11-9839-2011, 2011.

Ma, Q., Cai, S., Wang, S., Zhao, B., Martin, R. V., Brauer, M., Cohen, A., Jiang, J., Zhou, W., Hao, J., Frostad, J., Forouzanfar, M. H., and Burnett, R. T.: Impacts of coal burning on ambient $\mathrm{PM}_{2.5}$ pollution in China, Atmos. Chem. Phys., 17, 4477-4491, https://doi.org/10.5194/acp-17-4477-2017, 2017.

Maithel, S.: Evaluating energy conservation potential of brick production in India, Greentech Knowledge Solutions Pvt Ldt., New Delhi, 2013.

Maithel, S., Lalchandani, D., Malhotra, G., Bhanware, P., Uma, R., Ragavan, S., Athalye, V., Bindiy, K. R., Reddy, S., Bond, T, Weyant, C., Baum, E., Kim Thoa, V. T., Thu Phuong, N., and Kim Thanh, T.: Brick Kilns performance assessment: A Roadmap for Cleaner Brick Production in India, Shakti Sustainable Energy Foundation and Climate Works Foundation Supported Initiative, New Delhi, 2012.

Malla, S.: Assessment of mobility and its impact on energy use and air pollution in Nepal, Energy, 69, 485-496, https://doi.org/10.1016/j.energy.2014.03.041, 2014.

METI (Ministry of Economy Trade and Industry of Japan): Reports of Pollutants Release and Transfer Register (2001-2015), Chemical Management Policy Division, 2003-2017 (in Japanese).
Mitchell, B. R.: International historical statistics: Africa, Asia \& Oceania, 1750-1993 3rd ed., Macmillan reference Ldt., 1998.

Mishra, D. and Goyal, P.: Estimation of vehicular emissions using dynamic emission factors: A case study of Delhi, India, Atmos. Environ., 98, 1-7, https://doi.org/10.1016/j.atmosenv.2014.08.047, 2014.

Miyazaki, K., Bowman, K., Sekiya, T., Eskes, H., Boersma, F., Worden, H., Livesey, N., Payne, V. H., Sudo, K., Kanaya, Y., Takigawa, M., and Ogochi, K.: Updated tropospheric chemistry reanalysis and emission estimates, TCR-2, for 2005-2018, Earth Syst. Sci. Data, 12, 2223-2259, https://doi.org/10.5194/essd-122223-2020, 2020.

MLTI (Ministry of Land, Infrastructure, Transport and Tourism of Japan): Annual Report of Road Statistics (1960-2015), Information Policy Division, 1961-2016 (in Japanese).

MOEJ (Ministry of Environment of Japan): Report on Volatile Organic Compound (VOC) Emission Inventory Compiled, available at: http://www.env.go.jp/air/osen/voc/inventory.html (last access: 1 August 2020), 2017 (in Japanese).

MRI (Mitsubishi Research Institute): Survey report for technologies used to overcome industrial air pollution in Japan, Environment \& Energy Research Division, Mitsubishi Research Institute, Inc., 2015 (in Japanese).

National Bureau of Statistics of China: China Statistical Yearbook (1985-2015), China Statistics Press, Beijing, 1986-2016.

National Bureau of Statistics of China: China Energy Statistical Yearbook (1985; 1995-2015), China Statistics Press, Beijing, 1986, 2001-2017.

Nishina, K., Ito, A., Hanasaki, N., and Hayashi, S.: Reconstruction of spatially detailed global map of $\mathrm{NH}_{4}^{+}$and $\mathrm{NO}_{3}^{-}$application in synthetic nitrogen fertilizer, Earth Syst. Sci. Data, 9, 149-162, https://doi.org/10.5194/essd-9-149-2017, 2017.

Ohara, T., Akimoto, H., Kurokawa, J., Horii, N., Yamaji, K., Yan, X., and Hayasaka, T.: An Asian emission inventory of anthropogenic emission sources for the period 1980-2020, Atmos. Chem. Phys., 7, 4419-4444, https://doi.org/10.5194/acp-7-44192007, 2007.

Paliwal, U., Sharma, M., and Burkhart, J. F.: Monthly and spatially resolved black carbon emission inventory of India: uncertainty analysis, Atmos. Chem. Phys., 16, 12457-12476, https://doi.org/10.5194/acp-16-12457-2016, 2016.

Pandey, A. and Venkataraman, C.: Estimating emissions from the Indian transport sector with on-road fleet composition and traffic volume, Atmos. Environ., 98, 123-133, https://doi.org/10.1016/j.atmosenv.2014.08.039, 2014.

Pandey, A., Sadavarte, P., Rao, A. B., and Venkataraman, C.: Trends in multi-pollutant emissions from a technologylinked inventory for India: II. Residential, agricultural and informal industry sectors, Atmos. Environ., 99, 341-352, https://doi.org/10.1016/j.atmosenv.2014.09.080, 2014.

Permadi D. A., Sofyan, A., and Oanh, N. T. K.: Assessment of emissions of greenhouse gases and air pollutants in Indonesia and impacts of national policy for elimination of kerosene use in cooking, Atmos. Environ., 154, 82-94, https://doi.org/10.1016/j.atmosenv.2017.01.041, 2017.

Pham, T. B. T., Manomaiphiboon, K., and Vongmahadlek, C.: Development of an inventory and temporal allocation profiles of emissions from power plants and industrial fa- 
cilities in Thailand, Sci. Total Environ., 397, 103-118, https://doi.org/10.1016/j.scitotenv.2008.01.066, 2008.

Platts: The UDI World Electric Power Plants Database, S \& P Global Platts, 2018.

Prakash, J. and Habib, G.: A technology-based mass emission factors of gases and aerosol precursor and spatial distribution of emissions from on-road transport sector in India, Atmos. Environ., 180, 192-205, https://doi.org/10.1016/j.atmosenv.2018.02.053, 2018.

Qu, Z., Henze, D. K., Li, C., Theys, N., Wang, Y., Wang, J., Wang, W., Han, J., Shim, C., Dickerson, R. R., and Ren, X.: $\mathrm{SO}_{2}$ emission estimates using $\mathrm{OMI} \mathrm{SO}_{2}$ retrievals for 2005-2017, J. Geophys. Res.-Atmos., 124, 8336-8359, https://doi.org/10.1029/2019JD030243, 2019.

Reddy, M. S. and Venkataraman, C.: Inventory of aerosol and sulphur dioxide emissions from India: I - Fossil fuel combustion, Atmos. Environ., 36, 677-697, https://doi.org/10.1016/S13522310(01)00463-0, 2002a.

Reddy, M. S. and Venkataraman, C.: Inventory of aerosol and sulphur dioxide emissions from India. Part II - biomass combustion, Atmos. Environ., 36, 699-712, https://doi.org/10.1016/S13522310(01)00464-2, 2002b.

Sadavarte, P. and Venkataraman, C.: Trends in multi-pollutant emissions from a technology-linked inventory for India: I. Industry and transport sectors, Atmos. Environ., 99, 353-364, https://doi.org/10.1016/j.atmosenv.2014.09.081, 2014.

Sadavarte, P., Rupakheti, M., Bhave, P., Shakya, K., and Lawrence, M.: Nepal emission inventory - Part I: Technologies and combustion sources (NEEMI-Tech) for 2001-2016, Atmos. Chem. Phys., 19, 12953-12973, https://doi.org/10.5194/acp-19-129532019, 2019.

Sahu, S. K., Beig, G., and Sharma, C.: Decadal growth of black carbon emissions in India, Geophys. Res. Lett., 35, L02807, https://doi.org/10.1029/2007GL032333, 2008.

Sahu, S. K., Beig, G., and Parkhi, N. S.: Emerging pattern of anthropogenic $\mathrm{NO}_{x}$ emission over Indian subcontinent during 1990s and 2000s, Atmos. Pollut. Res., 3, 262-269, https://doi.org/10.5094/APR.2012.021, 2012.

Sahu, S. K., Beig, G., and Parkhi, N. S.: Critical emissions from the largest on-road transport network in South Asia, Aerosol Air Qual. Res., 14, 135-144, https://doi.org/10.4209/aaqr.2013.04.0137, 2014.

Sharma, S., Goel, A., Gupta, D., Kumar, A., Mishra, A., Kundu, S., Chatani, S., and Klimont, Z.: Emission inventory of non-methane volatile organic compounds from anthropogenic sources in India, Atmos. Environ., 102, 209-219, https://doi.org/10.1016/j.atmosenv.2014.11.070, 2015.

Shimoda: History of Cement Manufacturing Technology (in Japanese), Report of National Museum of Nature and Science for systemization of technologies, 23, 1-115, 2016.

Shrestha, R. M., Kim Oanh, N. T., Shrestha, R. P., Rupakheti, M., Rajbhandari, S., Permadi, D. A., Kanabkaew, T., and Iyngararasan, M.: Atmospheric Brown Clouds (ABC) Emission Inventory Manual, United Nations Environment Programme, Nairobi, Kenya, 2013.

Sloss, L.: Mercury emissions from India and Southeast Asia, IEA Clean Coal Centre, ISBN 978-92-9029-528-0, 2012.

Smith, S. J., van Aardenne, J., Klimont, Z., Andres, R. J., Volke, A., and Delgado Arias, S.: Anthropogenic sulfur diox- ide emissions: 1850-2005, Atmos. Chem. Phys., 11, 1101-1116, https://doi.org/10.5194/acp-11-1101-2011, 2011.

Stavrakou, T., Muller, J. F., Bauwens, M., De Smedt, I.: Sources and long-term trends of ozone precursors to Asian Pollution, Air Pollution in Eastern Asia: an integrated perspective, edited by: Bouarar, I., Wang, X., and Brasseur, G., Springer international Publishing, 167-189, https://doi.org/10.1007/978-3-319-594897, 2017.

Stohl, A., Aamaas, B., Amann, M., Baker, L. H., Bellouin, N., Berntsen, T. K., Boucher, O., Cherian, R., Collins, W., Daskalakis, N., Dusinska, M., Eckhardt, S., Fuglestvedt, J. S., Harju, M., Heyes, C., Hodnebrog, Ø., Hao, J., Im, U., Kanakidou, M., Klimont, Z., Kupiainen, K., Law, K. S., Lund, M. T., Maas, R., MacIntosh, C. R., Myhre, G., Myriokefalitakis, S., Olivié, D., Quaas, J., Quennehen, B., Raut, J.-C., Rumbold, S. T., Samset, B. H., Schulz, M., Seland, Ø., Shine, K. P., Skeie, R. B., Wang, S., Yttri, K. E., and Zhu, T.: Evaluating the climate and air quality impacts of short-lived pollutants, Atmos. Chem. Phys., 15, 10529-10566, https://doi.org/10.5194/acp-15-105292015, 2015.

Streets, D. G., Tsai, N. Y., Akimoto, H., and Oka, K.: Sulfur dioxide emissions in Asia in the period 1985-1997, Atmos. Environ., 34, 4413-4424, https://doi.org/10.1016/S1352-2310(00)00187$4,2000$.

Streets, D. G., Bond, T. C., Carmichael, G. R., Fernandes, S. D., Fu, Q., He, D., Klimont, Z., Nelson, S. M., Tsai, N. Y., Wang, M. Q., Woo, J.-H., and Yarber, K. F.: An inventory of gaseous and primary aerosol emissions in Asia in the year 2000, J. Geophys. Res., 108, 8809, https://doi.org/10.1029/2002JD003093, 2003a.

Streets, D. G., Yarber, K. F., Woo, J.-H., and Carmichael, G. R.: Biomass burning in Asia: Annual and seasonal estimates and atmospheric emissions, Global Biogeochem. Cy., 17, 1099, https://doi.org/10.1029/2003GB002040, 2003b.

Sun, W., Shao, M., Granier, C., Liu, Y., Ye, C. S., and Zheng, J. Y.: Long-term trends of anthropogenic $\mathrm{SO}_{2}, \mathrm{NO}_{x}, \mathrm{CO}$, and NMVOCs emissions in China, Earth's Future, 6, 1112-1133, https://doi.org/10.1029/2018EF000822, 2018.

Suzuki, T: Combustion technology in steel industry (in Japanese), Iron and Steel, 6, 807-816, https://doi.org/10.2355/tetsutohagane1955.76.6_807, 1990.

TERI (The Energy Resources Institute): TERI Energy \& Environment Data Diary and Yearbook (2012/13; 2016/17), New Delhi, TERI, 2013, 2018.

UN (United Nations): Energy Statistics Database, United Nations Statistics Division, New York, 2016.

UN: Department of Economic and Social Affairs, Population Division, World Urbanization Prospects: The 2018 Revision, Online Edition, 2018.

UN Environment: Reducing mercury emission from coal combustion in the energy sector in Thailand prepared by P. Watchalayann et al., Thammasat University, UN Environment: Chemical and Wastes Branch, 2018.

UNEP (United Nations Environmental Programme): Air Pollution in Asia and the Pacific: Science-based Solutions, ISBN: 978-92807-3725-7, 2019.

US EPA (United States Environmental Protection Agency): Compilation of air pollutant emission factors (AP-42) Volume 1: Stationary point and area sources, United States Environmental Protection Agency, Research Triangle Park, NC, 1995. 
USGS (United States Geological Survey): Minerals Yearbook, Volume III, Area Reports: International (19942015), available at: https://www.usgs.gov/centers/nmic/ international-minerals-statistics-and-information (last access: 1 August 2020), 1994-2015.

Vallack, H. and Rypdal, K.: The Global Atmospheric Pollution Forum Air Pollutant Emission Inventory Manual, Stockholm Environment Institute, 2012.

Venkataraman, C., Brauer, M., Tibrewal, K., Sadavarte, P., Ma, Q., Cohen, A., Chaliyakunnel, S., Frostad, J., Klimont, Z., Martin, R. V., Millet, D. B., Philip, S., Walker, K., and Wang, S.: Source influence on emission pathways and ambient $\mathrm{PM}_{2.5}$ pollution over India (2015-2050), Atmos. Chem. Phys., 18, 8017-8039, https://doi.org/10.5194/acp-18-8017-2018, 2018.

Wang, R., Tao, S., Wang, W., Liu, J., Shen, H., Shen, G., Wang, B., Liu, X., Li, W., Huang, Y., Zhang, Y., Lu, Y., Chen, H., Chen, Y., Wang, C., Zhu, D., Wang, X., Li, B., Liu, W., and Ma, J.: Black Carbon Emissions in China from 1949 to 2050, Environ. Sci. Technol., 46, 7595-7603, https://doi.org/10.1021/es3003684, 2012.

Wang, S. X., Zhao, B., Cai, S. Y., Klimont, Z., Nielsen, C. P., Morikawa, T., Woo, J. H., Kim, Y., Fu, X., Xu, J. Y., Hao, J. M., and He, K. B.: Emission trends and mitigation options for air pollutants in East Asia, Atmos. Chem. Phys., 14, 6571-6603, https://doi.org/10.5194/acp-14-6571-2014, 2014.

Wei, W., Wang, S., Hao, J., and Cheng, S.: Projection of anthropogenic volatile organic compounds (VOCs) emissions in China for the period 2010-2020, Atmos. Environ., 45, 6863-6871, https://doi.org/10.1016/j.atmosenv.2011.01.013, 2011.

World Steel Association: Steel Statistical Yearbook (19782016), World Steel Association, Brussels, available at: https://www.worldsteel.org/steel-by-topic/statistics/ steel-statistical-yearbook.html (last access: 1 August 2019), 1978-2016.

Wu, Q., Gao, W., Wang, S., and Hao, J.: Updated atmospheric speciated mercury emissions from iron and steel production in China during 2000-2015, Atmos. Chem. Phys., 17, 1042310433, https://doi.org/10.5194/acp-17-10423-2017, 2017.

Xia, Y., Zhao, Y., and Nielsen, C. P.: Benefits of China's efforts in gaseous pollutant control indicated by the bottom-up emissions and satellite observations 2000-2014, 136, 43-53, https://doi.org/10.1016/j.atmosenv.2016.04.013, 2016.

Yamaji, K., Ohara, T., and Akimoto, H.: Regional-specific emission inventory for $\mathrm{NH}_{3}, \mathrm{~N}_{2} \mathrm{O}$, and $\mathrm{CH}_{4}$ via animal farming in South, Southeast, and East Asia, Atmos. Environ., 38, 71117121, https://doi.org/10.1016/j.atmosenv.2004.06.045, 2004.

Yan, X. and Crookes, R. J.: Reduction potentials of energy demand and GHG emissions in China's road transport sector, Energy Policy, 37, 658-668, https://doi.org/10.1016/j.enpol.2008.10.008, 2009.

Yan, X., Akimoto, H., and Ohara, T.: Estimation of nitrous oxide, nitric oxide, and ammonia emissions from croplands in East, Southeast, and South Asia, Global Change Biol., 9, 1080-1096, https://doi.org/10.1046/j.1365-2486.2003.00649.x, 2003.

Zhang, Q., Streets, D. G., He, K., Wang, Y., Richter, A., Burrows, J. P., Uno, I., Jang, C. J., Chen, D., Yao, Z., and Lei, Y.: $\mathrm{NO}_{x}$ emission trends for China, 1995-2004: The view from the ground and the view from space, J. Geophys. Res., 112, D22306, https://doi.org/10.1029/2007JD008684, 2007.
Zhang, Q., Streets, D. G., Carmichael, G. R., He, K. B., Huo, H., Kannari, A., Klimont, Z., Park, I. S., Reddy, S., Fu, J. S., Chen, D., Duan, L., Lei, Y., Wang, L. T., and Yao, Z. L.: Asian emissions in 2006 for the NASA INTEX-B mission, Atmos. Chem. Phys., 9, 5131-5153, https://doi.org/10.5194/acp-9-5131-2009, 2009.

Zhang, S., Wu, Y., Huang, R., Wang, J., Yan, H., Zheng, Y., and Hao, J.: High-resolution simulation of link-level vehicle emissions and concentrations for air pollutants in a trafficpopulated eastern Asian city, Atmos. Chem. Phys., 16, 99659981, https://doi.org/10.5194/acp-16-9965-2016, 2016.

Zhang, Z.: Energy efficiency and environmental pollution of brickmaking in China, Energy, 22, 33-42, https://doi.org/10.1016/S0360-5442(96)00078-3, 1997.

Zhao, Y., Nielsen, C. P., Lei, Y., McElroy, M. B., and Hao, J.: Quantifying the uncertainties of a bottom-up emission inventory of anthropogenic atmospheric pollutants in China, Atmos. Chem. Phys., 11, 2295-2308, https://doi.org/10.5194/acp-112295-2011, 2011.

Zhao, Y., Nielsen, C. P., McElroy, M. B., Zhang, L., and Zhang, J.: CO emissions in China: uncertainties and implications of improved energy efficiency and emission control, Atmos. Environ., 49, 103-113, https://doi.org/10.1016/j.atmosenv.2011.12.015, 2012.

Zhao, Y., Zhang, J., and Nielsen, C. P.: The effects of recent control policies on trends in emissions of anthropogenic atmospheric pollutants and $\mathrm{CO}_{2}$ in China, Atmos. Chem. Phys., 13, 487-508, https://doi.org/10.5194/acp-13-487-2013, 2013.

Zhao, Y., Zhang, J., and Nielsen, C. P.: The effects of energy paths and emission controls and standards on future trends in China's emissions of primary air pollutants, Atmos. Chem. Phys., 14, 8849-8868, https://doi.org/10.5194/acp-14-8849-2014, 2014.

Zhao, Y., Zhong, H., Zhang, J., and Nielsen, C. P.: Evaluating the effects of China's pollution controls on inter-annual trends and uncertainties of atmospheric mercury emissions, Atmos. Chem. Phys., 15, 4317-4337, https://doi.org/10.5194/acp-154317-2015, 2015.

Zheng, B., Huo, H., Zhang, Q., Yao, Z. L., Wang, X. T., Yang, X. F., Liu, H., and He, K. B.: High-resolution mapping of vehicle emissions in China in 2008, Atmos. Chem. Phys., 14, 9787-9805, https://doi.org/10.5194/acp-14-9787-2014, 2014.

Zheng, B., Tong, D., Li, M., Liu, F., Hong, C., Geng, G., Li, H., Li, X., Peng, L., Qi, J., Yan, L., Zhang, Y., Zhao, H., Zheng, Y., He, K., and Zhang, Q.: Trends in China's anthropogenic emissions since 2010 as the consequence of clean air actions, Atmos. Chem. Phys., 18, 14095-14111, https://doi.org/10.5194/acp-18-140952018, 2018.

Zheng, B., Chevallier, F., Yin, Y., Ciais, P., Fortems-Cheiney, A., Deeter, M. N., Parker, R. J., Wang, Y., Worden, H. M., and Zhao, Y.: Global atmospheric carbon monoxide budget 20002017 inferred from multi-species atmospheric inversions, Earth Syst. Sci. Data, 11, 1411-1436, https://doi.org/10.5194/essd-111411-2019, 2019.

Zheng, H., Cai, S., Wang, S., Zhao, B., Chang, X., and Hao, J.: Development of a unit-based industrial emission inventory in the Beijing-Tianjin-Hebei region and resulting improvement in air quality modeling, Atmos. Chem. Phys., 19, 3447-3462, https://doi.org/10.5194/acp-19-3447-2019, 2019. 
Zhu, C., Tian, H., Hao, Y., Gao, J., Hao, J., Wang, Y., Hua, S., Wang, K., and Liu, H.: A high-resolution emission inventory of anthropogenic trace elements in Beijing-TianjinHebei (BTH) region of China, Atmos. Environ., 191, 452-462, https://doi.org/10.1016/j.atmosenv.2018.08.035, 2018. 